DOI: $10.1002 /$ adma.201801079

Article type: Review - Hall of Fame Article

\title{
Recent Progress in High Mobility Organic Transistors: A Reality Check
}

Alexandra F. Paterson*, Saumya Singh, Kealan J. Fallon, Thomas Hodsden, Yang Han, Bob

C. Schroeder, Hugo Bronstein, Martin Heeney, Iain McCulloch, and Thomas D.

Anthopoulos*

Dr. A. F. Paterson, Prof. I. McCulloch, Prof. T. D. Anthopoulos

Division of Physical Sciences and Engineering

King Abdullah University of Science and Technology

Thuwal 23955-6900, Saudi Arabia

E-mail: thomas.anthopoulos@kaust.edu.sa

E-mail: alexandra.paterson@kaust.edu.sa

Mr. T. Hodsden, Dr Y. Han, Prof. M. Heeney

Department of Chemistry and Centre for Plastic Electronics

Imperial College London

South Kensington, London SW7 2AZ (UK)

Dr. K. J. Fallon, Dr. H. Bronstein

Department of Chemistry

University of Cambridge

Cambridge CB3 OHE (UK)

Dr. S. Singh, Dr. B. C. Schroeder

Department of Chemistry

University College London

London WC1H 0AJ (UK)

Keywords: organic semiconductors; organic field-effect transistor; carrier mobility; charge transport; contact resistance 


\begin{abstract}
Over the past three decades significant research efforts have focused on improving the charge carrier mobility of organic thin-film transistors (OTFTs). In recent years a commonly observed nonlinearity in OTFT current-voltage characteristics, known as the "kink" or "double slope", has led to widespread mobility ovestimations, contaminating the relevant literature. Here, published data from the past 30 years is reviewed to uncover the extent of the field-effect mobility hype and identify the progress that has actually been achieved in the field of OTFTs. Present carrier mobility-related challenges are identified, finding that reliable hole and electron mobility values of 20 and $10 \mathrm{~cm} 2 \mathrm{~V}-1 \mathrm{~s}-1$, respectively, have yet to be achieved. Based on the analysis, the literature is then reviewed to summarize the concepts behind the success of high performance p-type polymers, along with the latest understanding of the design criteria that will enable further mobility enhancement in n-type polymers and smallmolecules, and the reasons why high carrier mobility values have been consistently produced from small-molecule/polymer blend semiconductors. Overall, this review brings together important information that aids reliable OTFT data analysis, whilst providing guidelines for the development of next generation organic semiconductors.
\end{abstract}

\title{
1. Introduction
}

Organic semiconductors (OSCs) and their unique mechanical properties have received great interest since their first applications in several proof of principle devices at the end of the 20th century. One solid state device that has been at the heart of the quest for commercially viable plastic electronics is the field-effect transistor (FET), specifically the thin-film transistor (TFT). Conventional inorganic semiconductors have already taken the TFT down a successful path; inorganic TFT backplanes are used in mass-produced, commercially available displays. To make TFT backplanes using solution-processed organic thin-film transistors (OTFTs) would fit perfectly with the popular vision of large-area printed flexible, stretchable, foldable 
displays. Over the past 30 years, significant research efforts have been devoted to using OSCs to recreate the success of the inorganic TFT. But despite how widely and seemingly easily the inorganic TFT is incorporated into our everyday lives, this now well-known technology had its difficulties.

For that reason we'll stop here briefly to look at the history of the inorganic TFT. A good place to do this is in 1984, when the late T. Peter Brody, inventor of active matrix technologies and pioneer of TFT driven displays, wrote an insightful, honest and enthusiastic narrative of the history of the TFT. ${ }^{[1]}$ Brody recalls: "we were told that if TFT's did not make it in 1963, then we might as well forget about them!". We encourage the reader to take a moment to read Brody's impassioned tale of against-all-odds. Brody draws our attention to the TFT's arduous path between Lilenfield and Heil's field-effect patents in the early 1930's, ${ }^{[2]}[3]$ and Le Comber and Spear's hydrogenated amorphous silicon (a-Si:H) TFT in 1979. ${ }^{[4]}$ The thin-film transistor was disregarded as a useless lost cause and deemed an "obsolete' device". It had failed to make a breakthrough on two occasions: firstly in 1947 when it was beaten by the point contact transistor for the Bell Lab's team Nobel Prize winning discovery, and secondly in the early 1960's when it was defeated by the metal oxide semiconductor field-effect transistor (MOSFET) for a prized place in up-and-coming integrated circuitry.

Even though there was field-wide loss of confidence in the TFT, Brody's team continued their TFT research until a resurgence of interest in the device in the 1980's. This was a decision that, in the end, would see Brody both vindicated and triumphant. During this time they had also demonstrated the TFT's value in a broad range of applications, from power devices for cooking equipment to power-control circuitry for aircraft. In 1963, Brody describes making paper TFTs and flexible circuits that "could be bent into a 1/16 inch radius without apparent damage", not much dissimilar to the technology suggested for their organic counterpart nowadays. The organic counterpart that we are very much familiar with started its 
journey in the 1980's, when the TFT was only just out of its dark shadow for conventional semiconductors. The TFT had, in its own unique way, combined the two alien worlds of inorganic and the organic semiconductors. It therefore follows logically that key aspects from inorganic TFT history were carried into the new chapter that had begun for OTFTs.

One crucial element that was carried forward is Shockley's theory of "A Unipolar "Field-Effect" Transistor", i.e. the gradual channel approximation (GCA). ${ }^{[5]}$ The most popular operating parameter derived from the GCA is the well-known charge carrier mobility, $\mu$, used to describe how quickly charges are able to move through a semiconductor under an external electric field. There are a number of assumptions associated with Shockley's GCA: zero channel thickness, charges injected/extracted via Ohmic contacts (i.e. no contact resistance), no diffusion and the mobility is independent of biasing. ${ }^{[6]}{ }^{[7]}$ A TFT that satisfies these conditions is considered an "ideal" device. In reality, OSCs do not lend themselves to ideal TFTs. It is a double edged sword: the fundamental qualities that give organic materials their desirable mechanical properties cause many OTFTs to deviate from the ideal model. Covalently bonded molecules held together by weak van der Waals bonding result in often disordered microstructures, meaning OSCs have a lack of extended states, they are littered with trapping sites and support varying modes of transportation for charge carriers, as well as being sensitive to measurement peculiarities arising from minority carrier trapping and injection. To add to the complexity, these intrinsic electrical attributes are highly dependent on how OSCs are designed and processed, ${ }^{[6]}[8][9]$ and many of the intrinsic OSCs have characteristically wide bandgaps (2-4 eV), which can result in high Schottky barriers and large built-in voltages at the interface between the source/drain (S/D) electrodes and the OSCs. ${ }^{[10]}$. Indeed, over the years a wealth of experimental data has shown that incorporating unconventional, disordered organic materials into a TFT comes at a high risk of not meeting the criteria of the ideal device, and not satisfying the conditions for the GCA. 
One feature that shows an OTFT has deviated from the classical FET model is known as the "kink", "hump" or "double slope". In short, the kink is an artefact in the transconductance caused by contact resistance, $\mathrm{R}_{\mathrm{C}}$, and extracting $\mu$ from the steeper, low

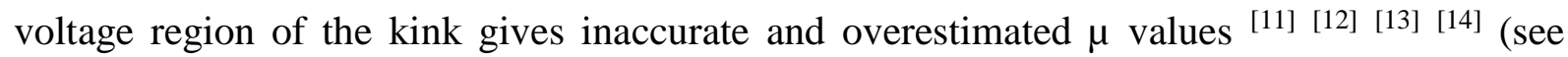
Figure 1, which will be discussed in detail later on). The origin of the contact resistance, on the other hand, may be attributed to different effects including, type of gate dielectric employed ${ }^{[15]}{ }^{[16]}$ presence of an injection barrier at the metal/semiconductor contact as well as charge trapping at the electrode interface. ${ }^{[17]}$ Despite its convoluted nature, however, $\mathrm{R}_{\mathrm{C}}$ is often quantified as a single variable the magnitude of which, as compared to the channel resistance, determines the severity of its impact on mobility estimation. Because $\mu$ is a key figure of merit used to gauge the performance of TFTs, this infamous problem has had considerable impact on the field, and has been mentioned in many recent publications. ${ }^{[11]}[13]$ ${ }^{[12]}{ }^{[18]}$ Here, we refer to the widespread contamination of the OTFT literature as the mobility hype.

Given the recent significance of the mobility hype, we begin this review article in Section 2 by reviewing the recent literature to answer the following questions: i) what is the mobility hype and how did it happen? ii) how can we improve contact resistance? iii) what is the best way to analyse OTFT data? iv) what impact has the mobility hype had on the literature and recent perceived progress? To answer the latter, we sift through the published mobility values from the past 30 years to find out what progress has actually been achieved in terms of mobility values.

Firstly, our dataset shows that although p-type mobilities have made significant progress, they only recently achieved the benchmark mobility of $10 \mathrm{~cm}^{2} / \mathrm{Vs}$, and have yet to achieve hole mobilities of $20 \mathrm{~cm}^{2} / \mathrm{Vs}$. Section 3 therefore reviews the key milestones that have been made in terms of design criteria for p-type polymer semiconductors, to outline the 
most important considerations for future high mobility polymer designs. Secondly, the data analysis shows that n-type semiconductors have yet to exceed the benchmark mobility of 10 $\mathrm{cm}^{2} /$ Vs. Therefore Section 4 will give an overview of the latest understanding of how we can improve electron mobilities in both polymers and molecular semiconductors. Finally, we find that small-molecule/polymer blends are consistently amongst the highest mobility OTFTs. Section 5 summarises the major achievements over the past decade for blend OTFTs, outlining the key principles for designing new high mobility small-molecule/polymer blend systems. Overall, we hope that this review article will act as a guide to high mobility OFETs in terms of both analysis and design.

\section{The mobility hype}

Here we wish to give an overview of the mobility hype and its causes by starting with Shockley's classic FET model, the GCA. The GCA describes how the field-effect modulates current in a solid-state electronic device:

$$
I_{\mathrm{D}}=\frac{w C_{\mathrm{i}}}{L} \mu \times\left(\left(V_{\mathrm{G}}-V_{\mathrm{T}}\right) \times V_{\mathrm{D}}-\frac{V_{\mathrm{D}}^{2}}{2}\right)
$$

where $I_{D}$ is the current in the channel, $\mathrm{W}$ is the channel width, $\mathrm{L}$ is the channel length, $\mathrm{C}_{\mathrm{i}}$ is the capacitance of the dielectric layer, $\mu$ is the carrier mobility, $V_{G}$ is the gate voltage, $V_{T}$ is the threshold voltage and $V_{D}$ is the drain voltage.

To calculate the mobility, the voltage conditions that apply to the linear $\left(\mathrm{V}_{\mathrm{D}}<<\mathrm{V}_{\mathrm{G}}\right)$ and saturation $\left(V_{D}=V_{G}-V_{T}\right)$ regimes in the channel are substituted into the GCA (Eq. 1), and rearranged to give:

$$
\mu_{\text {lin }}=\frac{L}{W C_{\mathrm{i}} V_{\mathrm{D}}} \frac{\partial I_{\mathrm{D} \_ \text {lin }}}{\partial V_{\mathrm{G}}}
$$




$$
\mu_{\text {sat }}=\frac{L}{W C_{\mathrm{i}}} \frac{\partial^{2} I_{\mathrm{D}}}{\partial V_{\mathrm{G}}^{2}}
$$

or

$$
\mu_{\mathrm{sat}}=\frac{2 L}{W C_{\mathrm{i}}}\left(\frac{\partial \sqrt{I_{\mathrm{D}}}}{\partial V_{\mathrm{G}}}\right)^{2}
$$

where $\mu_{\text {lin }}$ is the linear mobility and $\mu_{\text {sat }}$ is the saturation mobility. In particular, Eq. 4 is commonly used to extract $\mu_{\text {sat }}$ from the transconductance, $\mathrm{g}_{\mathrm{m}}$, where:

$$
g_{m}=\frac{\partial \sqrt{I_{D}}}{\partial V_{G}}
$$

in the saturation regime and:

$$
g_{m}=\frac{\partial I_{D}}{\partial V_{G}}
$$

in the linear regime.

An ideal FET has Ohmic contacts at the source/drain electrodes and hence $\mathrm{R}_{\mathrm{C}}=0 \Omega$. In this case, the drain current is only determined by the resistance across the channel, $\mathrm{R}_{\mathrm{CH}}$, which is modulated by (dependent on) $V_{G}$. The transconductance is therefore ${ }^{[19]}$ :

$$
g_{m}=\frac{\partial I_{D}}{\partial V_{G}}=-\frac{V_{D}}{\left(R_{C H}\right)^{2}} \frac{\partial R_{C H}}{\partial V_{G}}
$$

In reality, however, many OTFTs suffer from $R_{C}$. The latter is caused by a difference between the work function, $\varphi$, of the metal contact, $\varphi_{\mathrm{m}}$, and the corresponding energy band of the OSC and its work function, $\varphi_{\mathrm{s}}$. The energetic difference at the metal/semiconductor interface is reduced by charge carriers flowing from the semiconductor to the metal to balance the Fermi levels, leaving behind a space-charge/depletion region. The built-in electric field creates a potential barrier, i.e. a Schottky barrier (Figure 2), which needs to be overcome for charges to move across the interface. Therefore in the presence of a Schottky barrier, the drain 
current in a FET is determined by a combination of both $R_{C H}$ and $R_{C}$, i.e. by $R_{\text {TOTAL }}=R_{C}+$ $R_{C H}$. Ohm's law dictates that in this case the current across the channel is $I_{D}=V_{D} /\left(R_{C}+R_{C H}\right)$, therefore if a FET suffers from contact resistance, the transconductance is ${ }^{[19]}$ :

$$
g_{\mathrm{m}}=\frac{\partial I_{\mathrm{D}}}{\partial V_{\mathrm{G}}}=-\frac{V_{\mathrm{D}}}{\left(R_{\mathrm{ch}}+R_{\mathrm{c}}\right)^{2}}\left(\frac{\partial R_{\mathrm{ch}}}{\partial V_{\mathrm{G}}}+\frac{\partial R_{\mathrm{c}}}{\partial V_{\mathrm{G}}}\right)
$$

There are two things that can happen which result in an artefact in the transconductance: (i) if $\mathrm{R}_{\mathrm{CH}}$ is more dependent on $\mathrm{V}_{\mathrm{G}}$ than $\mathrm{R}_{\mathrm{C}}$, then the mobility calculated from the transconductance is underestimated; (ii) if $R_{C}$ is more dependent on $V_{G}$ than $R_{C H}$ is, then the mobility is overestimated. The latter case is particularly true when the channel resistance is low and $\mathrm{R}_{\mathrm{C}}$ decreases sharply to $\mathrm{R}_{\mathrm{CH}}$, which can happen with gated Schottky contacts in OTFTs. ${ }^{[20]}{ }^{[21]}$ Liu et al. have produced an excellent illustrative guide of how these $\mathrm{R}_{\mathrm{C}}$ conditions manifest themselves in OTFT experimental data and, in particular, how they impact the carrier mobility. ${ }^{[19]}$

Firstly, they explore the effect of $\mathrm{R}_{\mathrm{C}}$ in the linear regime for three different situations: (i) $\mathrm{R}_{\mathrm{C}}<\mathrm{R}_{\mathrm{CH}}$ and decreases slowly ("small $\mathrm{R}_{\mathrm{C}}$ "), (ii) $\mathrm{R}_{\mathrm{C}}>\mathrm{R}_{\mathrm{CH}}$ and rapidly decreases so that $\mathrm{R}_{\mathrm{C}}<\mathrm{R}_{\mathrm{CH}}$ ("large $\mathrm{R}_{\mathrm{C}}-\mathrm{I}$ "), iii) $\mathrm{R}_{\mathrm{C}}>\mathrm{R}_{\mathrm{CH}}$ and slowly decreases ("large $\mathrm{R}_{\mathrm{C}}$-II"). Figure 3 shows the results from their calculations. The form that the underestimation or overestimation takes strongly depends on the nature of $\mathrm{R}_{\mathrm{C}}$. If $\mathrm{R}_{\mathrm{C}}$ is small compared to the $\mathrm{R}_{\mathrm{CH}}$, then this can result in an underestimation, with the mobility in the plot of $\mu_{\text {lin }}$ vs. $V_{G}$ gradually decreasing with increasing $\mathrm{V}_{\mathrm{G}}$. If $\mathrm{R}_{\mathrm{C}}$ is large compared to $\mathrm{R}_{\mathrm{CH}}$ and changes quickly, this results in an overestimated peak in mobility. If $\mathrm{R}_{\mathrm{C}}$ is large compared to $\mathrm{R}_{\mathrm{CH}}$ and changes slowly, then there is a continual increase in the mobility with $\mathrm{V}_{\mathrm{G}}$. We note that, particularly for the case of the ordered semiconductor in Figure 3c, the mobility value stabilises at high $\mathrm{V}_{\mathrm{G}}$ following the peak, to a value resembling the real mobility of the semiconductor. 
Secondly, Liu et al. use technology computer-aided design (TCAD) 2D calculations to look at $R_{C}$ effects on the plot of $\sqrt{I}_{\mathrm{D}_{-} S A T} \mathrm{vs} . \mathrm{V}_{\mathrm{G}}$ and $\mu_{\text {sat }} \mathrm{vs}$. $\mathrm{V}_{\mathrm{G}}$. By fixing channel dimensions, highest occupied molecular orbital (HOMO) level and mobility whilst varying the workfunction of the metal, they not only demonstrate the origin of the kink, but also how the shape of $\sqrt{ }_{D_{-} \text {SAT }}$ varies under varying conditions of $\mathrm{R}_{\mathrm{C}}$ and OSC ordering. Figure 4 shows their results. When $R_{C}$ is negligible, a linear relationship between $\sqrt{ }_{D}$ and $V_{G}$ is observed (Figure 4d and Figure 4g), in-line with classic FET theory. ${ }^{[19]}$ Therefore the mobility is accurately extracted from this data. On the other hand, when $R_{C}$ becomes more significant, the kink is present (Figure 4e, $\mathbf{4 f}$ and $\mathbf{4 h}$ ). Each time the kink is present, there is a substantial overestimation in $\mu_{\text {sat }}$ (compared to the actual fixed $\mu_{\mathrm{sat}}=7 \mathrm{~cm}^{2} / \mathrm{Vs}$ ). For the disorder-free OSC case, the most extreme case of $R_{C}$ (Figure $4 \mathbf{f}$ ) results in a peak in $\mu_{\text {sat }}$ at $70.4 \mathrm{~cm}^{2} / \mathrm{Vs}$, around 10 times greater than the actual fixed mobility. In the case of the disordered OSC, the most extreme case of $\mathrm{R}_{\mathrm{C}}$ (Figure 4i), the kink is not present but there is not a linear relationship between $\sqrt{ }_{D}$ and $V_{G}$; here, the gradient of $\sqrt{ }_{D}$ gets steeper with increasing $V_{G}$, leading to a substantial mobility overestimate. This type of mobility dependency on $\mathrm{V}_{\mathrm{G}}$ has been highlighted before and has been seen observed in a number of OSC-based OTFTs. ${ }^{[8]}$

\subsection{The impact of contact resistance in OTFTs}

The prevalence and impact of overestimated mobility values analysed from the kink triggered experimental verification its origin. In 2016 Bittle et al. used impedance spectroscopy to separate the electrical behaviour at the contacts and the channel, demonstrating that, in such cases, $\mathrm{I}_{\mathrm{D}}$ is dictated by the $\mathrm{R}_{\mathrm{C}}$ dependency on $\mathrm{V}_{\mathrm{G}} \cdot{ }^{[12]}$ Using a single crystal rubrene FET with non-ideal characteristics, they show that the mobility calculated using the classical FET model can be overestimated by an order of magnitude, as $\mathrm{R}_{\mathrm{C}}$ varies strongly at low $\mathrm{V}_{\mathrm{G}}$ and transistor characteristics are governed by charge injection. An alternative technique, scanning Kelvin 
Probe microscopy, was used by $\mathrm{Hu}$ et. al. to study how $\mathrm{V}_{\mathrm{G}}$ influences both $\mathrm{R}_{\mathrm{C}}$ and $\mathrm{R}_{\mathrm{CH}}$ in poly(2,5-bis (2-octyldodecyl)-3-(5-(thieno[3,2-b]thiophen-2,5-yl)thiophen-2-yl)-6-(thiophen2,5-yl)pyrrolo[3,4-c]pyrrole-1,4(2H,5H)-di- one) (DPPT-TT) OTFTs. ${ }^{[22]}$ Uemura et al. also took an original experimental approach to verify the anomalistic nature of the kink. ${ }^{[13]}$ They made vacuum evaporated FETs from 2,9-didecyl-dinaphtho[2,3-b:2',3'-f]thieno[3,2b]thiophene $\left(\mathrm{C}_{10} \mathrm{DNTT}\right)$ that suffered from non-ideal characteristics. By gently annealing the devices they were able to resolve the non-ideal characteristics, thereby giving them a platform to investigate the differences between devices with the kink (pre-annealed) and without the kink (post-annealed). They began by measuring the mobility of the pre-annealed OTFTs using two techniques. Firstly, they used the standard two-probe transmission line method (TLM) to measure the apparent mobility, $\mu_{\text {app}}$, from steepest part of the kink, i.e. the superlinear transconductance at low gate voltages. In the most extreme case, $\mu_{\text {app }}$ reached mobilities up to $100 \mathrm{~cm}^{2} /$ Vs. Secondly, they used a gated four-point probe (gFPP) method to measure the intrinsic mobility, $\mu_{\text {int }}$, as this method allows mobility to be measured without contact effects. This demonstrated a significant difference between $\mu_{\text {app }}$ and $\mu_{\text {int }}$, with the worst-case scenario being a factor of 10 difference.

By annealing the OTFTs, $R_{C}$ was significantly minimised by improving the metal/semiconductor interface (shown in Figure 5). Not only did the transfer characteristics improve, but re-measuring $\mu_{\text {app }}$ using the TLM method gave the same values as $\mu_{\text {int }}$ measured with gFPP. This therefore demonstrates that $R_{C}$ was indeed responsible for the peaks in $\mu_{\text {app}}$, and could lead to a significantly overestimated $\mu_{\text {app. }}$ Other important points that Uemura et al. highlight are that this overestimation is more significant at longer channel lengths and in the saturation regime, as well as that $R_{C}$ dependency on $V_{G}$ may not be shown in the output curves as might be expected (i.e. $R_{C}$ issues may not be shown by nonlinearities at low $V_{D}$ ). Additionally, they emphasise that high mobility OSCs are more likely to suffer from this 
issue. Collectively, this work shows that the kink in $\sqrt{I}_{\mathrm{D}}$ vs. $\mathrm{V}_{\mathrm{G}}$ comes from modulation of $\mathrm{R}_{\mathrm{C}}$ whilst $\mathrm{V}_{\mathrm{G}}$ is swept during transistor operation. As the OSC is electrostatically doped during device operation, the charge injection barrier changes significantly, altering how the charges are injected, significantly impacting the overall transport and capacitance approximation. ${ }^{[23]}$ [19]

There are also experimental evidence that demonstrate how the Schottky barrier at the contacts is effected by both $V_{G}$ and $V_{D}$. ${ }^{[24]}{ }^{[25]}{ }^{[26]} \mathrm{Xu}$ et al. showed how the effective Schottky barrier height, $\varphi_{\mathrm{B}}+\varphi_{\mathrm{i}}$, seen by holes changes with the application of $\mathrm{V}_{\mathrm{G}}$ in TG-BC OTFTs made from two of the most prominent high mobility polymers, DPPT-TT and IDT-BT. ${ }^{[10]}$ By applying thermionic emission theory to the output characteristics in the linear regime, they are able to extract the barrier height. ${ }^{[27]}$ They find that, in DPPT-TT OTFTs, $\Phi_{\mathrm{B}}$ decreases quickly following $\propto\left(\mathrm{V}_{\mathrm{G}}\right)^{0.5}$, and in IDT-BT, $\Phi_{\mathrm{B}}$ is found to decrease with both $\mathrm{V}_{\mathrm{G}}$ and $\mathrm{V}_{\mathrm{D}}$ following $\propto(\mathrm{V})^{0.5}$. Importantly, in the latter IDT-BT devices, as $\mathrm{V}_{\mathrm{G}}$ is swept from 0 to $-20 \mathrm{~V}$ the effective Schottky barrier is decreased from $\Phi_{\mathrm{B}, \mathrm{p} 0}=0.64 \mathrm{eV}$ to $\Phi_{\mathrm{B}, \mathrm{p}}=0.24 \mathrm{eV}-$ translating into a reduction in $\mathrm{R}_{\mathrm{C}}$ by $5.4 \times 10^{6}$ times its initial value in the low $\mathrm{V}_{\mathrm{G}}$ region. The impact of this is that the measured increase in $I_{D}$ is entirely due to this decrease in $R_{C},{ }^{[21]}$ i.e. in this low $\mathrm{V}_{\mathrm{G}}$ region the overall charge transport is dictated by access at the contact. ${ }^{[10]} \mathrm{Xu}$ et al. explained that when this effect is superimposed onto charge accumulation in the channel, it results in a steeper/superlinear increase in $\mathrm{I}_{\mathrm{D}}$ with increasing $\mathrm{V}_{\mathrm{G}}$.

Another demonstration of how changing the Schottky barrier with $V_{G}$ affects the performance of a TFT was reported by Liu et al. ${ }^{[19]}$ They model how the HOMO level band bending evolves with $\mathrm{V}_{\mathrm{G}}$ for both an Ohmic and a Schottky contact, to directly compare the two situations. They explain that, in a TFT with Schottky barriers at the contacts, there are essentially two modes of operation, separated by a transition voltage, $\mathrm{V}_{\text {TRAN }}$. The first mode occurs at low voltage, when the only way the carriers can cross the depletion region is via 
thermal emission, due to the Schottky barrier causing high resistance; additionally, the voltage across the channel is limited, because the voltage between the source and the pinch point is consumed at the contact area. Here, the device works in the same way as it does in the subthreshold regime, when the accumulation of charge carriers at the channel is limited. This is referred to as the Schottky barrier transistor (SBT) mode.

With increasing $\mathrm{V}_{\mathrm{G}}$, the HOMO level is eventually bent enough to reduce the width of the barrier, allowing carriers to tunnel across. The Schottky barrier has changed to an Ohmic-like contact and the voltage decrease now happens at the channel. This is described as the TFT mode. However, If $\mathrm{V}_{\mathrm{G}}$ is not big enough to bend the HOMO level, the transistor will always operate in SBT mode. One example of the latter injection issues is the $\mathrm{V}_{\mathrm{G}}$ dependent mobility value that stretches over several magnitudes (also shown in Figure 4i). Liu et al. also highlight that a low capacitance dielectric layer, increased dielectric layer thickness, as well as high channel devices (that are still operating in SBT mode) can result in more serious mobility overestimations.

\subsection{Improving the contact resistance}

There are a number of variables that influence the severity of $R_{c}$ in OTFTs. For example, the ordering of the OSC, the OSC energy levels, the material used for source/drain electrodes and the dielectric that has been used for a particular device. ${ }^{[15]}$ There are several approaches that are available for improving contact resistance in OTFTs - many of which are easily available and widely used. Here we will give a brief overview of how morphology impacts $R_{C}$ as well a discussion on how doping, which could be instrumental in resolving OTFT $R_{C}$ issues, can be implemented experimentally. For further information about how the dielectric layer influences $\mathrm{Rc}$, we refer the reader to the work by Liu et al. ${ }^{[15]}$. 


\subsubsection{Microstructure}

Microstructural ordering of OSCs can have an impact on $\mathrm{R}_{\mathrm{C}}$. One morphology-related situation can occur due to the device architecture, for example, in bottom-contact OSCs, the morphology at the contacts may be very different to the morphology of the OSC at the channel. ${ }^{[10]}$ Indeed, there is a known link between ordering and contact resistance; the injection barrier at the metal/semiconductor interface can decrease with the narrowed density of states in a more ordered polymer ${ }^{[28]}{ }^{[29]}$ and is associated with a interfacial properties, such as a higher number of available gap states at the OSC interface, the Richardson-Schottky effect or an image barrier. [9] [30] [31] To this end, Bittle et al. demonstrated the impact of morphology and ordering in a study on regioregular poly(3-hexylthiophene-2,5-diyl) (rrP3HT) fabricated from different solvents, to allow varying times of film formation, and hence resulting in varying ordering. ${ }^{[9]}$ They find that, with increasing order, the TFT characteristics progress from nonideal to ideal: $\mathrm{R}_{\mathrm{C}}$ decreases, s-shaped diode-like output characteristics become linear, and mobility is constant rather than bias dependent (Figure 6).

\subsubsection{Doping}

One way to improve contact resistance in OTFTs by reducing the height of the Schottky barrier, $\varphi_{\mathrm{B}}$, is to choose a metal contact with a similar $\varphi_{\mathrm{m}}$ to the OSC transport level (HOMO or LUMO). However, the choice of materials available is often limited; for example, metals that typically have suitable work functions for electron injection in $n$-type OTFTs are very reactive and unsuitable for use in ambient conditions. Another approach widely employed to address $R_{C}$ in OTFTs is tuning the work function using thiol-based self-assembled monolayers (SAMs) or a charge injection layer between the injecting contacts and the OSC. These approaches have been covered in detail in other excellent review papers. ${ }^{[23,32]}$ Although 
these techniques are widely used and are certainly beneficial, they have not yet provided a universal approach for eliminating $\mathrm{R}_{\mathrm{C}}$ altogether.

Alternatively, the Schottky contacts can be transformed into Ohmic contacts in two ways: (i) choose $\varphi_{\mathrm{m}}>\varphi_{\mathrm{s}}$ for a $p$-type semiconductor, and $\varphi_{\mathrm{m}}<\varphi_{\mathrm{s}}$ for an $n$-type semiconductor. (ii) Reduce the width of the depletion region so that it is thin enough to allow tunnelling in both directions, forming a quasi-Ohmic contact with very little resistance. Point (i) is, of course, an intrinsic property of the metals used for the contacts in TFTs - which we note are often modified by surface or interfacial states in real devices - and therefore depends on the choice of material used for device engineering. On the other hand, point (ii) can be achieved by doping and is the approach widely used by the inorganic semiconductor industry, ${ }^{[33]}{ }^{[34]}$ for example, selective contact doping is used in silicon metal-oxidesemiconductor field-effect transistors ( $\mathrm{Si}$ MOSFETs) to produce Ohmic contacts. ${ }^{[35]}$ Introducing a dopant generates charge carriers in the semiconductor, moving the Fermi level towards either the HOMO or the lowest unoccupied molecular orbital (LUMO), depending on the materials, and the shift in $\mathrm{E}_{\mathrm{F}}$ changes $\varphi_{\mathrm{s}}$ because:

$$
\phi_{\mathrm{s}} \equiv\left(E_{0}-E_{\mathrm{F}}\right) / q
$$

which therefore changes the built-in voltage, $\varphi_{\mathrm{i}}$ :

$$
q \phi_{\mathrm{i}} \equiv q \phi_{\mathrm{m}}-q \phi_{\mathrm{s}}=q \phi_{\mathrm{B}}-\left(E_{\mathrm{F}}-E_{\mathrm{HOMO}}\right)_{\text {bulk }}
$$

Using Poisson's equation and the depletion approximation gives the relationship between $\varphi_{\mathrm{i}}$ and the depletion region as: $:^{[36]}$

$$
\phi_{\mathrm{i}}=\phi_{\mathrm{m}}-\phi_{\mathrm{s}}=\frac{1}{2} \frac{q N_{d}}{k \epsilon_{\mathrm{o}}} x_{d}^{2}
$$


where $\mathrm{N}_{\mathrm{d}}$ is the doping density, $\mathrm{k}$ is Coulomb's law constant, $\epsilon_{0}$ is the permittivity of free space and $x_{d}$ is the width of the depletion region. Rearranging Eq. 11 gives the width of the depletion layer as: ${ }^{[36]}$

$$
x_{d}=\sqrt{\frac{2 k \epsilon_{0} \phi_{i}}{q N_{d}}}
$$

which depends on both $\varphi_{i}$ and $N_{d}$. Therefore if $N_{d}$ is large then $x_{d}$ becomes small. If $x_{d}$ is small enough $\left(\mathrm{x}_{\mathrm{d}} \leq 25-50 \AA\right)$ then a low resistance quasi-Ohmic contact forms and tunnelling can occur, compared to large barrier widths where injection occurs by thermionic emission. Doping the OSC can therefore enable efficient charge injection in OTFTs, regardless of the barrier height from the mismatch between $\varphi_{m}$ and the OSC transport level, by reducing the depletion layer width and hence reducing contact resistance. ${ }^{[37]}{ }^{[38]}$ For example, doping dependent depletion region width was shown by Olthof et al. who measured $x_{d}$ in $\mathrm{N}, \mathrm{N}, \mathrm{N}^{\prime}, \mathrm{N}^{\prime}-$ tetrakis(4-methoxyphenyl)-benzidine (MeO-TPD) doped with $\mathrm{F}_{4}$-TCNQ via co-evaporation, using Ag, ITO and PEDOT:PSS as the electrode materials. ${ }^{[39]}$

But doping in OTFTs doesn't only have the power to resolve $\mathrm{R}_{\mathrm{C}}$ issues; doping also has the power to make striking improvements to all aspects of TFT operation, such as bias

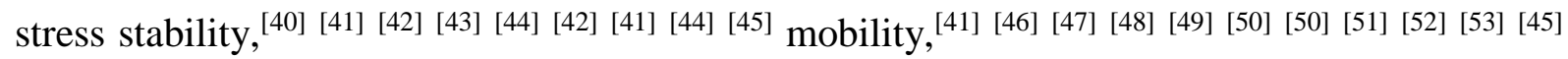
threshold voltages, ${ }^{[37] ~[54] ~[55] ~[56] ~[57] ~}$ and has also been seen to improve device uniformity. ${ }^{[58]}$ However, despite the known significance of this technique, the controlled, intentional doping of OTFTs has yet to be realised with the same substantial impact that it has had for inorganics due to practical utilisation issues; namely, introducing a dopant into an OSC runs a high risk of interfering with the OSC host lattice and decreasing the mobility. To this end, the topic of doping in OTFTs has been covered in great detail in the recent literature review by Lüssem et al., ${ }^{[33]}$ dopant design rules have been covered by Salzmann et al. ${ }^{[59]}$ and doping mechanisms (charge-transfer complex and ion pair formation) covered by both Salzmann et al. and Jacobs 
and Moule. ${ }^{[60]}$ Therefore, here we will give an overview of the key techniques that are used to implement doping for $\mathrm{R}_{\mathrm{C}}$ improvement.

\section{Contact doping and interlayer doping}

The most common method for doping OTFTs, used to avoid lattice interruptions which ultimately increase disorder in an OSC system, is to introduce an extra layer into the structure.

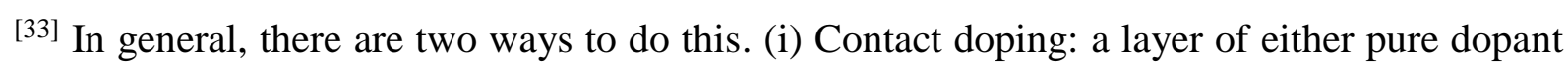
or dopant/semiconductor mix is deposited at the source and drain metal/semiconductor interface (Figure 7). ${ }^{[61]}{ }^{[62]}$ Contact doping is a widely studied technique for reducing contact resistance in OTFTs; and there are many examples in the literature of this technique being used [57] [49] [61] [62] [63] [64] [65]. Self-assembled monolayers (SAMs), such as pentafluorothiophenol (PFBT) [66] [65] [67] [68] [69], and injection layers, such as molybdenum(VI) oxide $\left(\mathrm{MoO}_{3}\right)^{[70]}{ }^{[71]}$, have become commonplace in an OTFT fabrication laboratory. (ii) Inserting a dopant interlayer either above or below the OSC. This approach has been shown to increase conductivity and shift the threshold voltage. ${ }^{[33] ~[72] ~[73] ~[74] ~ I n ~ t h i s ~ c a s e, ~}$ the thickness of the dopant layer must be carefully optimised, as demonstrated by Lüssem et al. ${ }^{[56]}$, or the thickness of the OSC must be optimised, as demonstrated by Hählen et al. ${ }^{[75]}$, depending on where the dopant layer is placed in the chosen OTFT structure.

\section{Chemical vapour treatment}

Another way to dope OTFTs is to use a chemical vapour treatment. ${ }^{[76] ~[77] ~ O n e ~ e x a m p l e ~ i s ~ b y ~}$ Lee et al., who start their work by highlighting the need for a method to dope OSCs without the resistivity/nanomorphology being affected and hence mobility inhibited. ${ }^{[78]}$ They suggest chemical vapour treatment is a good option and subsequently use this approach to dope poly[4-(4,4-dihexadecyl-4H-cyclopenta[1,2-b:5,4-b']dithiophen-2-yl)-alt-[1,2,5]thiadiazolo- 
[3,4-c]pyridine] (PCDTPT) that had been externally aligned. Using an iodine $\left(\mathrm{I}_{2}\right)$ vapour treatment, they report an increase in carrier density, a shift in $V_{T}$ and a reduction in the contact resistance, as well as reported increased mobility values. In addition to performance improvement, this is also a good example of how OTFT gas-based doping could lend itself to chemical/gas sensor applications ${ }^{[79]}{ }^{[80]}$.

\section{Modulation doping}

In the field of inorganic electronics, a process known as modulation doping is used whereby the dopant is not located within the channel, but the dopant-induced free carriers are still able to populate the channel. This results in spatial separation between the dopant and the free charge carriers and hence avoids adverse scattering effects. Modulation doping is used in, for example, $\mathrm{AlGaAs} / \mathrm{GaAs}$ heterostructures and modulation-doped field effect transistors (MODFETs).

Realising modulation doping in OTFTs would mean that the dopant molecules would not reduce OSC crystallinity at the channel, which is important because is currently one of the biggest setbacks for doping in OTFTs ${ }^{[33]}$. Modulation doping-like techniques are therefore an extremely attractive option for organic electronics, but the number of relevant studies involving OTFTs are few and far between. One example is by Zhao et al., who designed an organic heterojunction with aligned energy levels in contact with an OTFT channel. ${ }^{[81]}$ The heterojunction is comprised of a layer of N,N'-diphenyl-N,N'-bis(1-naphthyl)-1,1'-biphenyl4,4'-diamine ( $\alpha$-NPD) that has been doped with Mo(tfd) 3 (labelled " $p$-doped $\alpha$-NPD") on top of a layer of pentacene. The free holes are generated in the $p$-doped $\alpha$-NPD and remotely transferred to the pentacene channel because the ionisation energy (IE) of the pentacene is equivalent to the work function of the $p$-doped $\alpha$-NPD; this subsequently increases OTFT conductivity without the dopant acting as a trapping or scattering centre. Another example is 
by Paterson et al., who demonstrated modulation doping-like behaviour by simply adding a dopant to a channel composed of a phase separated small-molecule/polymer blend. ${ }^{[52,58]}$ The latter system will be discussed in further detail in Section 5.

\subsection{How to analyse OTFT data}

\subsubsection{Alternative approaches}

There are numerous other approaches that have been suggested for accurate mobility analysis. Using an alternative model, ${ }^{[7]}$ or a different measurement technique to avoid the OTFT contact resistance issues, ${ }^{[82] ~[83] ~[84] ~[85] ~[18] ~[86] ~[87] ~[88] ~[89] ~[90] ~[91] ~[92] ~ i s ~ o n e ~ a p p r o a c h ; ~ f o r ~}$ example, scanning Kelvin probe microscopy, ${ }^{[87] ~[88]}$ gated four point probe, ${ }^{[92]}\left[{ }^{[93]}{ }^{[94]}\right.$ gated van der Pauw method. ${ }^{[18]}$ These techniques are excellent for mobility verification or for further understanding of the underlying charge transport in OSCs.

As well as measurement techniques, alternative analytical models with alternative measurements and/or analysis of the transistor data have been suggested numerous times over the years. ${ }^{[6]}$ [95] [96] [20] [97] [6] [98] [99] [100] [23] [101] Although some of these approaches add complications by requiring alterative set of measurements, for example, requiring a range of uniform devices with varying channel lengths (TLM), ${ }^{[23]}$ some other are easier to implement, for example, the Y-function method. [96] [99] [32] The latter method is a straightforward approach that can be used with transistor data already available. However, the technique is not only limited to the linear regime, but it also assumes that $\mathrm{R}_{\mathrm{C}}$ is $\mathrm{V}_{\mathrm{G}}$-independent. ${ }^{[96]}$ Another simple way to extract the mobility is from the conductance of the output curves. [20] [98] [32] This method is known to yield conservative estimates of the mobility, simply because measurements are conducted at large $\mathrm{V}_{\mathrm{G}},{ }^{[20]}$ where Ohmic-like injection prevails due to barrier suppression. ${ }^{[19]}$ 


\subsubsection{Using the gradual channel approximation}

As the GCA will undoubtedly be used for the foreseeable future, we recommend that authors show all of their OTFT measurement data in their publications: output curve, transfer curve, $\mu$ vs. $V_{G}, \sqrt{I}_{D_{-} \text {SAT }}$ vs. $V_{\mathrm{G}}$ and/or $\mathrm{I}_{\mathrm{D}_{-} \text {LIN }} \mathrm{vs} . \mathrm{V}_{\mathrm{G}}$. By thoroughly examining all of the experimental TFT data together it will be clear to identify any problems and see if/how the data deviates from the ideal model. This is important because non-ideal behaviour has been observed in almost all types of OSCs, from amorphous to single crystals and, and although the kink has recently become the flagship symbol of mobility overestimation, $\mathrm{V}_{\mathrm{G}}$ can still have caused a nonlinear increase in $I_{D}$ without the kink being present. ${ }^{[19]}$

Values for both $\mu_{\text {sat }}$ and $\mu_{\text {lin }}$ should also be given in publications. We suggest that, in the case where $R_{C}$ causes a kink in $\sqrt{I}_{D}$ vs. $V_{G}$ or a peak in plot of $\mu$ vs $V_{G}$, a reasonable estimate of $\mu_{\text {sat }}$ can be extrapolated from the plot of $\mu$ vs $V_{G}$, after the peak when the mobility value stabilises at higher $\mathrm{V}_{\mathrm{G}}$. This bias condition implies that the OTFT has transitioned out of SBT mode and into TFT mode (also, see Figure 4). The linear mobility is less likely to suffer from inaccurate mobility analysis and therefore should be quoted alongside $\mu_{\text {sat. }}$ Additionally, $\mathrm{R}_{\mathrm{C}}$ analysis could be included for OTFTs that are found to suffer from severe problems (Figure 8).

To establish how "well" the device is working in comparison to the ideal FET model, the following describes what to look out for in terms of nonidealities, in line with the Institute of Electrical and Electronics Engineers (IEEE) recommendations: ${ }^{[102]}$

i. The output curves. The slope of the output curve is the conductance, $\mathrm{g}_{\mathrm{s}}$, where ${ }^{[102]}$ :

$$
g_{s}=\frac{\partial I_{D}}{\partial V_{D}}
$$

The conductance should exhibit a linear relationship, not an s-shaped conductance, which has been readily observed in OTFT output characteristics. This nonideality is 
frequently attributed to contact resistance, ${ }^{[103]}$ although it has been shown that the s-shape only occurs when a device suffers from large $R_{C}$, when compared to channel resistance, and also has a power law mobility dependence. ${ }^{\text {[9] }[104]}{ }^{[105]}$ In addition to considering the s-shaped non-ideality, the output curves must exhibit clear saturation at the $\mathrm{V}_{\mathrm{D}}$ used to calculate the saturation regime mobility.

ii. The transfer characteristics, $\sqrt{I_{D_{-} S A T}}$ vs. $V_{G}$ and/or $I_{D_{-} L I N} v s . V_{G}$. There should be a linear relationship between $\mathrm{I}_{\mathrm{D} \_ \text {LIN }}$ and $\sqrt{ }_{\mathrm{I}_{\mathrm{D}} \mathrm{SAT}}$ with increasing $\mathrm{V}_{\mathrm{G}}$. Any nonlinearities are $g_{m}$ artefacts. Figure 4, Figure $\mathbf{3 b}$ and Figure 5d demonstrate nonlinearities to look out for and can be used as a guide to explaining the origin of the artefact, although there are other forms that the nonlinearity can take. ${ }^{[14]}$ Two key $\mathrm{R}_{\mathrm{C}-\text {-related }}$ features to look out for are the kink (Figure $\mathbf{4 e}, \mathbf{4 f}$ and $\mathbf{4 h}$ ), or a superlinear increase in $\sqrt{I_{D}}$ with $V_{G}$ (Figure 4i).

iii. The $\mu$ dependence on $V_{G}$. Liu et al. have produced a very useful diagnostics tool, shown in Figure 9, that can be compared against experimental data to help explore some of the reasons for OTFT mobilities that vary with $\mathrm{V}_{\mathrm{G}}$.

Choi et al. recently published a thorough article suggesting the use of a measurement reliability factor, $r$, which acts as a numerical description of how closely to an ideal FET the device is operating. ${ }^{[14]}$ The maximum value, $r=100 \%$, represents an ideal FET, as described by Shockley's model, with a linear relationship between conductivity and carrier density, negligible threshold voltage and constant mobility. The measurement reliability factor can be calculated for both the linear and saturation regimes using: 


$$
\begin{aligned}
& r_{\text {lin }}=\left(\frac{\left|I_{S D}\right|^{\max }-\left|I_{S D}^{0}\right|}{\left|V_{G}\right|^{\max }}\right) /\left(\frac{\left|V_{S D}\right| W C_{i}}{L} \mu_{\text {lin }}\right)_{\text {claimed }} \\
& r_{\text {sat }}=\left(\frac{\sqrt{\left|I_{S D}\right|^{\max }}-\sqrt{\left|I_{S D}^{0}\right|}}{\left|V_{G}\right|^{\max }}\right)^{2} /\left(\frac{W C_{i}}{2 L} \mu_{\text {sat }}\right)_{\text {claimed }}
\end{aligned}
$$

\subsection{What impact has the "mobility hype" had on the literature?}

To answer this question, we have examined the literature from the past 30 years to get an idea of how often reported saturation mobility values have been extracted from OTFTs that show the aforementioned nonidealities. Additionally, we noted whether the mobilities were for p-type or n-type OTFTs, and whether the reported mobilities were from solution-processed, vacuum-processed or single-crystal OSCs.

Figure 1a shows a plot of reported mobility values versus time based on charge carrier type, suggesting that electron mobilities are approaching hole mobilities. Figure 1b shows how published mobility values correlate with processing, suggesting that the reported solution-processed mobility values are now comparable to those for single crystal and vacuum processed OSCs. Figure 1c shows the same data set, but this time the mobility values are separated into categories based on the OTFT experimental data that they were extracted from: (i) the data exhibits a nonlinear relationship between $\sqrt{ }_{\mathrm{D}}$ and $\mathrm{V}_{\mathrm{G}}$, (ii) the data has nonsaturated output characteristics, (iii) the publication does not show the data used to calculate mobility (i.e. does not show the plot of $\mu$ vs. $V_{G}$ or $\sqrt{I}_{D}$ vs. $V_{G}$ ), (iv) the gradient of $\sqrt{I}_{D}$ vs. $V_{G}$ gets steeper with increasing $\mathrm{V}_{\mathrm{G}},(\mathrm{v})$ we can't observe any nonidealities in the data presented, referred to as "reliable". It should be noted that, for the latter point, in some cases the output curves are not presented or the data for the highest claimed carrier mobility isn't shown. This 
graph is designed to give us a general, although not exhaustive, idea of how many published mobility values have been affected by nonidealities over the past 30 years.

In Figure 1c, we can clearly see the impact and timelines of $\sqrt{ }_{D}$ vs. $V_{G}$ nonlinearities, namely the kink. Figure S1 shows the same data with a focus on recently reported (2000 to 2018) high mobility $\left(>1 \mathrm{~cm}^{2} / \mathrm{Vs}\right)$ data that are difficult to distinguish in Figure 1c. As mobilities started improving in the early 2000's, the kink became more prominent, until it completely dominates the high mobility publications, resulting in the mobility hype in 2012 . A closer look at the graph suggests that the mobility hype was waiting to happen; since 2004, mobility values analysed from a kink (or transistors exhibiting other nonidealities) are becoming more commonplace in the OTFT literature; as intrinsic mobilities improved, $\mathrm{R}_{\mathrm{CH}}$ decreased, making the issue of $\mathrm{R}_{\mathrm{C}}$ more apparent. ${ }^{[106]}$ We also found that the highest reported solution processed mobilities are taken from data that shows nonidealities - primarily interpreted from the kink. (We note that we can't include the reliable mobilities associated with this data, as it is not our aim to re-analyse the literature. However, we also note that it's possible that these values are overestimated by an order of magnitude. ${ }^{[19]}{ }^{[12]}$ Therefore, we can only base the trends on mobilities that, to our knowledge based on the data presented, have been extracted from reliable data, in this particular dataset).

The impact of this data analysis culminates in Figure 1d. Here, we only show solution processed mobilities close to or greater than $1 \mathrm{~cm}^{2} / \mathrm{Vs}$; we take around $1 \mathrm{~cm}^{2} / \mathrm{Vs}$ as a benchmark mobility because the performance is comparable to a-Si TFTs. Hole mobilities are represented by circles and electron mobilities are represented by triangles. If the mobility value has been extracted from OTFT data showing nonidealities, or not showing the data that the mobility has been extracted from, then the point on the graph has been greyed out. The mobility values extracted from "reliable" data have been kept in bold. Based on this dataset, since hole mobilities started approaching $1 \mathrm{~cm}^{2} / \mathrm{Vs}, 55 \%$ of the mobility values published in 
the literature contains experimental data that appears to deviate from the classical FET model. But we also note that this data set suggests that there has been a highly encouraging, constant improvement of mobility values over time. Actually, the irony of the mobility hype is that impressive improvements in mobility were being achieved, but just not as much as the numbers suggested in the literature.

We also see that OTFT hole mobilities only exceeded $10 \mathrm{~cm}^{2} / \mathrm{Vs}$ in 2015 , and they have yet to exceed $20 \mathrm{~cm}^{2} / \mathrm{Vs}$. On the other hand, n-type solution processed OSCs have yet to exceed benchmark mobilities of $10 \mathrm{~cm}^{2} / \mathrm{Vs}$. We observe that small-molecules still show the highest mobility values, and that, over the years, small-molecule/polymer blend systems have been consistently amongst the highest reliably reported solution-processed OTFT mobilities. ${ }^{[107][52] ~[108] ~[108] ~[108] ~}$

\section{Design strategies for p-type semiconductors}

Figure 1d shows that, despite some distraction from the mobility hype, significant and great progress has been made over the years in terms of improving charge carrier mobilities of p-type OSCs. Although p-type molecular semiconductors still show the highest mobilities, p-type polymers in particular have made remarkable improvements in fundamental design and overall electrical performance. Here we will focus on the design criteria and key concepts that have, over time, been behind these successes, rather than focus on specific/highest mobility values that have been recently reported.

\subsection{Polythiophenes}

When it comes to understanding the relationship between polymer microstructure and charge carrier mobility, regioregular (rr) P3HT (P1, see Figure 10) is one of the most well-studied polymers. In rr-P3HT, strong interchain $\pi-\pi$ stacking is favoured, allowing polymer chains to 
self-organise into lamellar structures, where closely packed backbones are separated by extended, disordered alkyl chains. One of the key aspects that determines the electrical performance of this polymer is how the polymer backbones are orientated relative to the substrate. For instance, it's been shown that, if rr-P3HT adopts an edge-on backbone orientation relative to the substrate, then the highest hole mobility values are achieved, in the range of $0.1 \mathrm{~cm}^{2} / \mathrm{Vs}^{[109]}$ On the other hand, if the polymer backbone adopts a face-on orientation, the mobility values are reduced by one order of magnitude, highlighting the importance of morphology control for maximising mobilities.

Although the lamellar packing and edge-on orientation of P3HT are well-known to be advantageous for mobility, the low ionisation potential (IP) of the thiophene rich P3HT backbone can result in OTFTs that exhibit poor stability in ambient conditions, resulting in a drive for researchers to improve the ambient stability of these semiconducting materials. One approach was to introduce structural deviations in the polythiophene backbones; for example, introducing unsubstituted thiophene repeat units or thieno[3,2-b]thiophene repeat units produced polymers PQT-12 (P2) and pBTTT (P3), respectively. PQT-12 has been shown to exhibit hole mobilities exceeding $0.1 \mathrm{~cm}^{2} / \mathrm{Vs}^{[110]}$ and pBTTT have demonstrated hole mobilities of $0.2-0.6 \mathrm{~cm}^{2} / \mathrm{Vs}^{[111]}$

Regarding the latter, pBTTT polymers show IP around $5.10 \mathrm{eV}$, which is $\approx 0.3 \mathrm{eV}$ higher than P3HT, without compromising on coplanarity in the polymer backbone. ${ }^{[12]}$ This is because of the reduced delocalization of electrons from the fused thieno[3,2- $b]$ thiophene unit into the polymer backbone. Additionally, the order in pBTTT can be enhanced even further by side chain interdigitation, which results in a highly ordered three-dimensional microstructure with large domain sizes. These domain sizes are ultimately responsible for the improved charge carrier mobilities compared to other polythiophene derived polymers. ${ }^{[113]}$ The side-chain regiochemistry in pBTTT derivatives has also been shown to have a 
significant impact on mobility. ${ }^{[114]}$ For example, Fei et al. showed that, by judiciously placing the solubilising alkyl side-chains in P4 - P6, the effective conjugation length was enlarged, resulting in impressive maximum hole mobilities of $4.6 \mathrm{~cm}^{2} / \mathrm{Vs}(\mathbf{P 6})$. These high mobility values strongly suggested that semiconducting polymer design is not limited to the conjugated backbone; namely, to maximize polymer performance, it is also important to carefully consider the geometry and positioning of the side chains.

\subsection{Co-polymers incorporating fused aromatic units}

With the development of synthetically complicated semiconducting polymer structures, many of the design rules established for polythiophenes are no longer applicable. In recent years, polymers with apparently poorly ordered microstructures have somewhat unexpectedly outperformed the likes of pBTTT in terms of OTFT mobility, although we note that there is one design motif that has continued to predominate: the requirement for low energetic disorder along the conjugated backbone. This requirement is typically achieved by introducing fused building blocks with rigid aromatic monomer units and extended $\pi$-conjugation. For example, Liu et al. synthesized a series of copolymers based on $\mathrm{N}$-alkyl dithieno[3,2-b:2',3'-d]pyrroles (DTP) and thiophene and - despite a poorly ordered lamellar structure in thin-film - charge carrier mobilities up to $0.21 \mathrm{~cm}^{2} /$ Vs were achieved $(\mathbf{P 7}) .{ }^{[115]} \mathrm{In}$ contrast to "traditional" polythiophenes, the mobility of DTP based polymers are less dependent on crystallinity and long-range order. By systematically introducing fused aromatic building blocks (for example, fluorine and indenofluorene), the rigidity of the polymer backbones was increased, but at the same time, the large torsional angles between adjacent phenyl rings led to an increase of rotational disorder along the backbone, inhibiting higher charge carrier mobilities. However, the backbone planarity was increased by substituting the peripheral six-membered benzene rings on the repeat units for five-membered thiophene 
moieties. This approach allowed a reduction of the torsional angles between aromatic building blocks in the polymer backbone, whilst maintaining the rigid character of the fused ringsystem favoring intramolecular $\pi$-orbital overlap.

One of the most prominent building blocks incorporating the aforementioned design rules is indacenodithiophene (4,9-dihydro-s-indaceno[1,2-b:5,6- $b^{\prime}$ ]dithiophene, IDT). Although this material has been shown to exhibit hole mobility values of $0.15 \mathrm{~cm}^{2} / \mathrm{Vs}$ when polymerized with the electron-rich thieno[3,2-b]thiophene unit, ${ }^{[116]}$ it was only after copolymerizing the IDT unit with the electron deficient benzothiadiazole (BT) that its full potential was reached. The resulting IDT-BT copolymer achieved a maximum hole mobility of up to $1 \mathrm{~cm}^{2} / \mathrm{Vs}$ and, by carefully modifying the alkyl side-chains on the IDT moiety, the IDT-BT copolymer with hexadecyl side chains (P8) achieved mobility values of 1.2 $\mathrm{cm}^{2} / \mathrm{Vs}{ }^{[117]}$ Yet the striking improvement in mobility came from increasing the molecular weight to produce the copolymer $\mathrm{C}_{16}$ IDT-BT, which resulted in a remarkable hole mobilities of up to $3.6 \mathrm{~cm}^{2} / \mathrm{Vs} .{ }^{[118]}$ This significant result also helped shed some light on the role of high molecular weight polymer chains in terms of improving mobility: long conjugated chains act as electrical pathways by bridging the amorphous and poorly ordered regions with polymer aggregates, and in doing so, allow more efficient charge transport throughout the film. ${ }^{[119]}$ By extensively studying the relationship between microstructure and mobility with diffraction and polarizing spectroscopy techniques, the $\mathrm{C}_{16}$ IDT-BT copolymer was found to be mainly amorphous in nature. Additonally, $\mathrm{C}_{16}$ IDT-BT has a preferential face-on orientation of backbone chains relative to the substrate plane, in stark contrast to the edge-on orientation favored by polythiophenes. ${ }^{[120]}$

These studies have conclusively shown that charge transport in poorly ordered polymeric materials, like IDT-BT, predominantly occurs along the polymer chain with occasional interchain hopping. In this new family of materials, a long-range order 
microstructure and edge-on orientation are no longer crucial for achieving high charge carrier mobilities. The transport along the conjugated backbone in IDT-BT is further favored by its unusually rigid and low disorder backbone, as determined by Urbach energy measurements. Theoretical studies suggest that there is a low energy barrier to planarization for IDT-BT, but there is also a high energy barrier for rotation, meaning that co-planarity is preserved even in disordered regions, which results in a "ribbon-like" backbone conformation. ${ }^{[121]}$

Following the success of the fused IDT unit, several derivatives have since been synthesized with the aim of further extending the fused ring system and enhancing the charge carrier properties. For example, the seven fused aromatic ring copolymers with both indacenodithieno[3,2-b]thiophene (IDTT) and dithiopheneindenofluorene co-polymerized with benzothiadiazole (P9, P10) have produced OTFTs with improved mobility values. ${ }^{[122,123]}$ Another approach is to change the heteroatom of IDT from sulfur to selenium; co-polymers of the resulting alkylated analaogue have been shown to exhibit improved mobility. ${ }^{[124]}$ An additional note is that, in the case of IDTT-BT, there are significant device-related benefits from using an electron-blocking electrode treatment, namely copper(I) thiocyanate $(\mathrm{CuSCN}) .{ }^{[122]}$

\subsection{Taking advantage of noncovalent conformational locks}

But reducing the torsional disorder along the polymer backbone is not only achieved by covalently linking aromatic units into large fused moieties. This can also be achieved by introducing noncovalent conformational locks along the polymer backbone. ${ }^{[125]}$ The two most prominent building blocks illustrating this approach are the electron deficient diketopyrrolopyrrole (DPP) and isoindigo units containing bis-lactam cores. Single crystal X-ray diffraction experiments have shown that favourable oxygen-hydrogen interactions 
planarize the monomer core, resulting in highly coplanar polymer chains, with reduced torsional disorder along the polymer chain. ${ }^{[126]}$

One of the first pieces of work to highlight the potential of DPP based polymers reported a DPP-thiophene co-polymer (P11, see Figure 11) that exhibited ambipolar charge transport with hole and electron mobilities of around $0.1 \mathrm{~cm}^{2} / \mathrm{Vs} .{ }^{[127]}$ By copolymerizing the DPP unit with large fused electron rich comonomers, like DTP, the hole mobilities were improved up to $0.41 \mathrm{~cm}^{2} / \mathrm{Vs}(\mathbf{P 1 2}) \cdot{ }^{[128]}$ By further planarizing the conjugated backbone using less sterically hindering thiophene comonomers, and carefully adjusting the side chain density and polymer solubility, the hole mobilities could be increased to $0.74 \mathrm{~cm}^{2} / \mathrm{Vs}(\mathbf{P 1 3}) .{ }^{[129]}$ Interestingly, the reported DPP based polymers did not show a significant dependence on orientation relative to the substrate, as is typically observed for polythiophenes. This is a particularly intriguing point to note because this is highly beneficial for device fabrication. With further optimization, a balanced ambipolar transport with hole and electron mobilities both on the order of $1.0 \mathrm{~cm}^{2} / \mathrm{Vs}$ was obtained for DPPT-TT (P14) based OTFTs. ${ }^{[130]}$ Co-polymerisation with an extended thiophene terminated core, like dithieno[3,2-b:6,7b]fluorine, also resulted in further mobility enhancements. ${ }^{[131]}$ Additionally, flanking the DPP core with thieno[3,2-b]thiophene can increase hole mobility values without the need for high-temperature annealing (P16). ${ }^{[132]}$ Recently, a copolymer (P17) of DPP and the nonaromatic 5,5-dimethylcyclopentadiene monomer was synthesized following room temperature Suzuki copolymerization; ${ }^{[133]}$ the polymer thin-films showed a mixed microstructure, containing both edge-on and face-on orientated domains relative to the substrate, and a large $\pi-\pi$ stacking distance of $4.26 \AA$. Remarkably, and despite the complex and a priori "unfavorable" microstructure, top-gate bottom contact OTFTs exhibited biasindependent saturation hole mobilities of up to $3.1 \mathrm{~cm}^{2} / \mathrm{Vs}$. 
Isoindigo is another lactam containing, planar, electron poor monomer unit which is regularly incorporated into high-performing polymers. Isoindigo copolymers $(\mathbf{P 1 8}, \mathbf{P 1 9})$ have been reported to produce air stable OTFTs with good hole mobilities. ${ }^{[134]}$ After further substituting the isoindigo core with fluorine to induce intrachain short contacts along the polymer backbone (P20), air stable ambipolar OTFTs have been achieved. ${ }^{[135]}$ To avoid using supramolecular locks for planarising the conjugated backbone, benzene rings can be substituted in isoindigo by thieno[3,2- $b]$ thiophene, reducing the steric hindrance between adjacent building blocks in the polymer backbone (P21). ${ }^{[136]}$ The thieno[3,2-b]thiophene isoindigo (iITT) containing polymers (P22) exhibit good ambipolar charge transport with hole and electron mobilities up to $0.4 \mathrm{~cm}^{2} / \mathrm{Vs}$ and $0.7 \mathrm{~cm}^{2} / \mathrm{Vs}$, respectively. ${ }^{[137]}$

One technique that has gained popularity in recent years for planarising conjugated backbones is to use intramolecular noncovalent interactions. Free rotation of sigma bonds can be restricted by $\mathrm{X} \cdots \mathrm{S}$ (where $\mathrm{X}=\mathrm{Cl}, \mathrm{Br}, \mathrm{F}$ ), $\mathrm{H} \cdots \mathrm{S}, \mathrm{O} \cdots \mathrm{S}$, and $\mathrm{N} \cdots \mathrm{S}$ through-space interactions resulting in rigid and planar polymer backbones. ${ }^{[125]}$ However, we note that many of the reported polymers containing conformational locks exhibit non-ideal transfer characteristics. One example of an exception to this general trend are p- and n-type conjugated polymers that incorporate selenophene-based building blocks featuring Se $\cdots \mathrm{O}$ noncovalent conformational locks. ${ }^{[138]}$ These polymers have been used to produce OTFTs with improved hole (P23) and electron (P24) mobilities. Another interesting example relies on favourable $\mathrm{F} \cdots \mathrm{H}$ interactions in cyclopentadithiophene-difluorophenylene copolymers (P25). ${ }^{[139]}$ In this case, improved hole mobilities were shown for polymers with more liner and rigid backbones, which produced bottom-gate bottom-contact OTFTs with mobilities up to $1.1 \mathrm{~cm}^{2} / \mathrm{Vs}$.

\section{N-type organic semiconductors}


With or without the mobility hype, there are far fewer examples of high mobility n-type OTFTs. The principle reason that the development of high mobility n-type OSCs has generally lagged behind that of p-type OSCs (see Figure 1a), both for polymeric and molecular materials is that, in order to facilitate the injection of charges from the electrode material, n-type OSCs need to be electron deficient with low LUMOs. A low LUMO level must also be in conjunction with a reduction potential below that of water or oxygen, so that the OTFT is stable in ambient environments. ${ }^{[140]}$ In this respect, experiments have shown that LUMO levels below $\sim-4 \mathrm{eV}$ are typically required for stable device operation in air. ${ }^{[141]}$

After reviewing the literature (Figure 1), we found two things for n-type OSCs: (i) the challenge still remains to produce n-type OTFTs with mobilities exceeding $10 \mathrm{~cm}^{2} / \mathrm{Vs}$, and (ii) like hole mobilities, electron mobilities have been making impressive progress over the last 30 years. For these reasons, here we will review the literature to pull out the key approaches and design concepts at the heart of these mobility improvements so that they can be used to make further improvements going forward, both for n-type conjugated polymers and molecular semiconductors.

As a "mobility disclaimer", we note that, at this moment in time, it's impossible to give a quantitative analysis of OTFT electron mobilities. Therefore our aim here is to use the reported mobility values to give a qualitative insight, enabling a discussion about the latest approaches for improving n-type mobilities. For general guidance, we will put a $*$ next to the reported mobility values where the reader may want to consider the data sets behind the numbers. The $*$ will be representative of any nonlinearity in $\sqrt{ }_{\mathrm{D}_{-} \mathrm{SAT}} \mathrm{vs} . \mathrm{V}_{\mathrm{G}}$, not specifically the kink, but often s-shaped plots where $\sqrt{ }_{\mathrm{D}}$ slopes down at high $\mathrm{V}_{\mathrm{G}}$ and also devices where the gradient of $\sqrt{ }_{\mathrm{I}_{-} \mathrm{SAT}}$ increases with increasing $\mathrm{V}_{\mathrm{G}}$. The $*$ will also represent reported values that don't show where mobility was extrapolated from, or the data for the highest reported 
mobility is not shown, as well as output curves that have not saturated. Further information and guidelines on mobility analysis are discussed in detail in Section 1.

\subsection{Design strategies for $n$-type polymers}

We will start by reviewing polymeric n-type OSCs. There are many similarities in molecular design for electron and hole transporting OSCs, for example, both require delocalised aromatic cores exhibiting low energetic disorder as well as good intramolecular $\pi$-orbital overlap. Here, we use materials that have been reported to produce OTFTs with mobilities above reported values of $0.5 \mathrm{~cm}^{2} / \mathrm{Vs}$ as a relative guide to establish design criteria. We find that there are only five building blocks that have produced polymers that fall into this category (Table S1).

\subsubsection{Naphthalene diimide (NDI)}

Until recently, the best performing polymer was the well-known PNDI2OD-2T, independently reported in 2008 by Watson et al. ${ }^{[142]}$ and in 2009 Facchetti et al. ${ }^{[143]}$ This polymer, also known as $\mathrm{N} 2200$, has demonstrated n-type mobilities up to $0.85 \mathrm{~cm}^{2} / \mathrm{Vs}$ in topgate bottom-contact architectures and excellent ambient stability. ${ }^{[143]} \mathrm{N} 2200$ is based on a napthalenediimide core and has a deep HOMO of $-4 \mathrm{eV}$, which allows facile electron injection, as well as enables the fabrication of OTFTs that are stable in air. The success of this material prompted researchers to investigate the structure-property relationships of n-type polymers, using N2200 as a starting point. For example, Lee et al. demonstrated that by simply optimising the side-chain of the N2200 polymer they were able to enhance the n-type mobilities to reported values of $1.90 \mathrm{~cm}^{2} / \mathrm{Vs}^{*}{ }^{[144]}$ Additionally, by replacing the 2octylydodecyl side chains with shorter 2-hexyldecyl ones (P26 in Figure 12 and Table S1), enhanced crystallinity was observed, thereby facilitating charge transport in three dimensions 
(3D). ${ }^{[144]}$ Another demonstration of improvements due to side chain modification was carried out by Kang et al., who showed that semi-fluorinated alkyl side chains induce strong selforganization, which subsequently induces a high degree of order in the polymer backbone. ${ }^{[145]}$ By enhancing the order along the polymer backbone direction the n-type charge carrier mobility of $\mathbf{P 2 7}$ in BGTC configuration was reported to be $6.5 \mathrm{~cm}^{2} / \mathrm{Vs} *$. Furthermore, by introducing hybrid siloxane to the alkyl chain terminus (P28), Kim et al. further demonstrated the powerful impact that alkyl chain optimization can have on these materials. ${ }^{[146]}$ They also highlight the importance of face-on vs. edge-on polymer orientation, by changing the spincoating solvent from chloronapthaleneto chloroform, which was shown to vary the face-on to edge-on orientation ratio. When chloroform was used, a mixture of face-on and edge-on orientations were observed and characterised by GIXD and NEXAFS, resulting in an increase in electron mobility up to $1.04 \mathrm{~cm}^{2} / \mathrm{Vs}^{*}$.

In conjunction with alkyl chain optimization, efforts to optimize the bithiophene co-monomer have also had good success. By introducing a vinylene link between the two thiophenes (TVT), Kim et al. obtained a polymer (P29) with high mobility $\left(1.8 \mathrm{~cm}^{2} / \mathrm{Vs}\right)$ and high ambient stability in a top-gate bottom-contact OTFT. ${ }^{[147]}$ The improved device performance and good on/off ratio (i.e. $\mathrm{I}_{\mathrm{ON} / \mathrm{OFF}}=10^{6}$ ) were attributed to improved $\pi-\pi$ intermolecular interactions from the extension of conjugation through the vinylene linker. The same TVT polymeric backbone was also reported with oligo(ethylene glycol) linear side chains (P30). ${ }^{[148]}$ Interestingly, the pristine electron mobility of $\mathbf{P 3 0}$ of $0.51 \mathrm{~cm}^{2} / \mathrm{Vs}$ was improved to $1.6 \mathrm{~cm}^{2} / \mathrm{Vs}^{*}$ by using a chloronaphthalene additive. In this case the pristine electron mobility of $\mathbf{P 3 0}$ was reported to improve when chloronaphthalene was used as an additive, although further studies would be required to find out how beneficial the additive actually is for mobility. The mobility of P30 was also shown to vary by several orders of magnitude depending on whether the ethylene glycol units were introduced close to the 
semiconducting core; this particular study demonstrates that researchers should not limit their investigations to purely hydrocarbon containing side chains. By further extending the concept of vinylene linkage, Dong et al. introduced conformational locking ethoxide groups. Furthermore, using selenophene instead of thiophene based flanking units was found to enhance non-covalent interactions, and lead to a highly planar polymer (P24). ${ }^{[138]}$ This novel linker is easy to synthesize and its planarity has been demonstrated using density functional theory (DFT) calculations and X-ray diffraction (XRD). Additionally, including this unit into the NDI class of polymers resulted in a bottom-gate top-contact OTFTs with n-type mobilities of $0.65 \mathrm{~cm}^{2} / \mathrm{Vs}^{*}$.

Overall, we can see that improvements in electrical performance have been achieved for NDI polymers. The literature qualitatively suggests that both alkyl chain optimization and co-monomer variation lead to increased planarity and crystallinity, which cause an overall increase in charge carrier mobility. These design approaches represent significant advances in n-type OSC design and demonstrate the potential that NDI has as a building block for future high performance n-type polymers.

\subsubsection{Diketopyrrolopyrrole (DPP)}

DPP has rapidly become one of the most commonly used motifs in conjugated polymer electronics; its highly planar and electron deficient core mean that it's perfectly suited to ntype OSCs. As with the NDI family of materials, there are several synthetic methodologies that have been used to improve and understand how electron transport is supported in these materials. One aspect that has helped enable this is that it's relatively simple to manipulate the nature of the solubilising alkyl chain, the flanking aromatic moieties and/or the co-monomer. For example, Lee et al. reported the effect of side-chain engineering on a series of thiophene flanked DPP polymers, using selenophene as the choice of co-monomer and hybrid siloxanes 
as their choice of solubilizing groups. ${ }^{[149]}$ The alkyl spacer length of the side chains was systematically tuned to boost performance, and from a combination of atomic force microscopy (AFM) and grazing incidence X-ray diffraction (GIXD), it was found that three dimensional (3-D) charge transport occurs with optimized pentyl spacers (P31), resulting in ntype mobilities of $1.13 \mathrm{~cm}^{2} / \mathrm{Vs}$ in bottom-gate top-contact devices. These mobility values were achieved by spin-coated, but it was also shown that the mobility value could be improved further to $4.34 \mathrm{~cm}^{2} / \mathrm{Vs}^{*}$ by using a solution-sheering method. A similar study into solubilising chain linker distance was performed by $\mathrm{Yu}$ et al., but this time using more conventional branched alkyl chains. ${ }^{[150]} \mathrm{C} 1$ and $\mathrm{C} 6$ spacers were introduced onto a thiopheneflanked DPP monomer unit, and this was then co-polymerised with electron deficient, transplanar bithiazole (P32). In contrast to the previous study, here it was found that the shortest alkyl chain spacer resulted in the greatest mobility $\left(1.87 \mathrm{~cm}^{2} / \mathrm{Vs}^{*}\right)$; the authors suggested this was because acceptor-donor-acceptor (A-D-A) type semiconductors have relatively weaker intermolecular interactions than more conventional donor-acceptor-donor (D-A-D) semiconductors.

A DPP-based conjugated polymer using a novel variation of the TVT co-monomer was reported Kim et al. ${ }^{[151]}$ By introducing electron deficient cyano groups at the three positions of the TVT monomer, they were able to convert a predominantly p-type polymer into one that produced n-type OTFTs, presumably because they lowered the LUMO, which in turn facilitated electron injection. The authors also compared alkyl chain spacer length and found that this didn't affect n-type mobility values, with both C1 (P33) and C6 spacer distances reported to have given the same average electron mobility values. Another DPPbased conjugated polymer, this time with a phenyl co-monomer, was used for structureproperty relationship studies carried out by Park et al. ${ }^{[152]}$ The LUMO energy level was deepened by systematically increasing the number of fluorine substitutions on the phenyl co- 
monomer, which caused face-on orientation to become more favourable. As a result, the charge-transport behaviour in bottom-gate top-contact TFTs changed from p-type to n-type, with the tetrafluoro substituted co-monomer (P34) in particular exhibiting the highest reported mobility, $2.36 \mathrm{~cm}^{2} / \mathrm{Vs}$. Furthermore, this polymer displayed excellent stability; OTFTs were able to perform well even after 7 months of storage in ambient conditions.

Varying the co-monomer is also known to have an effect on thiophene flanked DPP. Gruber et al. demonstrated this using benzotriazoles that allowed for the introduction of additional solubilising side-chains. ${ }^{[153]}$ Interestingly, two different synthetic routes were compared: direct arylation and Suzuki-polycondensation. Direct arylation was shown to produce polymers with lower electrical performance, presumably due to a greater number of defects. In particular, P35, which has linear alkyl chains on the DPP and a branched chain on the co-monomer, gives exceptionally nearly balanced average electron and hole mobilities in a top-gate configuration. A modification to the DPP flanking units was reported by Sun et al.; here, the traditional flanking thiophenes were replaced with 2-pyridinyl substituents, resulting in a unit with a reduced LUMO energy but which still maintained a high degree of co-planarity, an important requirement for efficient charge transport. The novel monomer was copolymerised with bithiophene (P36) and thienothiophene (P37) to give polymers with very short $\pi-\pi$ stacking distances and high values of n-type mobility of $6.3 \mathrm{~cm}^{2} / \mathrm{Vs}^{*}$ and $3.36 \mathrm{~cm}^{2} /$ Vs respectively; ${ }^{[154,155]}$ we note that, for the latter, whilst the authors report an $\sqrt{ }_{\mathrm{D}}$ vs. $V_{G}$ plot of a typical P37 device, the plot for the highest performance device is not given.

As with the NDI conjugated polymer family, a similar picture emerges for DPP, whereby increasing the electron deficiency of a conjugated polymer typically improves n-type transporting properties. The more facile synthesis of DPP relative to NDI allows greater variation of the chemical structure and a wider range of structure-property relationships. Whilst the reports of DPP polymers have typically shown device performance that is more in 
tune with the ideal FET model, we highlight the importance of transparency when reporting ultra-high mobilities.

\subsubsection{Benzodifurandione phenylenevinylene (BDO)}

A motif that recently emerged as a candidate for high performance n-type polymers is the benzodifurandione-based oligo(p-phenylenevinylene (BDO or BDPPV). This large, fused heptacyclic unit is both highly electron deficient and planar, which makes it ideal for n-type OTFTs. In addition, BDO has two 5-membered lactam rings, which can be alkylated in a similar fashion to DPP, making this polymer soluble. The peripheral fused phenyl rings can also be chemically manipulated, as well as the choice of co-monomer, giving chemists the freedom to optimise the energy levels and solid state packing structure. Dou et al. reported six BDO based polymers, with various side-chain branching positions, in order to systematically study the effect of side-chains on OTFT performance. ${ }^{[156]}$ By increasing the alkyl chain branching point distance, closer $\pi-\pi$ stacking was achieved, but this did not necessarily correlate with increased n-type mobility. P38 which had a C3 length alkyl chain displayed electron mobility up to $1.4 \mathrm{~cm}^{2} / \mathrm{Vs}$. An identical system was reported by Lei et al., who added electron withdrawing fluorine atoms on the peripheral fused phenyl rings, to lower the LUMO levels down to $-4.30 \mathrm{eV} \cdot{ }^{[157]}$ In this case the fluorination also served to conformationally lock the polymer backbone via interactions with the vinylene co-monomer protons. This resulted in P39 having an n-type mobility of $1.7 \mathrm{~cm}^{2} / \mathrm{Vs}$, using a similar device architecture to Dou et al. Replacing the vinylene co-monomer with bithiophene $(\mathbf{P 4 0})$ allowed Lei et al. to fabricate top-gate bottom-contact devices with electron mobilities up to $1.74 \mathrm{~cm}^{2} / \mathrm{Vs}$; impressively, devices that were both fabricated and tested under ambient conditions maintained an electron mobility of up to $1.45 \mathrm{~cm}^{2} / \mathrm{Vs}^{*}{ }^{[158]}$ Dai et al. reported an identical polymer to $\mathbf{P 4 0}$, but this time a pyridyl nitrogen was incorporated into the peripherally fused phenyl rings to produce 
azaBDO (P41). ${ }^{[159]}$ The nitrogen atom acted to further lower the LUMO, whilst encouraging a greater degree of backbone planarity. Additionally, DFT suggests that the presence of an S-N interaction acts as a conformational lock to decrease energetic disorder in the polymer backbone. The combination of decrease energetic disorder and a deeper LUMO were suggested to be the reason for the significantly higher electron mobility of $3.22 \mathrm{~cm}^{2} / \mathrm{Vs}^{*}$.

By using the same azaBDO monomer and copolymerising it with an alkylated bithiophene (P42) and TVT co-monomers, Zhang et al. were able to continue with and further expanded this concept (note: P42-44 are not shown in Figure 12 due to their close similarities to the other BDO polymers that we have shown in Figure 12), reporting electron mobilities of up to $1.86 \mathrm{~cm}^{2} / \mathrm{Vs}^{*} .{ }^{[160]}$ A similar fluorination strategy to Lei et al. ${ }^{[157]}$ was reported by Zheng et al. ${ }^{[161]}$ Here they used a tetra-fluorinated BDO monomer (P43), suggesting that the fluorination might have a double function as a conformational lock. The plot of the $\sqrt{ }_{\mathrm{D}} \mathrm{vs} . \mathrm{V}_{\mathrm{G}}$ for this polymer shows a severe kink, but the authors provide a more reliable mobility of 1.24 $\mathrm{cm}^{2} / \mathrm{Vs}$ that has been taken from the high $\mathrm{V}_{\mathrm{G}}$ region. A final systematic study by Zhou et al. showed that by using the standard BDO monomer and varying the co-monomer, the frontier molecular orbitals could be tuned. ${ }^{[162]}$ In particular, the use of thienothiophene (P44) gave ntype mobilities up to $1.37 \mathrm{~cm}^{2} / \mathrm{Vs}$.

It is clear that BDO and its analogues have excellent potential for n-type OTFTs. BDO's planar structure and deep HOMO mean that it is has a high degree of tolerance to substitution, whilst still giving high performance. The tendency for BDO OTFTs to exhibit nonlinearities in transfer characteristics means that future studies will need to address these issues, as outlined earlier in this review.

\subsubsection{Isoindigo (iI)}


Isoindigo (iI) is another commonly used monomer in high performance conjugated polymers. In its unsubstituted form it has a relatively high LUMO level, which normally prevents it from being used as an n-type OSC. However, in recent years, researchers have introduced subtle modifications that have resulted in impressive device performance. In a similar manner to the approaches taken for BDO polymers, Yue et al. introduced a pyridyl nitrogen into the peripheral phenyl ring of the isoindigo unit and co-polymerisation with an electron deficient benzothiadiazole monomer resulted in a polymer that has a highly planar backbone $(\mathbf{P 4 5}) .{ }^{[163]}$ Studies on how fluorination affects isoindigo have been published independently by Gao et al. and Yang et al. ${ }^{[164]}{ }^{[165]}$ Both groups reported the introduction of two fluorine atoms onto the isoindigo monomer and its subsequent polymerisations with fluorinated thiophene based comonomers. By increasing the number of fluorine substitutions, the LUMO levels were found to deepen and, in general, n-type mobilities was seen to increase. $\mathbf{P 4 6}$ reported by Gao et al. displayed electron mobility up to $4.97 \mathrm{~cm}^{2} / \mathrm{Vs}^{*}{ }^{[164]}$ and $\mathbf{P 4 7}$ reported by Yang et al. exhibited n-type performance with a mobility of $9.70 \mathrm{~cm}^{2} / \mathrm{Vs} ;{ }^{[165]}$ for the latter, we note that some output curves do not show saturation, but not those associated with $\mathbf{P 4 7}$, so in this instance it would be better to see all of the data specifically for the highest mobility device. The hole and electron effective masses were also predicted using DFT with the aim of rationalising the observed high mobilities. Finally, Meager et al. suggested that extending the fused nature of the isoindigo core is a good way to enhance charge-transport, because this improves the molecular overlap along the polymer backbone. They modified the peripheral phenyl ring of isoindigo to a fused thieno[3,2-b]thiophene and its subsequent co-polymerisations, demonstrating n-type mobilities of $0.7 \mathrm{~cm}^{2} / \mathrm{Vs}$ in top-gate bottom-contact OTFTs from copolymerisation with benzothiadiazole $(\mathbf{P 2 2}) .{ }^{[137]}$

\subsubsection{Indolonaphthyridine}


Indolonaphthyridinedione thiophene (INDT) is a novel monomer unit derived from naturally occurring indigo. Fallon et al. reported that copolymerising INDT based polymers with benzothiadiazole can produce n-type OTFTs with electron mobilities of up to $3.1 \mathrm{~cm}^{2} / \mathrm{Vs}$ (P48), explaining that the prominent charge-transporting ability is because this polymer has a remarkably high crystallinity along the polymer backbone. ${ }^{[166]}$ OTFTs made using these polymers showed strong evidence of contact resistance issues and contact limited device performance, however, the analysis of $\mu_{\mathrm{sat}}$ vs. $\mathrm{V}_{\mathrm{G}}$ provides strong argument for this high n-type performance.

\subsection{N-type molecular semiconductors}

Next, we will look at n-type molecular semiconducting, or small-molecule, OSCs. One advantage of molecular semiconductors is that they are chemically distinct, which means that synthetic impurities can be readily identified and removed. This is in contrast to their polymeric other half, where impurities can be difficult or impossible to remove, and their statistical nature can lead to batch-to-batch variations in molecular weight and dispersity, often affecting device reproducibility. Because many of the same electron deficient building blocks are used for molecular and polymeric materials, the development of these two classes of materials have gone hand-in-hand with each other. In this discussion we will focus on selected examples of solution processed n-type molecular semiconductors since 2012, which have been reported to exhibit mobilities greater than $0.1 \mathrm{~cm}^{2} / \mathrm{Vs}$.

\subsubsection{Quinoidal semiconductors}

Quinoidal semiconductors have been extensively investigated as n-type materials in organic electronics. The quinoidal structure typically has a significantly reduced HOMO-LUMO gap compared to the aromatic analogue, with the lower lying LUMO level attractive for electron 
transport materials. Although several approaches have been developed in order to stabilise the quinoidal structure, ${ }^{[167]}$ the most common and successful approach for n-type small-molecules has been to include strongly electron withdrawing dicyano end groups. Therefore, we will focus our discussion here solely on these types of material. Indeed, some of the earliest n-type materials were based on the inclusion of two such groups at either end of a terthiophene core. Prior to 2012, significant work had focussed upon improving the charge carrier mobility via the extension of the oligothiophene core, with the resulting reduction in solubility compensated by the inclusion of alkyl solubilizing groups.

As an alternative strategy to improve solubility, Li et al. recently reported the preparation of terthiophene analogue in which the central thiophene ring was replaced by furan (SM1, shown in Figure 13). ${ }^{[168]}$ They found that the resulting molecule exhibited improved solubility in comparison to the all thiophene analogues, a property common for many furan containing materials. They also found that the relative stability of the structural isomers was different for the furan analogue versus the thiophene, with the E,E isomer (as shown in Figure 13) favoured in the solid state. Interestingly, the furan material performed significantly better in OTFT devices (see Table S2), with a saturated electron mobility up to $1.1 \mathrm{~cm}^{2} / \mathrm{Vs}^{*}$ for spin cast films annealed at $150^{\circ} \mathrm{C}$, approximately 20 times higher than the thiophene analogue under identical conditions. Additionally, even higher mobilities were found for devices fabricated directly on single crystal wires.

The above example also serves to highlight the issue of possible E/Z isomerisation, which can occur in quinoidal oligothiophenes with respect to the double bond between heterocycles. The presence of isomers, even in small amounts, is a possible source of disorder, and is likely to have a negative impact on device performance. One approach to eliminate this issue is to utilise fused aromatic systems with no possible regioisomers. Such an approach has already been described by Zhu and co-workers in 2011, where they reported 
a fused tetrathienoquinoid with a mobility up to $0.9 \mathrm{~cm}^{2} / \mathrm{Vs}^{[169]}$ More recently a five ring quinoidal dithieno[2,3-d;2',3'-d']benzo[1,2-b;4,5- $\left.b^{\prime}\right]$ dithiophene (SM2) has been reported. ${ }^{[170]}$ Extending the conjugated core did not result in an improved charge carrier mobility (Table 2), but interestingly the nature of the sidechain was found to have an influence on the ambipolarity of the device. Hence SM2a was a unipolar n-type material whilst SM2c was ambipolar, albeit with a lower hole mobility $\left(0.006 \mathrm{~cm}^{2} / \mathrm{Vs}\right)$ than electron $\left(0.13 \mathrm{~cm}^{2} / \mathrm{vs} *\right)$. SM2b exhibited ambipolar performance when coated from concentrated solution, but unipolar n-type behaviour for films cast from more dilute solution. All three materials exhibited identical electrochemistry, but differences were observed in the thin-film crystallinity, with unipolar materials exhibiting a single crystalline phase whereas the ambipolar materials exhibited a dual phase. The authors speculated that different hole and electron pathways might therefore be present.

Synthetically less complex three ring systems have been also reported, such as dithienothiophenoquinoids $(\mathbf{S M 3})^{[171]}$ and quinoidal benzo[1,2-b:4,5-b]dithiophene (SM4) ${ }^{[172]}$. Both materials have LUMO levels below $-4.2 \mathrm{eV}$ and are reported to produce OTFTs with good ambient stability. SM4 had a high propensity to self-assemble into micron sized wires and therefore these could be used to extract a single wire/crystal mobility (Table S2). For SM3, the processability was dependent on the nature of the alkyl group R, with the optimum performance obtained for a linear undecyl sidechain. A simple spin-coating technique produced OTFTs with electron mobility values on the order of $10^{-2} \mathrm{~cm}^{2} / \mathrm{Vs}$, but this could be improved by depositing the OSC films from a sheared solution, which resulted in the formation of larger crystalline domains. These result highlight once more that OTFT mobility values depend on a complex interplay of material properties, such as the solid state overlap of the transfer integrals in the OSC and the number/nature of grain boundaries in a thin-film, as well as device properties. 
This is further illustrated in the case of molecule SM5, where an electron deficient DPP core was integrated into the quinoidal structure. As discussed in Section $\mathbf{4}$ and earlier in Section 5, DPP has been widely utilised as a building block for the development of p- and n-type polymeric semiconductors. Here, its inclusion within the quinoidal framework led to strongly electron deficient systems with LUMO levels below $-4.4 \mathrm{eV}$, but when substituted with a branched 2-ethylhexyl sidechain (SM5a), good device performance $\left(\mu_{\mathrm{SAT}}=0.45\right.$ $\mathrm{cm}^{2} / \mathrm{Vs}$ ) could only be achieved by vacuum deposition at elevated temperature. ${ }^{[173]}$ Solution processability was achieved by moving a linear hexadecyl sidechain (SM5b), but during any deposition attempts SM5b dewetted from HMDS treated silicon dioxide substrates, making it difficult to form a solution-processed film. ${ }^{[174]}$ This problem was alleviated by blending the semiconductor with an electrically inert polymer, in this case poly(alpha-methyl)styrene, which improved the solution viscosity, thereby facilitating surface wetting as well as enabling a level of control over the rate of crystallisation (the benefits of blending molecular semiconductors with polymers will be discussed in more detail in Section 5). In this example, top-gate devices exhibited promising mobility performance $\left(\mu_{\mathrm{SAT}} 0.5 \mathrm{~cm}^{2} / \mathrm{Vs}\right)$ as well as stability. We also note that the linear and saturated mobilities were comparable in magnitude. The influence of the length and branching position of the sidechain was investigated in later work, resulting in slightly improved performance $\left(\mu_{\mathrm{SAT}} 0.69 \mathrm{~cm}^{2} / \mathrm{Vs} *\right)$ for spin-coated SM5c devices. ${ }^{[175]}$ It was also found that increasing the length of the conjugated core by changing from thiophene to thieno[3,2-b]thiophene (SM6) did not result in any beneficial device improvements. ${ }^{[176]}$

An interesting approach to further stabilise the LUMO involves the incorporation of thieno(3,4- $b$ )thiophene into the quinoidal terthiophene quinoid structure. ${ }^{[177]}$ These were also combined with an electron deficient thienopyrrolodione, bearing a branched 2-ethylhexyl sidechain, to ensure good solubility (SM7a \& 8a). The proaromatic fused thiophene of the 
thieno(3,4- $b$ )thiophene helps to stabilise the quinoidal state by its gain of aromaticity. Two isomers were prepared, where the thieno(3,4-b)thiophene was coupled with a distal (SM7a) or proximal (SM8a) arrangement; solution NMR studies suggested the latter existed as a single isomer in solution, whereas the former was in thermodynamic equilibrium, with the majority being the E/E product shown in combination with $14 \%$ of an $\mathrm{E} / \mathrm{Z}$ isomer (SM7a). A single crystal of the E/E isomer was also grown and shown to exhibit an almost co-planar backbone (torsional twist of $5.3^{\circ}$ ). The two isomers exhibited different electrochemistry in solution with a lower LUMO (-4.77 eV) for SM8a versus SM7a $(-4.51 \mathrm{eV})$, and although similar optical spectra were found in solution, they were significantly different in thin-films, with SM7a exhibiting much larger red shift compared to the solution phase, indicative of $J$-aggregation. OTFT results were also reported to be significantly different, with SM7a exhibiting a mobility of $3 \mathrm{~cm}^{2} / \mathrm{Vs}^{*}$ and SM8a (after annealing at both $160^{\circ} \mathrm{C}$ and $190^{\circ} \mathrm{C}$ ) having a mobility of $0.44 \mathrm{~cm}^{2} / \mathrm{Vs}$, with the latter lower mobility isomer showing no signs of the kink.

A follow-up study examined the same isomers, but this time using different sidechains on the thienopyrrolodione (either linear dodecyl (SM7/8b) or branched 2-octyldodecyl (SM7/8c) with the aim of further controlling the thin-film morphology. ${ }^{[178]}$ Again, significant differences were observed in the thin-film morphology, with the distal orientation promoting a 3D crystal packing, and the proximal a more liquid crystalline type morphology. The nature of the sidechain was also found to affect packing in single crystals, with linear sidechains favouring a herringbone type packing, whilst the branched groups featured a '2D brickwork' type motif; the latter is often suggested to favour $\pi$-overlap and $2 \mathrm{D}$ charge transport. In terms of OTFT performance, the distal materials with branched sidechains gave the best apparent performance, with a mobility up to $5.5 \mathrm{~cm}^{2} / \mathrm{Vs}^{*}$ reported, almost an order of magnitude higher than the linear chain analogue. The same group also investigated the performance of the simpler dimer system, SM9, which was found to exist only in the E isomer. ${ }^{[179]}$ The relative 
regiochemistry of the thieno[3,4-b]thiophenes was again found to influence thin-film crystallinity and device performance. In this case, the lower symmetry regioisomer SM9 exhibited the best transistor performance, with a mobility up to $0.32 \mathrm{~cm}^{2} / \mathrm{Vs}$, compared to a best value of $0.15 \mathrm{~cm}^{2} / \mathrm{Vs}$ for two isomers with higher $\mathrm{C}_{2 h}$ symmetry (not shown). The higher device performance was related to higher thin-film crystallinity and the absence of any polymorphism for this isomer. The authors suggest the asymmetric structure, which afforded a slight molecular dipole, may have helped to promote the high thin-film order.

\subsubsection{Diimide, Amide and Acene based semiconductors}

The imide group is noticeably prevalent in n-type OSCs, because its strong electron withdrawing ability helps to stabilise the molecular LUMO, and the $\mathrm{N}$-atom serves as a convenient attachment point for solubilising groups. It is particularly well-known for being combined with rylenes, especially peryelene diimide (PDI), and acenes, especially naphthalene to form naphthalene diimide (NDI). ${ }^{[180]}$

One of the trends for NDI-based materials is the expansion of the conjugated core, motivated by a desire to increase the molecular overlap of the $\pi$-systems in the solid state (Figure 14). Fusion of the NDI core with two 2-(1,3-dithiol-2-ylidene)malononitrile groups affords a planar molecule (SM10) with a significantly reduced LUMO level (ca. $-4.3 \mathrm{eV}$, compared to the starting NDI LUMO ca. $-3.4 \mathrm{eV}) .{ }^{[181]}$ Initial reports found that promising electron mobilities up to $0.51 \mathrm{~cm}^{2} / \mathrm{Vs}$ can be achieved by spin coating. Later investigations focussed on tuning the thin-film morphology by manipulation of the branching points of the solubilising side-chain (SM10a-c).${ }^{[182]}$ Although moving the branching point further from the conjugated backbone resulted in subtle changes to the thin-film microstructure, the overall trend was an increase in crystalline grain size and tilt angle - towards perfectly edge-on - as the branching point increased. As expected, the annealing temperature had a significant 
impact on both OTFT performance and thin-film microstructure, with all materials exhibiting a phase change upon annealing. OTFT results suggested similar performance for SM10a and SM10c in a variety of device architectures, whilst SM10b was had significantly better electron mobilities, up to $3.5 \mathrm{~cm}^{2} / \mathrm{Vs} *$ in bottom-gate bottom-contact devices.

Replacing one of the strongly electron withdrawing 2-(1,3-dithiol-2ylidene)malononitrile groups with electron donating 1,2-benzenedithiol resulted in the asymmetric SM11, in which the LUMO (ca. $-4.2 \mathrm{eV}$ ) is slightly raised with respect to the parent SM10. ${ }^{[183]}$ The HOMO is more significantly raised and the replacement of both 2-(1,3dithiol-2-ylidene)malononitrile groups afford an ambipolar material. In the case of SM11, only electron mobilities are observed, and they are slightly reduced when compared to SM10. This is probably related to the deviation from planarity that happened because 1,2benzenedithiol was included. More complex derivatives have also been reported, such as $\mathbf{S M 1 2 a} / \mathbf{b}$. In this case the replacement of 2-(1,3-dithiol-2-ylidene)malononitrile with $(1,3-$ dithiol-2-ylidene)acetonitrile affords the opportunity to dimerise the molecule to a vinylogous tetrathiafulvalene type structure. ${ }^{[184]}$ As expected, the increased conjugation results in a reduction in optical band gap (1.4 eV for SM12b) compared to SM10, mainly as a result of an increase in the HOMO energy level. Although calculations predict that the dimers should be significantly twisted (dihedral angle between 111 and $123^{\circ}$ ), OTFT's still exhibit promising performances (Table S2). Furthermore, a chemically fused dimer, SM13, was reported by Pei and Zhao; ${ }^{[185]}$ calculations suggested that this dimer should be close to co-planar. This molecule exhibited a remarkably low LUMO level of $-4.72 \mathrm{eV}$, measured by cyclic voltammetry, in combination with a low optical band gap close to $1.1 \mathrm{eV}$. Top-gate OTFTs exhibited promising performances, with mobility values up to $0.96 \mathrm{~cm}^{2} / \mathrm{Vs}$, as well as low hysteresis. 
Fusing aromatic groups to NDI cores is another approach that has also received great interest, especially because many of these building blocks are also useful for n-type polymeric OSCs. In particular, fusing thieno groups to the periphery of NDI has been investigated for small-molecules and the chlorination of the thiophene has been reported to produce good performance in OTFTs. However, in this instance the performance was only shown for vacuum processed devices. ${ }^{[186]}$ To investigate the solution processable traits of this material, long branched alkyl sidechains were included by combining the substitution with benzo[b]thiophene (SM14a) or naphtha[2,3-b]thiophene (SM14b). ${ }^{[187]}$ The electron accepting properties were modulated by combining fused thiophene and electron rich aryl substituents, which resulted in OTFTs with ambipolar characteristics when measured in ambient conditions. For SM14a, the hole mobility was lower than the electron mobility (Table S2), but balanced ambipolarity was achieved for SM14b. By replacing the fused thiophene with thiazole, the more electron deficient SM15 is produced and in this case, only unipolar behaviour was observed. ${ }^{[188]}$

Another approach for extending the conjugation length is to link two terminal NDI units via a central conjugated core, such as vinylene (SM16 ${ }^{[189]}$ or a more electron deficient thiophene-tetrazine-thiophene (SM17). ${ }^{[190]}$ The former was developed for organic solar cells as an alternative electron acceptor to fullerene, but it was also found to exhibit reasonable OTFT performance with good stability in ambient environments. In the latter example, the inclusion of the electron deficient tetrazine resulted in a moderate (in comparison to NDI) lowering of the LUMO by about $0.12 \mathrm{eV}$, with the resultant OTFTs showing good operational stability and ambient stability. Good OTFT performance under standard test conditions was observed (Table S2) and most notably, this level of performance was retained for all ink-jet printed devices made on flexible substrates. In SM18, the NDI like units are linked via the 4,5-positions to a fused acene central unit, rather than the more common 2,3-positions seen 
earlier. ${ }^{[191]}$ Again, this material was initially developed as a solar cell acceptor, but was also found to exhibit reasonable OTFT performance.

A final notable class of NDI type materials are SM19-SM21. ${ }^{[192-194]}$ In these cases the transistor performance is based on single crystal measurements, where needles of single crystals (typically with widths $\leq 1 \mu \mathrm{m}$ and lengths of 10 to several hundred $\mu \mathrm{m}$ ) are deposited along with a gold source/drain top contact via a shadow masking technique. The mobility can be calculated using the dimensions of the crystal as the channel width (Table S2). The high order in the single crystals results in significantly higher performance compared to thin-film devices made from the same material. For example SM21 exhibits a mobility around $10^{-4}$ $\mathrm{cm}^{2} / \mathrm{Vs}$ for spin cast devices, ${ }^{[194]}$ substantially lower than the single crystal value up to $1.5 \mathrm{~cm}^{2} / \mathrm{Vs} *$. The improved single crystal mobility value suggests that, under the appropriate processing conditions, it would be possible to achieve a similar performance in the thin-film devices.

Expanding the core to larger conjugated systems has been a prominent approach that has been explored by researchers for many years (Figure 15). Perylene diimide (PDI) based materials have been extensively explored in terms of, for example, how a number of substituents on the diimide group and the perylene core influence the properties. One promising approach that has been relatively unexplored is the substitution of the imide oxygen with sulfur. For example, solution cast OTFTs of SM22 showed a two hundred fold improvement in performance when compared to the parent PDI, exhibiting electron mobilities up to $0.16 \mathrm{~cm}^{2} / \mathrm{Vs}^{[195]}$ This improvement appears to be related to an increase in the electron affinity with thionation, as well as a modified thin-film morphology with larger domains and more continuous grain boundaries. Additionally, although the thermal stability of thioketones can often be low, in this case thermogravimetric analysis (TGA) measurements demonstrated that $\mathbf{S M 2 2}$ was stable up to $175^{\circ} \mathrm{C} .^{[195]}$ 
In a similar manner to NDI derivatives, there has been a trend for fusing additional aromatics to PDI cores (Figure 15). In the case of SM23, two PDI units are effectively linked together through the bay positions and, by simply spin-coating thin-films and thermally annealing them at $120{ }^{\circ} \mathrm{C}$, this gave promising OTFT performance. ${ }^{[196]}$ Single crystal devices based on micron sized needles of the related $\mathbf{S M 2 3 b}$ were reported to achieve mobilities up to $4.65 \mathrm{~cm}^{2} / \mathrm{Vs}^{*} \cdot{ }^{[197]} \mathrm{We}$ note that, in SM24, two NDI units have been fused to the bay positions of PDI and in SM25, two dicyanoethylenes were effectively fused to produce a coronenediimide, which does not result in any significant OTFT improvements. ${ }^{[198]}{ }^{[199]}$ Although SM26 is not quite related to PDI, this ovalene derivative contains the same diimide motif, and when it's combined with two cyano groups it produces borderline air-stable LUMO levels of $-3.9 \mathrm{eV} \cdot{ }^{[200]}$ OTFTs made from this showed promising performance whilst they were operating in a nitrogen environment, with reported electron mobilities of $1 \mathrm{~cm}^{2} / \mathrm{Vs}$, that dropped down to $0.5 \mathrm{~cm}^{2} / \mathrm{Vs}^{*}$ when operating in ambient atmosphere.

Soluble acene derivatives also form a notable class of OSC. By changing from purely carbon based acenes to those based on $\mathrm{N}$-containing heterocycles, the electron affinity of the system can be increased so that n-type behaviour is observed. For example, high mobility values of $11 \mathrm{~cm}^{2} / \mathrm{Vs}^{*}$ were reported for drop cast crystalline films of SM27 made using a modified dielectric bilayer of $\mathrm{AlO}_{\mathrm{x}} / \mathrm{SiO}_{2}$ capped with phosphonic acid, although it was noted that there was deviation from ideal FET behaviour at high $\mathrm{V}_{\mathrm{G} .}{ }^{[201]}$ Extending the aromatic core to produce SM28 did not result in enhanced performance. ${ }^{[202]}$ Finally, we will discuss the electron deficient amide group. Typically it is not sufficiently electron withdrawing to enable electron transport on its own, but when it's combined with other electron withdrawing groups, such esters and fluorine (SM29) or pyrazine (SM30), low lying LUMO levels can be achieved and electron transport enabled. ${ }^{[203]}{ }^{[204]}$ Promising single crystal performance was observed for SM29 and, additionally, the number and regiochemistry of the fluorine substituents were 
found to have a significant influence on crystal packing and hence mobility. The SM29 derivative, SM29D, showed the best performance in OTFTs, with mobilities up to $12.6 \mathrm{~cm}^{2} / \mathrm{Vs}^{*}$ being reported in OTFTs made using single microwires. In these latest examples it is the ability of the amide group to act as an H-bond acceptor which has helped to planarise the molecular core.

\section{Molecular semiconductor/polymer blends}

In addition to chemical synthesis, other approaches for improving the mobility of OTFTs involve carefully controlling the formation of the OSC layer during fabrication. Generally, using various processing techniques, ${ }^{[205]}$ thin-film morphology can be controlled so that crystalline grains and conjugated polymers are aligned in such a way that charge transport is directional and OTFT performance is improved; further information on alignment and alignment strategies for conjugated polymers can be found in the recent review article by Khim and Luzio. ${ }^{[206]}$

Another approach for improving the mobility of OTFTs is to blend two or more OSC materials together. Blending materials to combine the beneficial properties of multiple components in a single system is not an uncommon process, known to mankind for many years, and used for many applications. [207] [208] [209]

Although there are some blended OTFT systems that combine two polymers ${ }^{[46]}{ }^{[210]}$, we will focus here on OTFT blend systems consisting of a molecular semiconductor, or a small-molecule, and a polymer. The idea underpinning this simple approach is to combine high charge carrier mobilities typically associated with the small-molecule, ${ }^{[211]}{ }^{[212]}{ }^{[213]}$ and the film forming traits of the polymer binder ${ }^{[213]}{ }^{[214]}$, in a system that offers the best of both Worlds. ${ }^{[107]}[215]$ 
Small-molecule/polymer blend systems have formed a prominent part of the OTFT mobility story, consistently producing some of the highest mobility OTFTs. Additionally, these blend systems have shown limited non-ideal characteristics, giving a clearer idea about the mobility values that can be achieved with these systems (Table 1). We note that the limited nonideal characteristics are potentially due to the ability of the polymer binder to reduce energetic disorder. [216] [215] Their encouraging journey over the past decade has allowed us to pull out some key design criteria for blend OTFTs, which we will summarise in this section.

\subsection{Molecular semiconductor/polymer blend morphology}

\subsubsection{Vertical phase separation and small-molecule formation}

One reason for their success is that small-molecule/polymer blends offer a wide range of morphologies compared to any single material system, which has made them highly attractive given the strong structure-property relationship exhibited in OSCs. The diverse range of morphologies that blend systems have to offer depends on a wide range of factors, such as: degree of polymer crystallinity, system miscibility, solvent choice, solvent evaporation rate, solution viscosity, polymer binder, diffusivity, solubility of the two solutes, choice of fabrication technique, temperature treatment, substrate/surface properties and interactions such as surface tension and wetting. ${ }^{[217] ~[218] ~[219] ~[220] ~}$

Out of the morphological qualities that the blend has to offer, the most critical characteristic tendency of the solution-processed blend is to undergo vertical phase separation; ${ }^{[221]}$ the end result of this nucleation and growth phase separation is typically a layer of small-molecule on top of a layer of polymer, i.e. vertical phase separation, which is ideally suited to top-gated structures. Although we note that, if desired, varying the processing 
parameters can result in lateral phase separation ${ }^{[222]}$ or even trilayer stratification (i.e. small-molecule/polymer/small-molecule). ${ }^{[223]}$

One advantage of the typical vertical phase separation is that it reduces the nucleation rate of the small-molecule layer formation on the surface/air interface. This enables an extra level of control over the growth processes of the small-molecule layer, improving the notoriously bad film-forming properties associated with some solution-processed smallmolecules, which are otherwise severely limited kinetically by fast solvent evaporation. ${ }^{[224]}$ ${ }^{[225]}$ Blending is therefore used as an approach to increase the sizes of the small-molecule crystallites and reduce the density of grain boundaries. This impacts mobility because efficient charge transport is enabled in ordered crystallites but inhibited and trapped at the disordered grain boundaries ${ }^{[226]}$, and therefore high mobilities are generally seen to correlate with larger grain sizes. Improving the quality of the small-molecule film not only improves mobility, but also impacts other OTFT characteristics by decreasing energetic disorder. Hamilton et al. have shown that, in blends made from 2,8-difluoro-5,11bis(triethylsilylethynyl)anthradithiophene (diF-TES ADT) and poly(triaryl amine) (PTAA), not only did the top-gate OTFTs show increased mobility due to the layer of high-mobility small-molecule at the channel, but improved hysteresis and threshold voltages were observed, indicating that blending improved energetic disorder. ${ }^{[107]}$

For these reasons, the well-known, highest mobility small-molecules have been widely researched in small-molecule/polymer blend systems, i.e. 6,13-bis(triisopropylsilylethynyl)pentacene (TIPS-pentacene) ${ }^{[227][228][229][230]}$,rubrene $^{[231][232]}$, dif-TES ADT ${ }^{[233]}{ }^{[234]}$ and 2,7-dioctyl[1] benzothieno[3,2-b][1]benzothiophene $\left(\mathrm{C}_{8}-\mathrm{BTBT}\right)^{[235]}$ [236] [235]. A number of variables have been found to have a strong influence on how the small-molecule nucleates in blend systems, and hence determine the mobility, such as solvent choice (including poor solvent introduction) ${ }^{[211] ~[231] ~[237] ~[238], ~ b l e n d ~ r a t i o ~}{ }^{[239]}{ }^{[240]}$, processing 
and substrate temperature ${ }^{[235]}$ [240] [231], surface treatment/wetting $^{[217]}{ }^{[241]}{ }^{[242]}$, and indeed the polymer binder in terms of molecular weight and whether it has amorphous or semi-crystalline properties. $^{[243][244][245][231][246]}$

\subsubsection{Processing techniques}

It's worth mentioning here that further control over the blend morphology, and hence mobility, can be achieved by using external processing techniques. Indeed, the impact of fabrication techniques on the versatile blend system has been demonstrated a number of times over the years. Examples of fabrication techniques include: spray deposition ${ }^{[247]}{ }^{[248]}$, lineprinting $^{[249]}$, air-brushing ${ }^{[250]}$, ink-jet printing ${ }^{[240]}$, dipping processes ${ }^{[227]}$, vertical flow ${ }^{[228]}$, blade coating $^{[237]}{ }^{[241]}$ and off-centre spin-coating ${ }^{[251]}$.

Blade coating has shown some particularly interesting blend results. For example, using diF-TES ADT and TIPS-pentacene-based blends, Niazi et al. highlighted that the blend nucleation and growth processes are different in blade coating than spin-coating. ${ }^{[241]}$ They take this work one step further in a later publication; by carefully controlling the processing conditions of the blade coating technique, they report diF-TES ADT:polystyrene blend OTFTs with mobilities close to the mobility values that have been reported for neat diFTES ADT single-crystal OTFTs. ${ }^{[237] ~[252]}$ Soeda et al. recently used a continuous growth edgecasting method to produce solution-processed single-crystal OTFTs from a blend of 3,11-didecyldinaphtho[2,3- $\left.d: 2^{\prime}, 3^{\prime}-d^{\prime}\right]$ benzo[1,2-b:4,5-b']dithiophene

(C10-DNBDT-NW) and poly(methyl methacrylate) (PMMA), achieving maximum mobilities of $17 \mathrm{~cm}^{2} / \mathrm{Vs} .^{[108]}$ Not only is this mobility higher than the neat C10-DNBDT-NW processed in the same way, but it is also one of the highest solution-processed mobilities to-date. This work demonstrates the impact of blending, as well as processing the blend using a complimentary processing technique. 


\subsection{Semiconducting polymer binders}

A very important point regarding small-molecule/polymer blend systems is that the polymer binder in a blend does not only impact charge transport properties by aiding film formation, morphology and nucleation/growth kinetics of the small-molecule - it also has an intrinsic role in the blend OTFT electrical performance. This was first demonstrated in 2009 by Hamilton et al., who showed that blending diF-TES ADT with PTAA will give higher mobility values than blending diF-TES ADT with poly( $\alpha$-methylstyrene) (P $\alpha M S)$, leading to record breaking solution-processed hole mobility values of $\mu_{\text {sat }}=2.4 \mathrm{~cm}^{2} / \mathrm{Vs}^{\left[{ }^{[107]}\right.}$ In 2012 , Smith et al. demonstrated that by changing the polymer binder to an even higher performing semiconducting polymer binder, poly(dioctylfluorene-co-bis-N,N'(2,4-dimethylphenyl)

diphenylaminedimethyl) (PF-TAA), ${ }^{[215]}$ under the same processing conditions, the mobility could be more than doubled, increasing from $2.4 \mathrm{~cm}^{2} / \mathrm{Vs}$ to $>5 \mathrm{~cm}^{2} / \mathrm{Vs}$.

To investigate this effect, Hunter and Anthopoulos used conductive atomic force microscopy (C-AFM) to look at the grain boundaries in blend films made with semiconducting polymer binders compared to neat small-molecule films as well as blend film made from insulating polymer binders. ${ }^{[253]}$ They found that, only for the case of the semiconducting binder, the grain boundaries - which are known to inhibit charge transport in $\mathrm{OSCs}^{[254]}{ }^{[239]}$ - of the small-molecule upper-layer appeared to exhibit surprisingly low resistance. This suggested that there is inter-grain connectivity at the channel, perhaps from a mixed-phase small-molecule/polymer grain boundary, which is formed during vertical phase separation, enabling transportation of holes between the crystalline high mobility domains. Based on these observations, when choosing a semiconducting polymer binder for a blend, it's also important to take into account energy level matching throughout the system, i.e. between the small-molecule, source/drain electrodes and the polymer binder. ${ }^{[215]}$ 


\subsection{Ternary blend systems: molecular semiconductor/polymer/dopant}

Recently, it was shown that by adding a third component, a molecular dopant, into smallmolecule/polymer blend systems can reduce energetic disorder even further and significantly increase the mobility. In 2016 Paterson et al. showed that adding a molecular dopant, $\mathrm{C}_{60} \mathrm{~F}_{48}$, into a blend of $\mathrm{C}_{8}$-BTBT and $\mathrm{C}_{16}$ IDT-BT, spin-coated hole mobilities of $13 \mathrm{~cm}^{2} / \mathrm{Vs}$ were achieved. This mobility was significantly higher than the values reported for spin-coated layers of the $\mathrm{C}_{8}$-BTBT $\left(2.6 \mathrm{~cm}^{2} / \mathrm{Vs}\right), \mathrm{C}_{16}$ IDT-BT $\left(3.1 \mathrm{~cm}^{2} / \mathrm{Vs}\right)$, and the pristine undoped blend $\left(4 \mathrm{~cm}^{2} / \mathrm{Vs}\right) \cdot{ }^{[52]}$ They showed that the molecular dopant plays a critical role in this system by deactivating hole traps. The impact of this was not only an improvement in mobility from an average of 1.4 to $7.8 \mathrm{~cm}^{2} / \mathrm{Vs}$ over 50 OTFTs, but also improving contact resistance, biasstress stability, threshold voltage and device homogeneity. Remarkably, the addition of the dopant at a range of concentrations also appeared to have no impact on the microstructure at the channel. By using various characterisation techniques, an unusual phase separation of the three materials was uncovered, whereby the dopant resided within the polymer layer. Because of the spatial separation between the small-molecule channel in the top-gate bottom-contact OTFTs and the dopant molecules, doping mechanisms and electrical benefits associated with were observed in the OTFTs (Figure 16), but with none of the typical practical utilisation drawbacks. $^{[58]}$ This is a highly encouraging demonstration of modulation doping-like behaviour.

The benefits of the ternary small-molecule/polymer/dopant blend approach further were demonstrated by Panidi et al. They used the Lewis acid tris(pentafluorophenyl)borane $\left(\mathrm{B}\left(\mathrm{C}_{6} \mathrm{~F}_{5}\right)_{3}\right)$ in a series of blends, polymers and small-molecules, ${ }^{[53]}$ and in each case, the $\mathrm{B}\left(\mathrm{C}_{6} \mathrm{~F}_{5}\right)_{3}$ was seen to improve mobility, with the most significant improvements seen in blend systems made for blends of TIPS-pentacene:PTAA, diF-TES ADT:PTAA and $\mathrm{C}_{8}{ }^{-}$ 
BTBT:C ${ }_{16}$ IDT-BT, which achieved maximum mobilities of $3.7,8$ and $11 \mathrm{~cm}^{2} / \mathrm{Vs}$, respectively. The improvements in mobility were attributed to the $\mathrm{B}\left(\mathrm{C}_{6} \mathrm{~F}_{5}\right)_{3}$ Lewis acid both pdoping the blend and inducing single-crystal-like long-range crystallinity in the surface morphology of the blend films. Panidi et al. also highlight that, as well a striking improvement in mobility, the doped blend systems showed improvements in $\mathrm{R}_{\mathrm{C}}$. We note that, in both of these ternary blend studies, the dopant was simply added into the blend during solution preparation, bypassing any need for additional processing steps or complications.

\subsection{OSC blend design criteria}

Looking back at the literature over the past decade has revealed some key principles for small-molecule/polymer blend systems:

(i) For many OSCs, blending a small-molecule with an insulating polymer binder will improve film forming properties, and hence electrical performance, than the pristine small-molecule counterpart processed under the same conditions, due to the characteristic vertical phase separation.

(ii) Exchanging the insulating polymer binder for a semiconducting polymer binder will tend to increase the mobility of the blend provided that a few key criteria are satisfied.

(iii) Exchanging the semiconducting polymer binder for a semiconducting polymer with higher mobility, further increases in the device mobility can be achieved.

(iv) Although doping in blends is still in its early stages, it has shown great potential for increasing the mobility of these blend systems even further as well as narrowing the device-to-device parameter variation. We also note that, if solution processing techniques, such as blade coating, are used, then the blend mobility could potentially be improved even further. 
Overall, blended systems have shown tremendous potential to further enhance charge carrier mobilities in organic semiconductors, by offering alternative OSC compositions without the need of synthesising new materials. Whilst there are still many questions regarding the blend systems at this point, we believe that the additional processing flexibility together with the vast library of organic polymers, molecular organic semiconductors and dopants already developed, offers exciting opportunities to further increase the electrical performance of OTFT devices in the near future. In particular, we highlight that doped blend systems have shown to exhibit high mobilities ad unique OTFT doping-related properties that will certainly benefit from further research, and are many opportunities for the development of high performance n-type and/or ambipolar blend systems.

\section{Outlook}

When an OTFT exhibits non-deal characteristics, it doesn't satisfy Shockley's FET model. The features of a nonideal transistor have been long established and are determined by looking at the transfer and output characteristics. Two characteristic nonidealities are bias dependent mobility ${ }^{[106]}$ often attributed to structural defects and trap states next to the transport band edge, ${ }^{[255]}[6]$ and s-shaped, diode-like behaviour in the output curves. ${ }^{[103]}[256]$ Another distinguishing feature of a nonideal OTFT, which has been particularly rife in recent years, is a "kink", "hump" or "double slope" in the plot of $\sqrt{ }_{\mathrm{D}} \mathrm{vs}_{\mathrm{G}} \mathrm{V}_{\mathrm{G} .}{ }^{[11]}$ Typically, the kink in $\sqrt{ }_{\mathrm{D}}$ vs $\mathrm{V}_{\mathrm{G}}$ is a nonlinear line which exhibits a steeper region at lower gate voltages and a shallow region at higher voltages. ${ }^{[13]}{ }^{[12]}$ The kink is a nonideality, or artefact, because classic FET theory states that the mobility can only be extracted when the linear regime $I_{D}$ or saturation regime $\sqrt{ } I_{D}$ follow a linear relationship with $V_{G} \cdot{ }^{[19]}$ One serious issue with the kink is that, if the gradient is taken from a steeper part of the nonlinear line and used to calculate the mobility, then it results to overestimated mobility values. Over the years, the kink, and 
mobility values associated with it, have become prevalent in OTFT literature. This has led to widespread contamination of the OTFT literature, which we refer to as the mobility hype; the mobility hype happened because, over the years, the intrinsic mobility of OSCs increased, which in turn decreased $\mathrm{R}_{\mathrm{CH}}$, making the issue of $\mathrm{R}_{\mathrm{C}}$ more apparent. ${ }^{[106]}$

We therefore sift through the mobility values published over the last 30 years to get a more clear idea of how many reported saturation mobility values have been extracted from OTFTs that deviate from the ideal FET model. We find that $55 \%$ of the OTFT literature with mobilities approaching $\geq 1 \mathrm{~cm}^{2} / \mathrm{Vs}$ contain nonidealities. Another striking finding is that the hole mobility of p-type materials have yet to exceed $20 \mathrm{~cm}^{2} / \mathrm{Vs}$, while for n-type materials this value is even lower and close to $10 \mathrm{~cm}^{2} / \mathrm{Vs}$. Interestingly, small-molecule/polymer blend systems are consistently amongst the highest reliably reported mobilities for solution-processed transistors. ${ }^{[52]}[107][108][107]$ Despite the widespread contamination of the OTFT literature, however, our analysis also shows that there has been a very encouraging, constant improvement in the carrier mobility values of OSCs over time. Despite some distraction from the mobility hype, impressive improvements in mobilities have still been achieved.

Going forward, we recommend that the following data plots are presented in all OTFT papers: output curves, transfer curves, $\mu$ vs. $V_{G}, \sqrt{I}_{D_{-} S A T}$ vs. $V_{G}$ and/or I I_LIN vs. $V_{G}$ narrowing. Presenting all OTFT data together enables the community to understand how the device are operating and if/how the data deviates from the ideal model. This request is simple to implement but important, as the gradual channel approximation will most likely be used for the foreseeable future, and, although the kink became symbolic of the mobility hype, overestimation can still occur without the kink. ${ }^{[14]}{ }^{[19]}$ Additionally, if there is a kink, we suggest that a reasonable estimate of $\mu_{\text {sat }}$ can be extrapolated from the plot of $\mu_{\text {sat }} v_{s} V_{G}$, at high $\mathrm{V}_{\mathrm{G}}$. At this bias condition the contact resistance in a high performance OTFT is expected 
to minimize and as such to have the minimum impact on the analysis. The linear mobility should also be specified, which can be conservatively evaluated from output curves; equally, mobility values can be used to simulate output curves for verification.

Practical approaches should also be taken to improve $\mathrm{R}_{\mathrm{C}}$ by doping the OSC and/or the contacts. Currently, the biggest setback for doping is the tendency of dopant molecules to interfere with the host lattice, reducing mobility values. However, with further research, doping not only has the potential to resolve $\mathrm{R}_{\mathrm{C}}$ issues in OTFTs, it also has the potential to be as revolutionary for OTFTs as it has been for other solid state devices.

After sifting through the mobility hype to find out what we can truly consider to be a high mobility OFET, we reviewed the literature to summarise our latest understanding in the key developments that have led to successful improvements in carrier mobility. To begin with, we looked at p-type polymers and co-polymers. When designing a high performing semiconducting polymer, there are two main design criteria. Firstly, the energetic disorder along the polymer chain needs to be minimized and the conjugated backbone designed to be as rigid as possible to maximize orbital overlap between the different building blocks, and minimize the torsional disorder. This can be achieved by either introducing large fused aromatic building blocks into the polymer backbone or alternatively by introducing conformational locks along the backbone to assist planarization. The crucial second parameter leading to high charge carrier mobilities is molecular weight. In the case of most thiophene containing polymers exhibiting a lamellar microstructure, there is a critical molecular weight that needs to be achieved, relative to the size of the domains. Once this chain length is reached, "tie'chains" can connect between domains, increasing charge carrier mobility. However, as molecular weight increases further, it becomes more difficult for thin-film crystallization, which can impede transport. For more amorphous polymers, there is a more 
monotonic relationship between transport and molecular weight, due to the increasing dependence on transport along the chain.

Whilst these design criteria might appear simplistic, the one factor which is more difficult to control is the polymer processability or solubility. By reducing the torsional disorder and stiffening the backbone, the polymer inevitably becomes less soluble. Therefore, it is important when synthesising conjugated polymers to find the right balance between rigid polymer backbones and sufficient solubilising side chains to develop the full semiconducting properties, rather than discarding a potentially interesting material simply because of a poor design judgement.

Next, we addressed n-type OSCs as, although hole mobilities still outperform electron mobilities, there have been significant improvements in mobilities as well as ambient stability in recent years. There are clear similarities between the different reported n-type structures and their respective strategies to improve the carrier mobility. By using the following three design principles, we anticipate that an entirely new generation of high mobility n-type conjugated polymers can be achieved:

(i) It is clear that a planar, electron deficient core monomer is necessary. Cyclic amides are clearly of use here as they are both electron deficient and also serve as a useful site for the introduction of a solubilizing side chain.

(ii) The choice of solubilizing alkyl chain is critical as this helps govern the solid state structure. The strategy of variation of branching point has proven successful but so far it appears that there are no generalised rules as to which branching point is 'best'.

(iii) The use of electron deficient co-monomers and conformational locks (i.e. pyridyl or fluorine substitution) can be extremely beneficial as they deepen the LUMO, allowing for improved electron injection and ambient stability, and enhance backbone planarity. 
In the case of small-molecule n-type materials, although the molecular requirements for high electron affinity can be relatively easily designed and achieved, the discovery of small molecules which exhibit the desired solid state morphology remains challenging. Small changes in the sidechains or backbone chemistry can result in significant changes in crystal packing which are difficult to predict. Expansion of the conjugated core has been a common theme but although often desirable to help control the molecular energetics, it is no guarantee of improved transistor performance. The higher mobility reported for single crystal devices suggests that further improvements of the device's architecture can be expected with a combination of molecular design and the appropriate processing techniques. In particular the blending approach appears promising, but has thus far been under explored for n-type materials.

Finally, we look at blending a small-molecule with a polymer as a technique for improving OFET mobility. By looking at the blend literature from the past decade, we find that there are some general design rules governing these systems:

(i) An insulating polymer binder will improve the film-forming qualities of a smallmolecule layer due to the often observed vertical phase separation of the two component materials.

(ii) Replacing the insulating polymer with a semiconducting polymer will further improve the mobility, with the blend performance increasing with the intrinsic performance of the semiconducting binder polymer.

(iii) The addition of a third component, a molecular dopant, to produce a ternary blend can even further improve the mobility.

In addition to the above design rules, investigating alternative solution-processing techniques, such as blade coating or edge-casting, can improve the mobility even further. Overall, we believe that the community should be highly encouraged by the significant 
progress made with high mobility OFETs and knowledge of OSC design - despite the temporary confusion of the mobility hype. Like any new technologies, the OFET was bound to encounter teething problems as part of its journey. As we progress we continue to gain a better understanding of how to integrate these unique materials into well-known devices. We started this review article by giving an overview of the difficulties faced by inorganic TFTs before they made it to market. Based on the true trend showing that OFET mobilities are increasing over time, we firmly believe that the mobility will continue to rise, for some time, with further research, and that the OTFT may find its own breakthrough just around the corner.

\section{Supporting Information}

Supporting Information is available from the Wiley Online Library or from the author.

\section{Acknowledgements}

A.F.P, I.M., and T.D.A., are grateful to King Abdullah University of Science and Technology (KAUST) for financial support. The authors would like to thank the British Council (Grant No: 337323) and EPRSC (Grant No. EP/L016702/1). B.C.S. and S.S. acknowledge financial support from the Leverhulme Trust (Grant No. RF-2017-65514) and British Council (Grant No. 337067), respectively.

Received: ((will be filled in by the editorial staff))

Revised: ((will be filled in by the editorial staff)) Published online: ((will be filled in by the editorial staff))

\section{References}

[1] T. P. Brody, IEEE Trans. Electron Devices 1984, 31, 1614.

[2] J. E. Lilienfeld, 1930, US patent 1.

[3] O. Heil, United Kingdom Patent, 1935.

[4] Y. Yoshitaka, Jpn. J. Appl. Phys. 2012, 51, 060001.

[5] W. Shockley, PROCEEDINGS OF THE I.R.E. 1952, 1376.

[6] C. Reese, Z. Bao, J. Appl. Phys. 2009, 105, 024506.

[7] H. Y. Li, Y. Li, H. Li, J. L. Bredas, Adv. Funct. Mater. 2017, $27,11$.

[8] H. Sirringhaus, Advanced Materials 2014, 26, 1319.

[9] E. G. Bittle, H. W. Ro, C. R. Snyder, S. Engmann, R. J. Kline, X. R. Zhang, O. D.

Jurchescu, D. M. DeLongchamp, D. J. Gundlach, J. Polym. Sci. Pt. B-Polym. Phys. 2017, 55, 1063. 
[10] Y. Xu, H. Sun, W. Li, Y.-F. Lin, F. Balestra, G. Ghibaudo, Y.-Y. Noh, Adv. Mater. 2017, 29, 1702729.

[11] I. McCulloch, A. Salleo, M. Chabinyc, Science 2016, 352, 1521.

[12] E. G. Bittle, J. I. Basham, T. N. Jackson, O. D. Jurchescu, D. J. Gundlach, Nature Nat. Commun. 2016, 7, 10908.

[13] T. Uemura, C. Rolin, T.-H. Ke, P. Fesenko, J. Genoe, P. Heremans, J. Takeya, Adv. Mater. 2016, 28, 151.

[14] H. H. Choi, K. Cho, C. D. Frisbie, H. Sirringhaus, V. Podzorov, Nature Materials 2017, $17,2$.

[15] C. Liu, Y. Xu, Y. Li, W. Scheideler, T. Minari, The Journal of Physical Chemistry C 2013, 117, 12337.

[16] G. B. Blanchet, C. R. Fincher, M. Lefenfeld, J. A. Rogers, Appl. Phys. Lett. 2004, 84, 296.

[17] T. Okachi, T. Kashiki, K. Ohya, SPIE Organic Photonics + Electronics, 2015, 9568, 8.

[18] C. Rolin, E. Kang, J. H. Lee, G. Borghs, P. Heremans, J. Genoe, Nat. Commun. 2017,

8,9 .

[19] C. Liu, G. Li, R. Di Pietro, J. Huang, Y.-Y. Noh, X. Liu, T. Minari, Phys. Rev. Appl. 2017, 117, 12337.

[20] C. Liu, G. Huseynova, Y. Xu, D. X. Long, W.-T. Park, X. Liu, T. Minari, Y.-Y. Noh, Sci Rep 2016, 6, 29811.

[21] S. Lee, A. Nathan, Science 2016, 354, 302.

[22] Y. Hu, G. Li, W. Peng, Z. Chen, IEEE Electron Device Lett. 2018, 39, 421.

[23] D. Natali, M. Caironi, Adv. Mater. 2012, 24, 1357.

[24] L. Burgi, H. Sirringhaus, R. H. Friend, Appl. Phys. Lett. 2002, 80, 2913.

[25] N. J. Watkins, L. Yan, Y. L. Gao, Appl. Phys. Lett. 2002, 80, 4384.

[26] N. Koch, A. Kahn, J. Ghijsen, J. J. Pireaux, J. Schwartz, R. L. Johnson, A. Elschner, Appl. Phys. Lett. 2003, 82, 70.

[27] E. H. Rhoderick, R. Williams, Metal-Semiconductor Contacts, Clarendon Press, Oxford, UK 1988.

[28] M. Oehzelt, N. Koch, G. Heimel, Nat. Commun. 2014, 5, 4174.

[29] J. Hwang, A. Wan, A. Kahn, Materials Science and Engineering: R: Reports 2009, 64, 1 .

[30] J. C. Scott, G. G. Malliaras, Chemical Physics Letters 1999, 299, 115.

[31] P. R. Emtage, J. J. O'Dwyer, Physical Review Letters 1966, 16, 356.

[32] C. Liu, Y. Xu, Y.-Y. Noh, Materials Today 2015, 18, 79.

[33] B. Lüssem, C.-M. Keum, D. Kasemann, B. Naab, Z. Bao, K. Leo, Chemical Reviews 2016, 116, 13714.

[34] H.-F. Meng, Polymer Electronics, Pan Standford Publishing, Singapore 2013.

[35] Y. Xu, H. Sun, E. Y. Shin, Y. F. Lin, W. W. Li, Y. Y. Noh, Adv. Mater. 2016, 28, 8531.

[36] C. Kittel, Introduction to solid state physics, Wiley, Hoboken, NJ 2005.

[37] C. Vanoni, S. Tsujino, T. A. Jung, Applied Physics Letters 2007, 90, 193119.

[38] J. Blochwitz, T. Fritz, M. Pfeiffer, K. Leo, D. M. Alloway, P. A. Lee, N. R. Armstrong, Organic Electronics 2001, 2, 97.

[39] S. Olthof, W. Tress, R. Meerheim, B. Lüssem, K. Leo, Journal of Applied Physics 2009, 106, 103711.

[40] P. Wei, J. H. Oh, G. Dong, Z. Bao, J. Am. Chem. Soc. 2010, 132, 8852.

[41] S. Rossbauer, C. Muller, T. D. Anthopoulos, Advanced Functional Materials 2014, 24, 7116.

[42] D. Khim, K.-J. Baeg, M. Caironi, C. Liu, Y. Xu, D.-Y. Kim, Y.-Y. Noh, Advanced Functional Materials 2014, 24, 6252. 
[43] P. Wei, T. Menke, B. D. Naab, K. Leo, M. Riede, Z. Bao, J. Am. Chem. Soc. 2012, $134,3999$.

[44] M. P. Hein, A. A. Zakhidov, B. Lüssem, J. Jankowski, M. L. Tietze, M. K. Riede, K. Leo, Applied Physics Letters 2014, 104, 013507.

[45] C. Liu, J. Jang, Y. Xu, H. J. Kim, D. Khim, W. T. Park, Y. Y. Noh, J. J. Kim, Advanced Functional Materials 2015, 25, 758.

[46] G. H. Lu, J. Blakesley, S. Himmelberger, P. Pingel, J. Frisch, I. Lieberwirth, I. Salzmann, M. Oehzelt, R. Di Pietro, A. Salleo, N. Koch, D. Neher, Nature Communications 2013, 4, 1588.

[47] S. Yoon, J. Cho, H.-K. Lee, S. Park, H. J. Son, D. S. Chung, Applied Physics Letters 2015, 107, 133302.

[48] B. D. Naab, S. Himmelberger, Y. Diao, K. Vandewal, P. Wei, B. Lussem, A. Salleo, Z. Bao, Advanced Materials 2013, 25, 4663.

[49] S. Singh, S. K. Mohapatra, A. Sharma, C. Fuentes-Hernandez, S. Barlow, S. R.

Marder, B. Kippelen, Applied Physics Letters 2013, 102.

[50] S. Olthof, S. Mehraeen, S. K. Mohapatra, S. Barlow, V. Coropceanu, J.-L. Brédas, S.

R. Marder, A. Kahn, Physical Review Letters 2012, 109, 176601.

[51] Y. Han, G. Barnes, Y.-H. Lin, J. Martin, M. Al-Hashimi, S. Y. AlQaradawi, T. D. Anthopoulos, M. Heeney, Chemistry of Materials 2016, 28, 8016.

[52] A. F. Paterson, N. D. Treat, W. Zhang, Z. Fei, G. Wyatt-Moon, H. Faber, G. Vourlias, P. A. Patsalas, O. Solomeshch, N. Tessler, M. Heeney, T. D. Anthopoulos, Advanced Materials 2016, 28, 7791.

[53] J. Panidi, A. F. Paterson, D. Khim, Z. Fei, Y. Han, L. Tsetseris, G. Vourlias, P. A. Patsalas, M. Heeney, T. D. Anthopoulos, Advanced Science, 2017, 5, 1700290.

[54] L. Ma, W. H. Lee, Y. D. Park, J. S. Kim, H. S. Lee, K. Cho, Applied Physics Letters 2008, 92, 063310 .

[55] J. Belasco, S. K. Mohapatra, Y. Zhang, S. Barlow, S. R. Marder, A. Kahn, Applied Physics Letters 2014, 105, 063301.

[56] B. Lüssem, M. L. Tietze, H. Kleemann, C. Hoßbach, J. W. Bartha, A. Zakhidov, K. Leo, Nature Communications 2013, 4, 2775.

[57] C.-T. Lee, H.-C. Chen, Organic Electronics 2011, 12, 1852.

[58] A. F. Paterson, Y.-H. Lin, A. D. Mottram, Z. Fei, M. R. Niazi, A. R. Kirmani, A. Amassian, O. Solomeshch, N. Tessler, M. Heeney, T. D. Anthopoulos, Advanced Electronic Materials, 1700464.

[59] I. Salzmann, G. Heimel, M. Oehzelt, S. Winkler, N. Koch, Accounts Chem. Res. 2016, 49,370 .

[60] I. E. Jacobs, A. J. Moulé, Adv. Mater. 2017, 29, 1703063.

[61] S. P. Tiwari, W. J. Potscavage, Jr., T. Sajoto, S. Barlow, S. R. Marder, B. Kippelen, Organic Electronics 2010, 11, 860.

[62] C. L. Fan, W. C. Lin, H. S. Chang, Y. Z. Lin, B. R. Huang, Materials 2016, 9.

[63] T. Minari, P. Darmawan, C. Liu, Y. Li, Y. Xu, K. Tsukagoshi, Applied Physics Letters 2012, 100, 59.

[64] J. Li, X.-W. Zhang, L. Zhang, H. Khizar ul, X.-Y. Jiang, W.-Q. Zhu, Z.-L. Zhang, Solid State Communications 2009, 149, 1826.

[65] F. Ante, D. Kaelblein, U. Zschieschang, T. W. Canzler, A. Werner, K. Takimiya, M. Ikeda, T. Sekitani, T. Someya, H. Klauk, Small 2011, 7, 1186.

[66] S. A. DiBenedetto, A. Facchetti, M. A. Ratner, T. J. Marks, Advanced Materials 2009, $21,1407$.

[67] G. Heimel, L. Romaner, E. Zojer, J.-L. Bredas, Accounts of Chemical Research 2008, 41,721 . 
[68] J. P. Hong, A. Y. Park, S. Lee, J. Kang, N. Shin, D. Y. Yoon, Applied Physics Letters 2008, 92, 2008.

[69] S. Kobayashi, T. Nishikawa, T. Takenobu, S. Mori, T. Shimoda, T. Mitani, H.

Shimotani, N. Yoshimoto, S. Ogawa, Y. Iwasa, Nat Mater 2004, 3, 317.

[70] C.-W. Chu, S.-H. Li, C.-W. Chen, V. Shrotriya, Y. Yang, Applied Physics Letters 2005, 87, 193508.

[71] M. Kano, T. Minari, K. Tsukagoshi, Applied Physics Letters 2009, 94, 143304.

[72] Y. Abe, T. Hasegawa, Y. Takahashi, T. Yamada, Y. Tokura, Applied Physics Letters 2005, 87, 153506 .

[73] J. H. Kim, S. W. Yun, B.-K. An, Y. D. Han, S.-J. Yoon, J. Joo, S. Y. Park, Advanced Materials 2013, 25, 719.

[74] J. Soeda, Y. Hirose, M. Yamagishi, A. Nakao, T. Uemura, K. Nakayama, M. Uno, Y. Nakazawa, K. Takimiya, J. Takeya, Advanced Materials 2011, 23, 3309.

[75] T. Hählen, C. Vanoni, C. Wäckerlin, T. A. Jung, S. Tsujino, Applied Physics Letters 2012, 101, 033305.

[76] F. Maddalena, E. J. Meijer, K. Asadi, D. M. de Leeuw, P. W. M. Blom, Applied Physics Letters 2010, 97, 158.

[77] P. Pacher, A. Lex, V. Proschek, H. Etschmaier, E. Tchernychova, M. Sezen, U. Scherf, W. Grogger, G. Trimmel, C. Slugovc, E. Zojer, Advanced Materials 2008, 20, 3143.

[78] B. H. Lee, G. C. Bazan, A. J. Heeger, Advanced Materials 2016, $28,57$.

[79] A. Das, R. Dost, T. H. Richardson, M. Grell, D. C. Wedge, D. B. Kell, J. J. Morrison, M. L. Turner, Sensors and Actuators B: Chemical 2009, 137, 586.

[80] T. Toccoli, A. Pallaoro, M. Tonezzer, N. Coppedè, S. Iannotta, Solid-State Electronics 2008, 52, 417.

[81] W. Zhao, Y. Qi, T. Sajoto, S. Barlow, S. R. Marder, A. Kahn, Applied Physics Letters 2010, 97, 123305.

[82] B. G. Alberding, W. R. Thurber, E. J. Heilweil, J. Opt. Soc. Am. B-Opt. Phys. 2017, 34, 1392.

[83] L. Bürgi, H. Sirringhaus, R. H. Friend, Appl. Phys. Lett. 2002, 80, 2913.

[84] G. de Tournadre, F. Reisdorffer, R. Rodel, O. Simonetti, H. Klauk, L. Giraudet, J. Appl. Phys. 2016, 119, 9.

[85] A. D. Meyertholen, Z. Q. Li, D. N. Basov, M. M. Fogler, M. C. Martin, G. M. Wang, A. S. Dhoot, D. Moses, A. J. Heeger, Appl. Phys. Lett. 2007, 90, 222108.

[86] Y. Tsutsui, G. Schweicher, B. Chattopadhyay, T. Sakurai, J. B. Arlin, C. Ruzie, A. Aliev, A. Ciesielski, S. Colella, A. R. Kennedy, V. Lemaur, Y. Olivier, R. Hadji, L. Sanguinet, F. Castet, S. Osella, D. Dudenko, D. Beljonne, J. Cornil, P. Samori, S. Seki, Y. H. Geerts, Adv. Mater. 2016, 28, 7106.

[87] L. Bürgi, T. J. Richards, R. H. Friend, H. Sirringhaus, J. Appl. Phys. 2003, 94, 6129.

[88] K. Seshadri, C. D. Frisbie, Appl. Phys. Lett. 2001, 78, 993.

[89] M. Caironi, M. Bird, D. Fazzi, Z. Chen, R. Di Pietro, C. Newman, A. Facchetti, H. Sirringhaus, Adv. Funct. Mater. 2011, 21, 3371.

[90] T. J. Richards, H. Sirringhaus, J. Appl. Phys. 2007, 102, 094510.

[91] P. V. Pesavento, K. P. Puntambekar, C. D. Frisbie, J. C. McKeen, P. P. Ruden, J. Appl. Phys. 2006, 99, 094504.

[92] B. Lussem, C. M. Keum, D. Kasemann, B. Naab, Z. N. Bao, K. Leo, Chem. Rev. 2016, $116,13714$.

[93] V. Podzorov, S. E. Sysoev, E. Loginova, V. M. Pudalov, M. E. Gershenson, Appl. Phys. Lett. 2003, 83, 3504.

[94] M. Ullah, R. Wawrzinek, R. C. R. Nagiri, S. C. Lo, E. B. Namdas, Adv. Opt. Mater. 2017, 5, 7 .

[95] O. Marinov, M. J. Deen, C. Feng, Y. Wu, J. Appl. Phys. 2014, 115, 034506. 
[96] G. Ghibaudo, in Electronics Letters, Vol. 24, Institution of Engineering and Technology, 1988, 24, 543.

[97] R. D. Pietro, D. Venkateshvaran, A. Klug, E. J. W. List-Kratochvil, A. Facchetti, H. Sirringhaus, D. Neher, Appl. Phys. Lett. 2014, 104, 193501.

[98] F. Torricelli, M. Ghittorelli, L. Colalongo, Z.-M. Kovacs-Vajna, Appl. Phys. Lett. 2014, 104, 093303.

[99] Y. Xu, T. Minari, K. Tsukagoshi, J. A. Chroboczek, G. Ghibaudo, J. Appl. Phys. 2010, $107,114507$.

[100] L. Zhou, L. J. Bu, D. F. Li, G. H. Lu, Appl. Phys. Lett. 2017, 110, 5.

[101] J. Zaumseil, K. W. Baldwin, J. A. Rogers, J. Appl. Phys. 2003, 93, 6117.

[102] IEEE Std 1620-2008 2008, 1.

[103] R. A. Street, A. Salleo, Appl. Phys. Lett. 2002, 81, 2887.

[104] A. Bolognesi, A. D. Carlo, P. Lugli, Appl. Phys. Lett. 2002, 81, 4646.

[105] S. Scheinert, G. Paasch, J. Appl. Phys. 2009, 105, 014509.

[106] G. Horowitz, P. Lang, M. Mottaghi, H. Aubin, Adv. Funct. Mater. 2004, 14, 1069.

[107] R. Hamilton, J. Smith, S. Ogier, M. Heeney, J. E. Anthony, I. McCulloch, J. Veres, D.

D. C. Bradley, T. D. Anthopoulos, Advanced Materials 2009, 21, 1166.

[108] J. Soeda, T. Okamoto, C. Mitsui, J. Takeya, Organic Electronics 2016, 39, 127.

[109] H. Sirringhaus, P. J. Brown, R. H. Friend, M. M. Nielsen, K. Bechgaard, B. M. W. Langeveld-Voss, A. J. H. Spiering, R. A. J. Janssen, E. W. Meijer, P. Herwig, D. M. de Leeuw, Nature 1999, 401, 685.

[110] B. S. Ong, Y. Wu, P. Liu, S. Gardner, Journal of the American Chemical Society 2004, $126,3378$.

[111] I. McCulloch, M. Heeney, C. Bailey, K. Genevicius, I. MacDonald, M. Shkunov, D. Sparrowe, S. Tierney, R. Wagner, W. Zhang, M. L. Chabinyc, R. J. Kline, M. D. McGehee, M. F. Toney, Nature Materials 2006, 5, 328.

[112] I. McCulloch, M. Heeney, C. Bailey, K. Genevicius, I. Macdonald, M. Shkunov, D. Sparrowe, S. Tierney, R. Wagner, W. Zhang, M. L. Chabinyc, R. J. Kline, M. D. McGehee, M. F. Toney, Nat Mater 2006, 5, 328.

[113] R. J. Kline, D. M. DeLongchamp, D. A. Fischer, E. K. Lin, L. J. Richter, M. L. Chabinyc, M. F. Toney, M. Heeney, I. McCulloch, Macromolecules 2007, 40, 7960.

[114] Z. Fei, P. Pattanasattayavong, Y. Han, B. C. Schroeder, F. Yan, R. J. Kline, T. D. Anthopoulos, M. Heeney, Journal of the American Chemical Society 2014, 136, 15154. [115] J. Liu, R. Zhang, G. Sauvé, T. Kowalewski, R. D. McCullough, Journal of the American Chemical Society 2008, 130, 13167.

[116] W. Zhang, J. Smith, S. E. Watkins, R. Gysel, M. McGehee, A. Salleo, J. Kirkpatrick, S. Ashraf, T. Anthopoulos, M. Heeney, I. McCulloch, J. Am. Chem. Soc. 2010, 132, 11437.

[117] H. Bronstein, D. S. Leem, R. Hamilton, P. Woebkenberg, S. King, W. Zhang, R. S. Ashraf, M. Heeney, T. D. Anthopoulos, J. d. Mello, I. McCulloch, Macromolecules 2011, 44, 6649.

[118] X. Zhang, H. Bronstein, A. J. Kronemeijer, J. Smith, Y. Kim, R. J. Kline, L. J. Richter, T. D. Anthopoulos, H. Sirringhaus, K. Song, M. Heeney, W. Zhang, I. McCulloch, D. M. DeLongchamp, Nature Communications 2013, 4, 2238.

[119] R. Noriega, J. Rivnay, K. Vandewal, F. P. V. Koch, N. Stingelin, P. Smith, M. F. Toney, A. Salleo, Nature Materials 2013, 12, 1038.

[120] X. Zhang, H. Bronstein, A. J. Kronemeijer, J. Smith, Y. Kim, R. J. Kline, L. J. Richter, T. D. Anthopoulos, H. Sirringhaus, K. Song, M. Heeney, W. Zhang, I. McCulloch, D. M. DeLongchamp, Nature Communications 2013, 4, 2238.

[121] D. Venkateshvaran, M. Nikolka, A. Sadhanala, V. Lemaur, M. Zelazny, M. Kepa, M. Hurhangee, A. J. Kronemeijer, V. Pecunia, I. Nasrallah, I. Romanov, K. Broch, I. McCulloch, D. Emin, Y. Olivier, J. Cornil, D. Beljonne, H. Sirringhaus, Nature 2014, 515, 384. 
[122] W. Zhang, Y. Han, X. Zhu, Z. Fei, Y. Feng, N. D. Treat, H. Faber, N. Stingelin, I. McCulloch, T. D. Anthopoulos, M. Heeney, Adv. Mater. 2016, 28, 3922.

[123] H. Chen, M. Hurhangee, M. Nikolka, W. Zhang, M. Kirkus, M. Neophytou, S. J. Cryer, D. Harkin, P. Hayoz, M. Abdi-Jalebi, C. R. McNeill, H. Sirringhaus, I. McCulloch, Advanced Materials 2017, 29, 1702523.

[124] Z. Fei, Y. Han, E. Gann, T. Hodsden, A. S. R. Chesman, C. R. McNeill, T. D. Anthopoulos, M. Heeney, J. Am. Chem. Soc. 2017, 139, 8552.

[125] H. Huang, L. Yang, A. Facchetti, T. J. Marks, Chemical Reviews 2017, 117, 10291.

[126] C. M. Mauck, P. E. Hartnett, E. A. Margulies, L. Ma, C. E. Miller, G. C. Schatz, T. J.

Marks, M. R. Wasielewski, Journal of the American Chemical Society 2016, 138, 11749.

[127] L. Bürgi, M. Turbiez, R. Pfeiffer, F. Bienewald, H.-J. Kirner, C. Winnewisser, Advanced Materials 2008, 20, 2217.

[128] T. L. Nelson, T. M. Young, J. Liu, S. P. Mishra, J. A. Belot, C. L. Balliet, A. E. Javier, T. Kowalewski, R. D. McCullough, Advanced Materials 2010, 22, 4617.

[129] X. Zhang, L. J. Richter, D. M. DeLongchamp, R. J. Kline, M. R. Hammond, I.

McCulloch, M. Heeney, R. S. Ashraf, J. N. Smith, T. D. Anthopoulos, B. Schroeder, Y. H. Geerts, D. A. Fischer, M. F. Toney, Journal of the American Chemical Society 2011, 133, 15073.

[130] Z. Chen, M. J. Lee, R. Shahid Ashraf, Y. Gu, S. Albert-Seifried, M. Meedom Nielsen, B. Schroeder, T. D. Anthopoulos, M. Heeney, I. McCulloch, H. Sirringhaus, Advanced Materials 2012, 24, 647.

[131] C.-H. Lee, Y.-Y. Lai, J.-Y. Hsu, P.-K. Huang, Y.-J. Cheng, Chemical Science 2017, 8, 2942.

[132] H. Bronstein, Z. Chen, R. S. Ashraf, W. Zhang, J. Du, J. R. Durrant, P. Shakya Tuladhar, K. Song, S. E. Watkins, Y. Geerts, M. M. Wienk, R. A. J. Janssen, T. Anthopoulos, H. Sirringhaus, M. Heeney, I. McCulloch, Journal of the American Chemical Society 2011, $133,3272$.

[133] Z. Fei, L. Chen, Y. Han, E. Gann, A. S. R. Chesman, C. R. McNeill, T. D.

Anthopoulos, M. Heeney, A. Pietrangelo, J. Am. Chem. Soc. 2017, 139, 8094.

[134] T. Lei, Y. Cao, Y. Fan, C.-J. Liu, S.-C. Yuan, J. Pei, Journal of the American Chemical Society 2011, 133, 6099.

[135] T. Lei, J.-H. Dou, Z.-J. Ma, C.-H. Yao, C.-J. Liu, J.-Y. Wang, J. Pei, Journal of the American Chemical Society 2012, 134, 20025.

[136] R. S. Ashraf, A. J. Kronemeijer, D. I. James, H. Sirringhaus, I. McCulloch, Chemical Communications 2012, 48, 3939.

[137] I. Meager, M. Nikolka, B. C. Schroeder, C. B. Nielsen, M. Planells, H. Bronstein, J. W. Rumer, D. I. James, R. S. Ashraf, A. Sadhanala, P. Hayoz, J.-C. Flores, H. Sirringhaus, I. McCulloch, Adv. Funct. Mater. 2014, 24, 7109.

[138] T. Dong, L. Lv, L. Feng, Y. Xia, W. Deng, P. Ye, B. Yang, S. Ding, A. Facchetti, H. Dong, H. Huang, Adv. Mater. 2017, 29, 1606025.

[139] M. Wang, M. J. Ford, C. Zhou, M. Seifrid, T.-Q. Nguyen, G. C. Bazan, Journal of the American Chemical Society 2017, 139, 17624.

[140] D. M. de Leeuw, M. M. J. Simenon, A. R. Brown, R. E. F. Einerhand, Synth. Met. 1997, 87, 53.

[141] T. D. Anthopoulos, F. B. Kooistra, H. J. Wondergem, D. Kronholm, J. C. Hummelen, D. M. de Leeuw, Adv. Mater. 2006, 18, 1679; B. A. Jones, A. Facchetti, M. R. Wasielewski, T. J. Marks, in J. Am. Chem. Soc., Vol. 129, 2007, 15259.

[142] X. Guo, M. D. Watson, Org. Lett. 2008, 10, 5333.

[143] H. Yan, Z. Chen, Y. Zheng, C. Newman, J. R. Quinn, F. Dotz, M. Kastler, A. Facchetti, Nature 2009, 457, 679. 
[144] W. Lee, C. Lee, H. Yu, D.-J. Kim, C. Wang, H. Y. Woo, J. H. Oh, B. J. Kim, Adv. Funct. Mater. 2016, 26, 1543.

[145] B. Kang, R. Kim, S. B. Lee, S. K. Kwon, Y. H. Kim, K. Cho, J. Am. Chem. Soc. 2016, $138,3679$.

[146] Y. Kim, D. X. Long, J. Lee, G. Kim, T. J. Shin, K.-W. Nam, Y.-Y. Noh, C. Yang, Macromolecules 2015, 48, 5179.

[147] R. Kim, P. S. K. Amegadze, I. Kang, H.-J. Yun, Y.-Y. Noh, S.-K. Kwon, Y.-H. Kim, Adv. Funct. Mater. 2013, 23, 5719.

[148] R. Kim, B. Kang, D. H. Sin, H. H. Choi, S.-K. Kwon, Y.-H. Kim, K. Cho, Chem. Commun. 2015, 51, 1524.

[149] J. Lee, A. R. Han, H. Yu, T. J. Shin, C. Yang, J. H. Oh, J. Am. Chem. Soc. 2013, 135, 9540.

[150] H. Yu, H. N. Kim, I. Song, Y. H. Ha, H. Ahn, J. H. Oh, Y.-H. Kim, J. Mater. Chem. C $2017,5,3616$.

[151] H. S. Kim, G. Huseynova, Y.-Y. Noh, D.-H. Hwang, Macromolecules 2017, 50, 7550.

[152] J. H. Park, E. H. Jung, J. W. Jung, W. H. Jo, Adv. Mater. 2013, 25, 2583.

[153] M. Gruber, S.-H. Jung, S. Schott, D. Venkateshvaran, A. J. Kronemeijer, J. W.

Andreasen, C. R. McNeill, W. W. H. Wong, M. Shahid, M. Heeney, J.-K. Lee, H. Sirringhaus, Chemical Science 2015, 6, 6949.

[154] B. Sun, W. Hong, H. Aziz, Y. Li, Polym. Chem. 2015, 6, 938.

[155] B. Sun, W. Hong, Z. Yan, H. Aziz, Y. Li, Adv. Mater. 2014, 26, 2636.

[156] J.-H. Dou, Y.-Q. Zheng, T. Lei, S.-D. Zhang, Z. Wang, W.-B. Zhang, J.-Y. Wang, J. Pei, Adv. Funct. Mater. 2014, 24, 6270.

[157] T. Lei, X. Xia, J.-Y. Wang, C.-J. Liu, J. Pei, J. Am. Chem. Soc. 2014, 136, 2135.

[158] T. Lei, J.-H. Dou, X.-Y. Cao, J.-Y. Wang, J. Pei, Adv. Mater. 2013, 25, 6589.

[159] Y.-Z. Dai, N. Ai, Y. Lu, Y.-Q. Zheng, J.-H. Dou, K. Shi, T. Lei, J.-Y. Wang, J. Pei,

Chem. Sci. 2016, 7, 5753.

[160] G. Zhang, Y. Dai, K. Song, H. Lee, F. Ge, L. Qiu, K. Cho, Polymer Chemistry 2017, 8, 2381.

[161] Y.-Q. Zheng, T. Lei, J.-H. Dou, X. Xia, J.-Y. Wang, C.-J. Liu, J. Pei, Adv. Mater. 2016, 28, 7213.

[162] X. Zhou, N. Ai, Z.-H. Guo, F.-D. Zhuang, Y.-S. Jiang, J.-Y. Wang, J. Pei, Chem. Mater. 2015, 27, 1815.

[163] W. Yue, M. Nikolka, M. Xiao, A. Sadhanala, C. B. Nielsen, A. J. P. White, H.-Y. Chen, A. Onwubiko, H. Sirringhaus, I. McCulloch, J. Mater. Chem. C 2016, 4, 9704.

[164] Y. Gao, Y. Deng, H. Tian, J. Zhang, D. Yan, Y. Geng, F. Wang, Adv. Mater. 2017, 29, 1606217.

[165] J. Yang, Z. Zhao, H. Geng, C. Cheng, J. Chen, Y. Sun, L. Shi, Y. Yi, Z. Shuai, Y. Guo, S. Wang, Y. Liu, Adv. Mater. 2017, 29, 1702115.

[166] K. J. Fallon, N. Wijeyasinghe, E. F. Manley, S. D. Dimitrov, S. A. Yousaf, R. S. Ashraf, W. Duffy, A. A. Y. Guilbert, D. M. E. Freeman, M. Al-Hashimi, J. Nelson, J. R. Durrant, L. X. Chen, I. McCulloch, T. J. Marks, T. M. Clarke, T. D. Anthopoulos, H. Bronstein, Chem. Mater. 2016, 28, 8366.

[167] J. Casado, R. Ponce Ortiz, J. T. Lopez Navarrete, Chem. Soc. Rev. 2012, 41, 5672.

[168] Y. Xiong, J. Tao, R. Wang, X. Qiao, X. Yang, D. Wang, H. Wu, H. Li, Adv. Mater. 2016, 28, 5949.

[169] Q. Wu, R. Li, W. Hong, H. Li, X. Gao, D. Zhu, Chem. Mater. 2011, 23, 3138.

[170] J. Li, X. Qiao, Y. Xiong, H. Li, D. Zhu, Chem. Mater. 2014, 26, 5782.

[171] S. Vegiraju, G.-Y. He, C. Kim, P. Priyanka, Y.-J. Chiu, C.-W. Liu, C.-Y. Huang, J.-S. Ni, Y.-W. Wu, Z. Chen, G.-H. Lee, S.-H. Tung, C.-L. Liu, M.-C. Chen, A. Facchetti, Adv. Funct. Mater. 2017, 27, 1606761. 
[172] S. Wang, M. Wang, X. Zhang, X. Yang, Q. Huang, X. Qiao, H. Zhang, Q. Wu, Y. Xiong, J. Gao, H. Li, Chem. Commun. 2014, 50, 985.

[173] Y. Qiao, Y. Guo, C. Yu, F. Zhang, W. Xu, Y. Liu, D. Zhu, J. Am. Chem. Soc. 2012, 134, 4084.

[174] H. L. Zhong, J. Smith, S. Rossbauer, A. J. P. White, T. D. Anthopoulos, M. Heeney, Adv. Mater. 2012, 24, 3205.

[175] C. Wang, Y. Qin, Y. Sun, Y.-S. Guan, W. Xu, D. Zhu, ACS Applied Materials \& Interfaces 2015, 7, 15978.

[176] C. Wang, Y. Zang, Y. Qin, Q. Zhang, Y. Sun, C.-a. Di, W. Xu, D. Zhu, Chemistry - A European Journal 2014, 20, 13755.

[177] C. Zhang, Y. Zang, E. Gann, C. R. McNeill, X. Zhu, C.-a. Di, D. Zhu, Journal of the American Chemical Society 2014, 136, 16176.

[178] C. Zhang, Y. Zang, F. Zhang, Y. Diao, C. R. McNeill, C.-a. Di, X. Zhu, D. Zhu, Advanced Materials 2016, 28, 8456.

[179] L. Ren, D. Yuan, E. Gann, Y. Guo, L. Thomsen, C. R. McNeill, C.-a. Di, Y. Yi, X. Zhu, D. Zhu, Chem. Mater. 2017, 29, 4999.

[180] X. Guo, A. Facchetti, T. J. Marks, Chem. Rev. 2014, 114, 8943.

[181] X. Gao, C.-a. Di, Y. Hu, X. Yang, H. Fan, F. Zhang, Y. Liu, H. Li, D. Zhu, J. Am. Chem. Soc. 2010, 132, 3697.

[182] F. Zhang, Y. Hu, T. Schuettfort, C.-a. Di, X. Gao, C. R. McNeill, L. Thomsen, S. C. B. Mannsfeld, W. Yuan, H. Sirringhaus, D. Zhu, Journal of the American Chemical Society 2013, 135, 2338.

[183] H. Luo, Z. Cai, L. Tan, Y. Guo, G. Yang, Z. Liu, G. Zhang, D. Zhang, W. Xu, Y. Liu, J. Mater. Chem. C 2013, 1, 2688.

[184] Y. Hu, Z. Wang, X. Zhang, X. Yang, C. Ge, L. Fu, X. Gao, Organic Letters 2017, 19, 468.

[185] J. Xie, K. Shi, K. Cai, D. Zhang, J.-Y. Wang, J. Pei, D. Zhao, Chemical Science 2016, 7, 499.

[186] M. Nakano, I. Osaka, D. Hashizume, K. Takimiya, Chem. Mater. 2015, 27, 6418.

[187] J.-Y. Hu, M. Nakano, I. Osaka, K. Takimiya, Journal of Materials Chemistry C 2015, $3,4244$.

[188] X. Chen, Y. Guo, L. Tan, G. Yang, Y. Li, G. Zhang, Z. Liu, W. Xu, D. Zhang, Journal of Materials Chemistry C 2013, 1, 1087.

[189] Y. Liu, L. Zhang, H. Lee, H.-W. Wang, A. Santala, F. Liu, Y. Diao, A. L. Briseno, T. P. Russell, Advanced Energy Materials 2015, 5, 1500195.

[190] D. K. Hwang, R. R. Dasari, M. Fenoll, V. Alain-Rizzo, A. Dindar, J. W. Shim, N. Deb, C. Fuentes-Hernandez, S. Barlow, D. G. Bucknall, P. Audebert, S. R. Marder, B. Kippelen, Adv. Mater. 2012, 24, 4445.

[191] H. Li, F. S. Kim, G. Ren, E. C. Hollenbeck, S. Subramaniyan, S. A. Jenekhe, Angewandte Chemie International Edition 2013, 52, 5513.

[192] T. He, M. Stolte, F. Würthner, Advanced Materials 2013, 25, 6951.

[193] W. Fan, C. Liu, Y. Li, Z. Wang, Chemical Communications 2017, 53, 188.

[194] X. Cui, C. Xiao, L. Zhang, Y. Li, Z. Wang, Chemical Communications 2016, 52, 13209.

[195] A. J. Tilley, C. Guo, M. B. Miltenburg, T. B. Schon, H. Yan, Y. Li, D. S. Seferos, Adv. Funct. Mater. 2015, 25, 3321.

[196] J. Zhang, L. Tan, W. Jiang, W. Hu, Z. Wang, J. Mater. Chem. C 2013, 1, 3200.

[197] A. Lv, S. R. Puniredd, J. Zhang, Z. Li, H. Zhu, W. Jiang, H. Dong, Y. He, L. Jiang, Y.

Li, W. Pisula, Q. Meng, W. Hu, Z. Wang, Adv. Mater. 2012, 24, 2626.

[198] C. Xiao, W. Jiang, X. Li, L. Hao, C. Liu, Z. Wang, ACS Applied Materials \& Interfaces 2014, 6, 18098. 
[199] C. Zhang, K. Shi, K. Cai, J. Xie, T. Lei, Q. Yan, J.-Y. Wang, J. Pei, D. Zhao, Chemical Communications 2015, 51, 7144.

[200] J. Li, J.-J. Chang, H. S. Tan, H. Jiang, X. Chen, Z. Chen, J. Zhang, J. Wu, Chemical Science 2012, 3, 846.

[201] X. Xu, Y. Yao, B. Shan, X. Gu, D. Liu, J. Liu, J. Xu, N. Zhao, W. Hu, Q. Miao, Advanced Materials 2016, 28, 5276.

[202] C. Wang, J. Zhang, G. Long, N. Aratani, H. Yamada, Y. Zhao, Q. Zhang, Angew. Chem. Int. Ed. 2015, 54, 6292.

[203] J.-H. Dou, Y.-Q. Zheng, Z.-F. Yao, Z.-A. Yu, T. Lei, X. Shen, X.-Y. Luo, J. Sun, S.-D. Zhang, Y.-F. Ding, G. Han, Y. Yi, J.-Y. Wang, J. Pei, Journal of the American Chemical Society 2015, 137, 15947.

[204] W. Hong, C. Guo, B. Sun, Z. Yan, C. Huang, Y. Hu, Y. Zheng, A. Facchetti, Y. Li, Journal of Materials Chemistry C 2013, 1, 5624.

[205] Y. Diao, L. Shaw, Z. Bao, S. C. B. Mannsfeld, Energy \& Environmental Science 2014, $7,2145$.

[206] D. Khim, A. Luzio, G. Bonacchini, G. Pace, M.-J. Lee, Y.-Y. Noh, M. Caironi, Uniaxial Alignment of Conjugated Polymer Films for High-Performance Organic Field-Effect Transistors, 2018.

[207] L. M. Robeson, Polymer Blends: A Comprehensive Review, Hanser, 2007.

[208] A. D. Scaccabarozzi, N. Stingelin, Journal of Materials Chemistry A 2014, 2, 10818.

[209] A. Claudia Arias, Journal of Macromolecular Science, Part C 2006, 46, 103.

[210] S. Goffri, C. Muller, N. Stingelin-Stutzmann, D. W. Breiby, C. P. Radano, J. W.

Andreasen, R. Thompson, R. A. J. Janssen, M. M. Nielsen, P. Smith, H. Sirringhaus, Nat

Mater 2006, 5, 950.

[211] D. K. Hwang, C. Fuentes-Hernandez, J. D. Berrigan, Y. Fang, J. Kim, W. J.

Potscavage, Jr., H. Cheun, K. H. Sandhage, B. Kippelen, Journal of Materials Chemistry 2012, 22, 5531.

[212] D. Guo, T. Miyadera, S. Ikeda, T. Shimada, K. Saiki, Journal of Applied Physics 2007, $102,023706$.

[213] C. D. Dimitrakopoulos, P. R. L. Malenfant, Advanced Materials 2002, 14, 99.

[214] I. McCulloch, M. Heeney, C. Bailey, K. Genevicius, I. MacDonald, M. Shkunov, D. Sparrowe, S. Tierney, R. Wagner, W. Zhang, M. L. Chabinyc, R. J. Kline, M. D. McGehee, M. F. Toney, Nat Mater 2006, 5, 328.

[215] J. Smith, W. M. Zhang, R. Sougrat, K. Zhao, R. P. Li, D. K. Cha, A. Amassian, M. Heeney, I. McCulloch, T. D. Anthopoulos, Advanced Materials 2012, 24, 2441.

[216] S. Hunter, J. Chen, T. D. Anthopoulos, Advanced Functional Materials 2014, 24, 5969.

[217] S. Y. Cho, J. M. Ko, J. Lim, J. Y. Lee, C. Lee, Journal of Materials Chemistry C 2013, 1,914 .

[218] S. Liu, W. M. Wang, A. L. Briseno, S. C. B. Mannsfeld, Z. Bao, Advanced Materials 2009, 21, 1217.

[219] J. Smith, R. Hamilton, I. McCulloch, N. Stingelin-Stutzmann, M. Heeney, D. D. C. Bradley, T. D. Anthopoulos, Journal of Materials Chemistry 2010, 20, 2562.

[220] C. Liu, Y. Li, M. V. Lee, A. Kumatani, K. Tsukagoshi, Phys Chem Chem Phys 2013, $15,7917$.

[221] A. Pérez-Rodríguez, I. Temiño, C. Ocal, M. Mas-Torrent, E. Barrena, ACS Applied Materials \& Interfaces 2018, 10, 7296.

[222] Z. He, D. Li, D. K. Hensley, A. J. Rondinone, J. Chen, Applied Physics Letters 2013, 103.

[223] K. Zhao, O. Wodo, D. Ren, H. U. Khan, M. R. Niazi, H. Hu, M. Abdelsamie, R. Li, E. Q. Li, L. Yu, B. Yan, M. M. Payne, J. Smith, J. E. Anthony, T. D. Anthopoulos, S. T. 
Thoroddsen, B. Ganapathysubramanian, A. Amassian, Advanced Functional Materials 2016, 26, 1737.

[224] S. Wo, R. L. Headrick, J. E. Anthony, Journal of Applied Physics 2012, 111, 073716. [225] S. S. Lee, C. S. Kim, E. D. Gomez, B. Purushothaman, M. F. Toney, C. Wang, A. Hexemer, J. E. Anthony, Y.-L. Loo, Advanced Materials 2009, 21, 3605.

[226] M. Tello, M. Chiesa, C. M. Duffy, H. Sirringhaus, Advanced Functional Materials 2008, 18, 3907.

[227] B. Park, H. G. Jeon, J. Choi, Y. K. Kim, J. Lim, J. Jung, S. Y. Cho, C. Lee, Journal of Materials Chemistry 2012, 22, 5641.

[228] J. H. Park, H. Lim, H. Cheong, K. M. Lee, H. C. Sohn, G. Lee, S. Im, Organic Electronics 2012, 13, 1250.

[229] T. Ohe, M. Kuribayashi, R. Yasuda, A. Tsuboi, K. Nomoto, K. Satori, M. Itabashi, J. Kasahara, Applied Physics Letters 2008, 93.

[230] J. Kang, N. Shin, D. Y. Jang, V. M. Prabhu, D. Y. Yoon, J. Am. Chem. Soc. 2008, 130, 12273.

[231] Y. Su, J. Liu, L. Zheng, Z. Ding, Y. Han, Rsc Advances 2012, 2, 5779.

[232] J. J. Kim, H. M. Lee, J. W. Park, S. O. Cho, Journal of Materials Chemistry C 2015, 3, 2650 .

[233] A. B. Naden, J. Loos, D. A. MacLaren, Journal of Materials Chemistry C 2014, 2, 245.

[234] J. Smith, M. Heeney, I. McCulloch, J. N. Malik, N. Stingelin, D. D. C. Bradley, T. D. Anthopoulos, Organic Electronics 2011, 12, 143.

[235] S. Kwon, J. Kim, G. Kim, K. Yu, Y.-R. Jo, B.-J. Kim, J. Kim, H. Kang, B. Park, K. Lee, Advanced Materials 2015, DOI:10.1002/adma.201502980.

[236] L. Yun, S. Huabin, S. Yi, T. Kazuhito, Science and Technology of Advanced Materials 2014, 15, 024203.

[237] M. R. Niazi, R. Li, E. Qiang Li, A. R. Kirmani, M. Abdelsamie, Q. Wang, W. Pan, M. M. Payne, J. E. Anthony, D.-M. Smilgies, S. T. Thoroddsen, E. P. Giannelis, A. Amassian, Nature Communications 2015, 6, 8598.

[238] M. B. Madec, S. Butterworth, P. Taboada, R. Heenan, M. Geoghegan, S. G. Yeates, Soft Matter 2011, 7, 7065.

[239] J. Smith, R. Hamilton, Y. Qi, A. Kahn, D. D. C. Bradley, M. Heeney, I. McCulloch, T. D. Anthopoulos, Advanced Functional Materials 2010, 20, 2330.

[240] X. R. Li, W. T. T. Smaal, C. Kjellander, B. van der Putten, K. Gualandris, E. C. P. Smits, J. Anthony, D. J. Broer, P. W. M. Blom, J. Genoe, G. Gelinck, Organic Electronics $2011,12,1319$.

[241] M. R. Niazi, R. Li, M. Abdelsamie, K. Zhao, D. H. Anjum, M. M. Payne, J. Anthony, D.-M. Smilgies, A. Amassian, Advanced Functional Materials 2015, n/a.

[242] A. Hamaguchi, T. Negishi, Y. Kimura, Y. Ikeda, K. Takimiya, S. Z. Bisri, Y. Iwasa, T. Shiro, Advanced Materials 2015, n/a.

[243] M.-B. Madec, D. Crouch, G. R. Llorente, T. J. Whittle, M. Geoghegan, S. G. Yeates, Journal of Materials Chemistry 2008, 18, 3230.

[244] T. Ohe, M. Kuribayashi, A. Tsuboi, K. Satori, M. Itabashi, K. Nomoto, Applied Physics Express 2009, 2.

[245] J.-H. Kwon, S.-I. Shin, K.-H. Kim, M. J. Cho, K. N. Kim, D. H. Choi, B.-K. Ju, Applied Physics Letters 2009, 94.

[246] P. S. Jo, D. T. Duong, J. Park, R. Sinclair, A. Salleo, Chemistry of Materials 2015, 27, 3979.

[247] B. S. Hunter, J. W. Ward, M. M. Payne, J. E. Anthony, O. D. Jurchescu, T. D.

Anthopoulos, Applied Physics Letters 2015, 106, 223304. 
[248] C. Pitsalidis, A. M. Pappa, S. Hunter, A. Laskarakis, T. Kaimakamis, M. M. Payne, J. E. Anthony, T. D. Anthopoulos, S. Logothetidis, Journal of Materials Chemistry C 2016, 4, 3499.

[249] S. Jin Lee, Y.-J. Kim, S. Young Yeo, E. Lee, H. Sun Lim, M. Kim, Y.-W. Song, J. Cho, J. Ah Lim, Scientific Reports 2015, 5, 14010.

[250] T. Kaimakamis, C. Pitsalidis, A. Papamichail, A. Laskarakis, S. Logothetidis, RSC Advances 2016, 6, 97077.

[251] Y. B. Yuan, G. Giri, A. L. Ayzner, A. P. Zoombelt, S. C. B. Mannsfeld, J. H. Chen, D. Nordlund, M. F. Toney, J. S. Huang, Z. N. Bao, Nature Communications 2014, 5, 3005. [252] O. D. Jurchescu, S. Subramanian, R. J. Kline, S. D. Hudson, J. E. Anthony, T. N. Jackson, D. J. Gundlach, Chemistry of Materials 2008, 20, 6733.

[253] S. Hunter, T. D. Anthopoulos, Advanced Materials 2013, 25, 4320.

[254] J. Rivnay, L. H. Jimison, J. E. Northrup, M. F. Toney, R. Noriega, S. Lu, T. J. Marks, A. Facchetti, A. Salleo, Nat Mater 2009, 8, 952.

[255] C. D. Dimitrakopoulos, S. Purushothaman, J. Kymissis, A. Callegari, J. M. Shaw, Science 1999, 283, 822.

[256] D. J. Gundlach, Y. Y. Lin, T. N. Jackson, S. F. Nelson, D. G. Schlom, IEEE Electron Device Lett. 1997, 18, 87.

[257] T. Minari, T. Miyadera, K. Tsukagoshi, Y. Aoyagi, H. Ito, Appl. Phys. Lett. 2007, 91, 053508.

[258] P. V. Pesavento, R. J. Chesterfield, C. R. Newman, C. D. Frisbie, J. Appl. Phys. 2004, $96,7312$. 


\section{Figures}
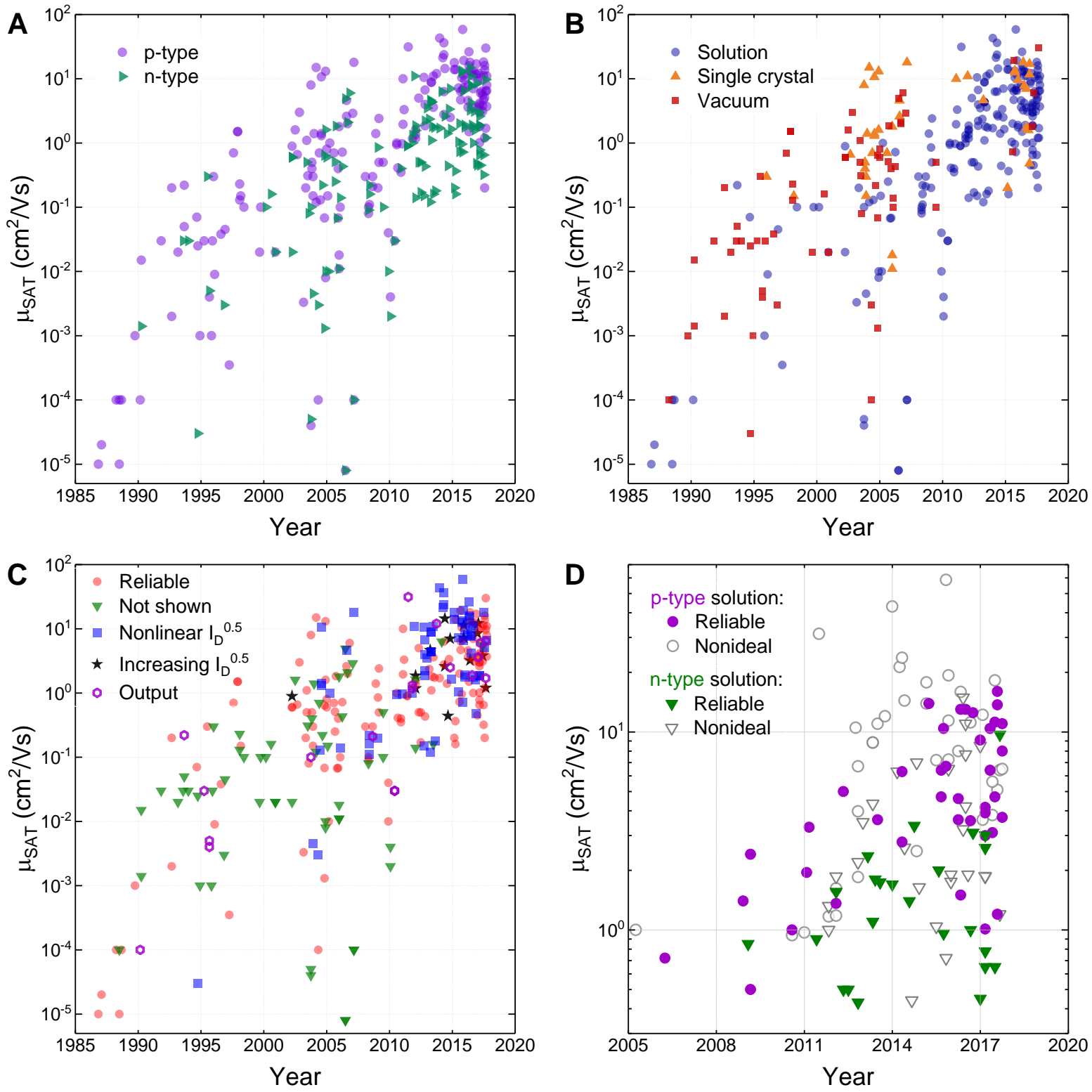

Figure 1. Plots of field-effect carrier mobility values over time. The data is has been separated into the following categories: (a) Charge carrier type: p-type and n-type. (b) Processing technique: solution processed, single crystal and vacuum. (c) Features in the experimental data to determine which data sets don't comply with the classical FET model: reliable (from the data sets shown, there are no obvious nonidealities), not shown (do not show the plot of $\mu$ vs. $V_{G}$ or $\mathrm{I}_{D}^{0.5}$ vs. $V_{G}$ ), nonlinear $\mathrm{I}_{\mathrm{D}}{ }^{0.5}$ (the kink or any s-shaped, nonlinear features in $\mathrm{I}_{\mathrm{D}}{ }^{0.5}$ vs. $\mathrm{V}_{\mathrm{G}}$ ), increasing $\mathrm{I}_{\mathrm{D}}{ }^{0.5}$ (the gradient of $\mathrm{I}_{\mathrm{D}}{ }^{0.5}$ gets steeper with $\mathrm{V}_{\mathrm{G}}$ ) and output (non-saturated output characteristics). (d) Solution-processed data with mobilities approaching $1 \mathrm{~cm}^{2} / \mathrm{Vs}$, by carrier type and data quality, suggesting that $55 \%$ of this data set is either doesn't show where mobility was calculated from or has some sort of nonideality. 
A
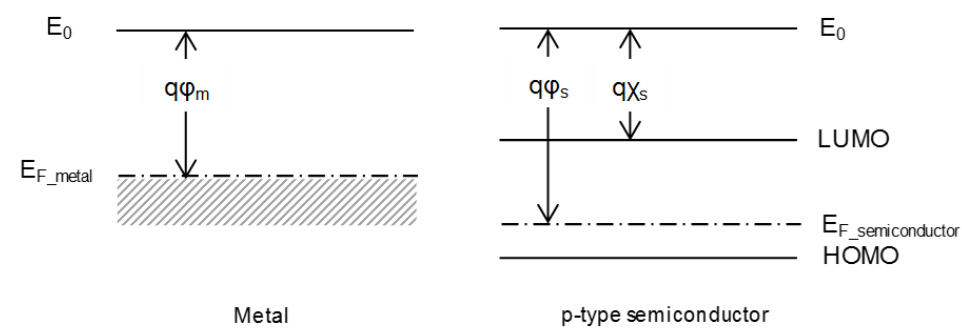

B

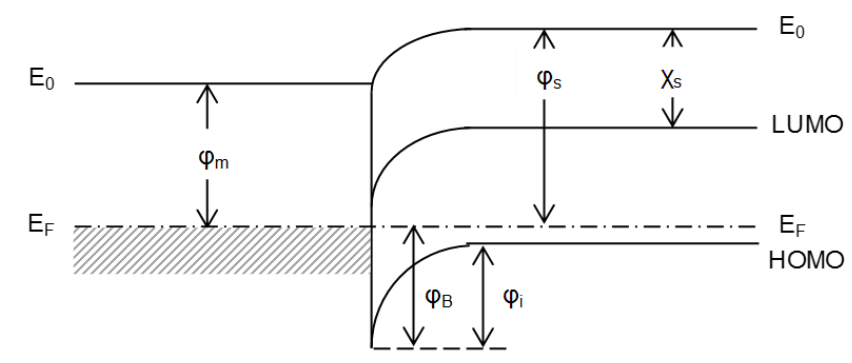

Figure 2. Band diagram of a metal and semiconductor interface. In (a), the two materials are not in contact and in (b) they are in contact.
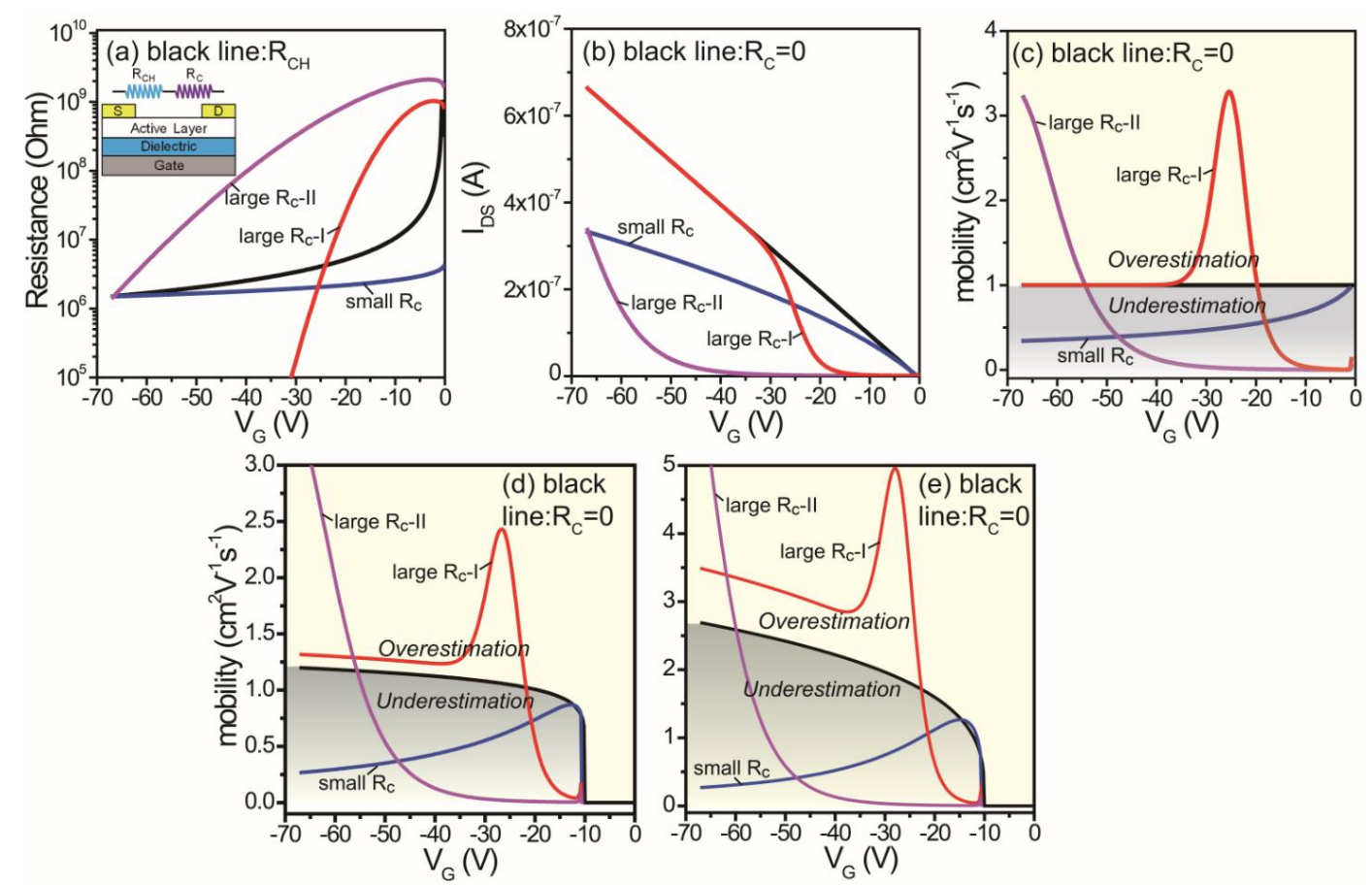

Figure 3. The impact of contact resistance on overestimation or underestimation of mobility in the linear regime, to determine how the classical FET model 'tolerates' different levels of contact resistance. The contact resistance is modelled for three different situations: $R_{C}<R_{C H}$ and decreases slowly, $\mathrm{R}_{\mathrm{C}}>\mathrm{R}_{\mathrm{CH}}$ and rapidly decreases so that $\mathrm{R}_{\mathrm{C}}<\mathrm{R}_{\mathrm{CH}}$ (i.e. "large $\mathrm{R}_{\mathrm{C}}-\mathrm{I}$ "), and $R_{C}>R_{C H}$ and slowly decreases (i.e. "large $R_{C}-I I$ "). (a) $V_{G}$ dependence of resistance $\left(R_{C}, R_{C H}\right)$. (b) $V_{G}$ dependence of I I_LIN. (c), (d) and (e) represent $V_{G}$ dependence of $\mu_{\text {LIN }}$, where $\mu_{\text {LIN }}$ is set to $1 \mathrm{~cm}^{2} / \mathrm{Vs}$, in an ordered system, (c), and in increasingly disordered systems, with (e) being a more disordered scenario than (d). Channel dimensions and capacitance are fixed. Reproduced with permission. ${ }^{[19]}$ Copyright 2017, American Physical Society. 

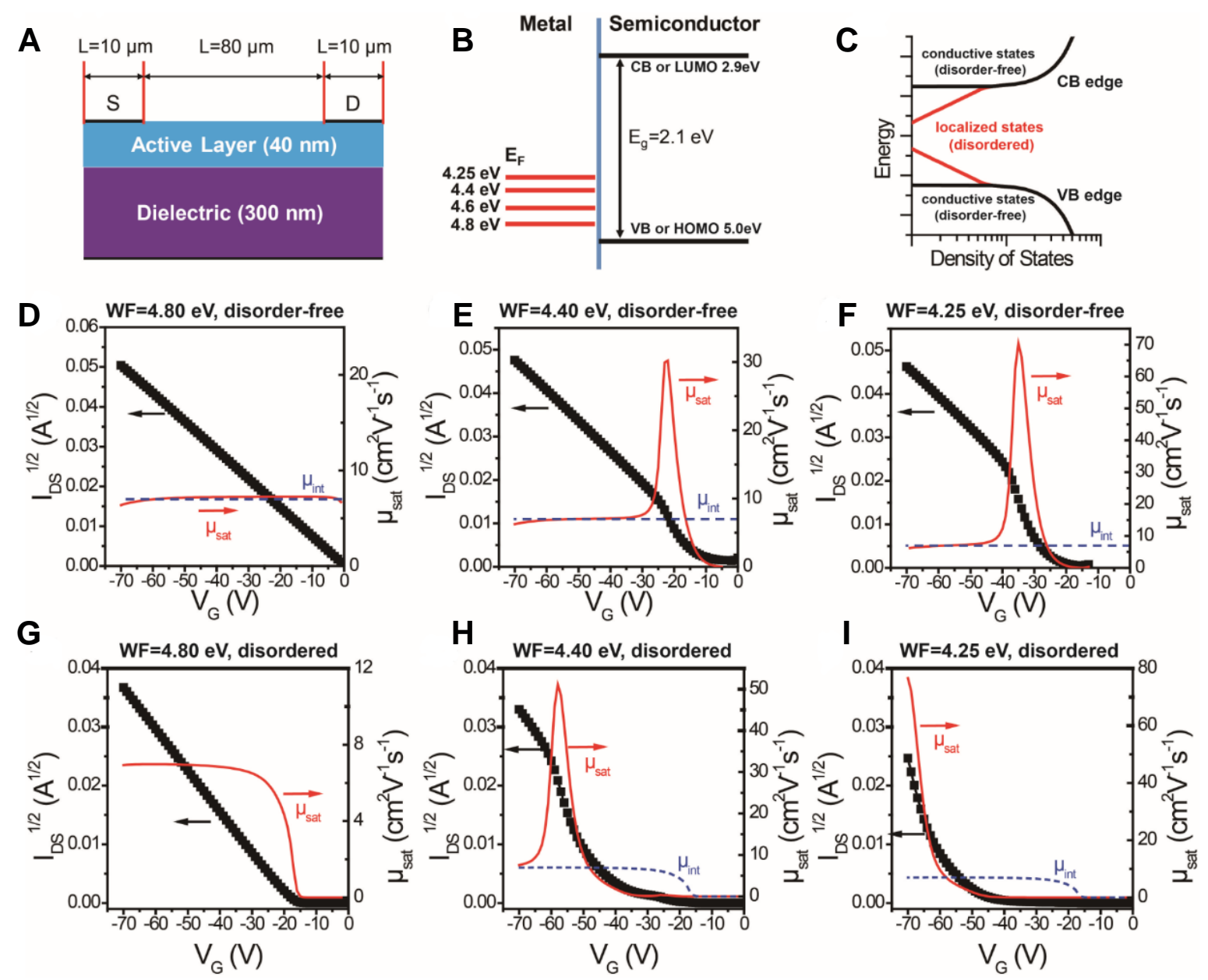

Figure 4. The kink dependency on injection barrier and how it corresponds to saturation mobility overestimation. (a) The device structure used in the TCAD 2D calculations. (b) Energy level diagram for the various conditions used in the modelling. (c) Density of states in the OSC for the 2D calculations, where the red line represents localised tail states in disordered OSCs and the black line represents a disorder free semiconductor. Cases for both disordered and ordered semiconductors are given when the work function is (d), $(\mathrm{g}) 4.25 \mathrm{eV}$, (e), (h) $4.40 \mathrm{eV}$ and (f), (i) $4.80 \mathrm{eV}$ to demonstrate a range of severity on the impact of transfer curves and field-effect mobility, compared to the set mobility (blue line). Reproduced with permission. ${ }^{[19]}$ Copyright 2017, American Physical Society. 

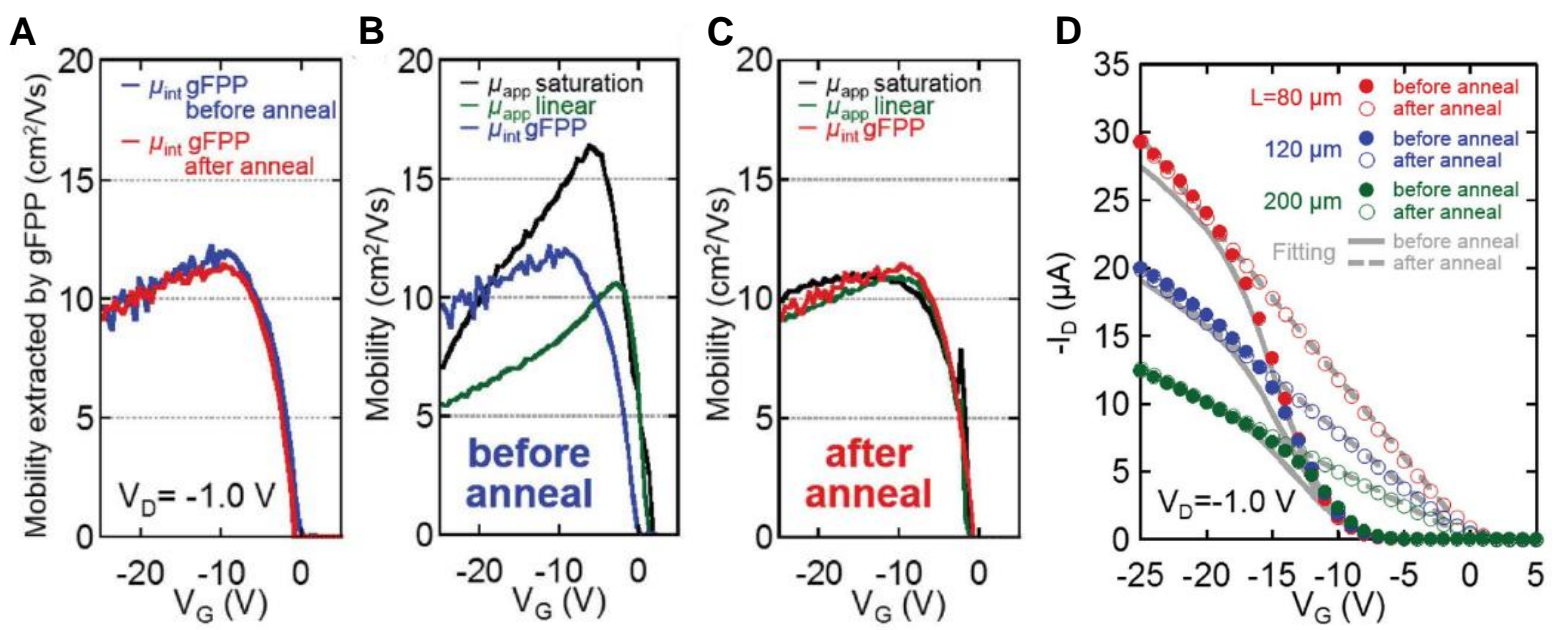

Figure 5. Experimental demonstration of the impact of contact resistance on mobility. (a) Mobility determined by gFPP measurements on $\mathrm{C}_{10}$ DNTT vacuum deposited TFTs before and after gentle annealing. (b) Pre-anneal linear and saturation mobilities determined by conventional TFT measurements, compared to gFPP measured mobility, demonstrating overestimation in conventional transconductance measurements/calculations. (c) Post-anneal data, showing that once the contact resistance has been resolved, the mobility can be extracted using TLM. (d) Data showing the impact of contact resistance (i.e. pre- and post- anneal) on transfer characteristics in the linear regime; when the TFT does not suffer from contact resistance, the line is straight (ideal), but when the TFT suffers from contact resistance there is an s-shaped bend ( $g_{m}$ artefact). Reproduced with permission. ${ }^{[13]}$ Copyright 2016, Wiley-VCH. 

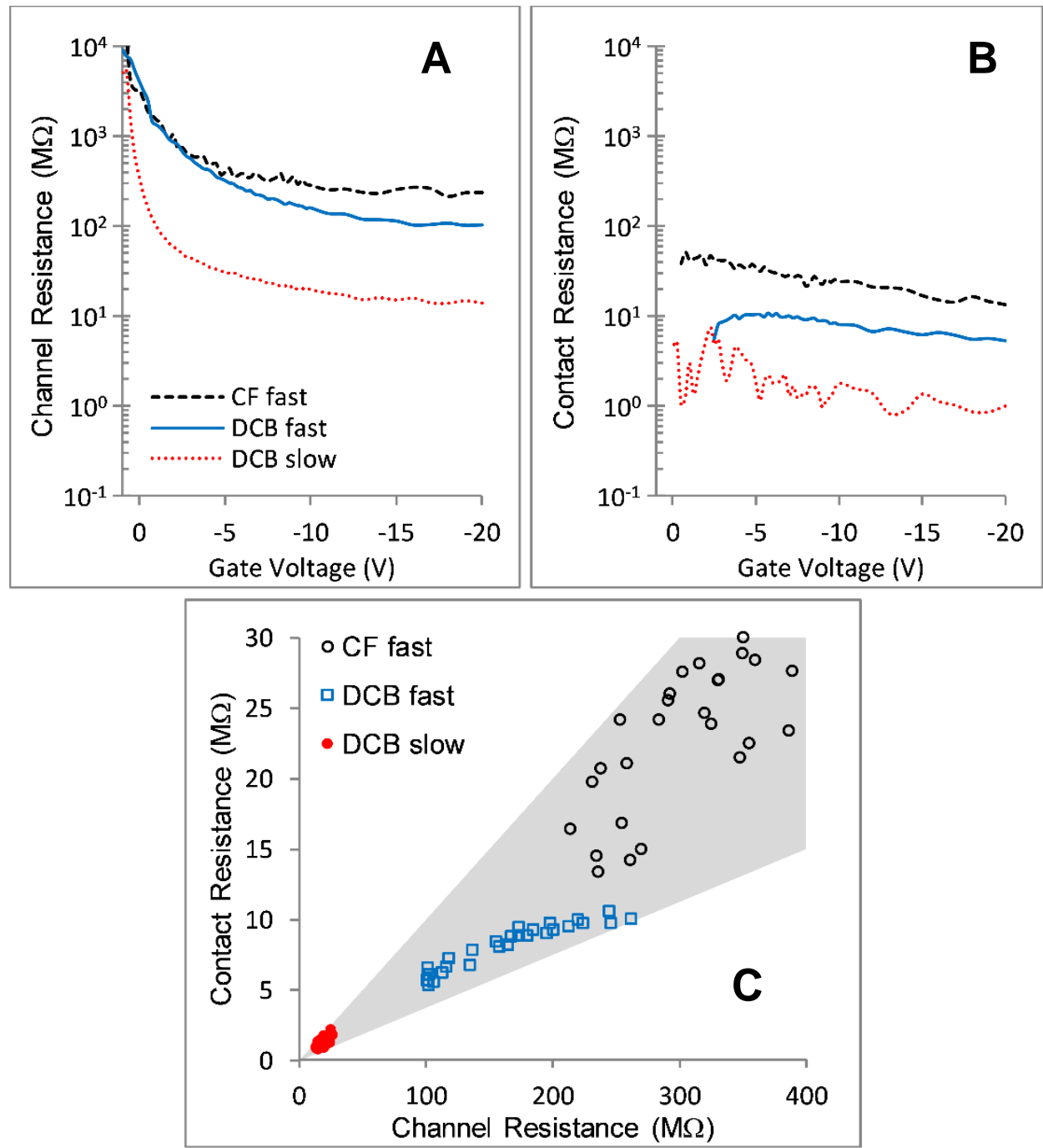

Figure 6. Demonstration of the effect of ordering on contact resistance. The crystallisation of the regioregular poly(3-hexylthiophene-2,5-diyl) is controlled by solvent choice and evaporation time; the more ordered the polymer, the lower the contact resistance. The shaded area in (c) shows that the ratio of $\mathrm{R}_{\mathrm{C}} / \mathrm{R}_{\mathrm{CH}}$ drops between $1 / 10$ and $1 / 25$ for data range $26 \mathrm{~V}<$ $\mathrm{V}_{\mathrm{G}}<220$ V. Reproduced with permission. ${ }^{[9]}$ Copyright 2017, Wiley-VCH. 


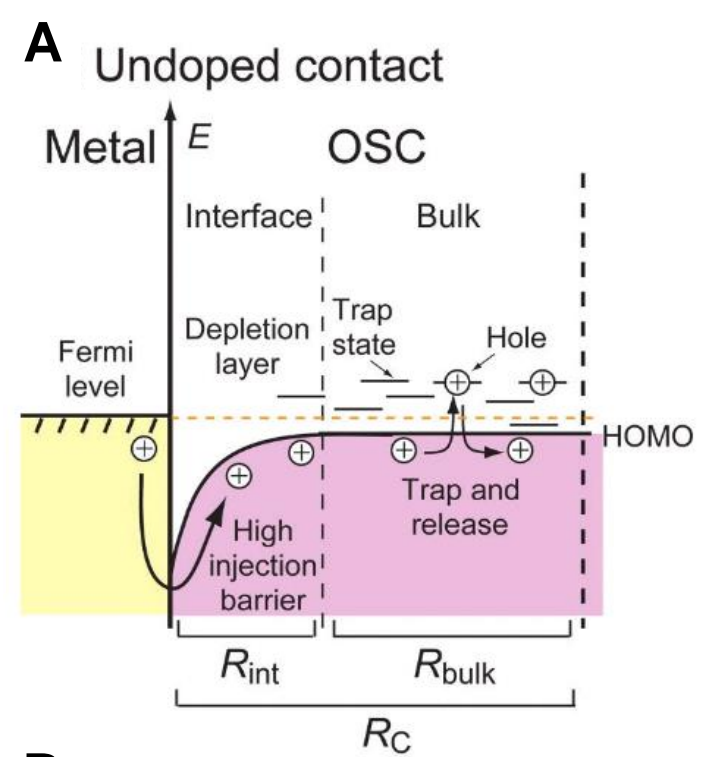

B $\mathrm{FeCl}_{3}$ doped contact

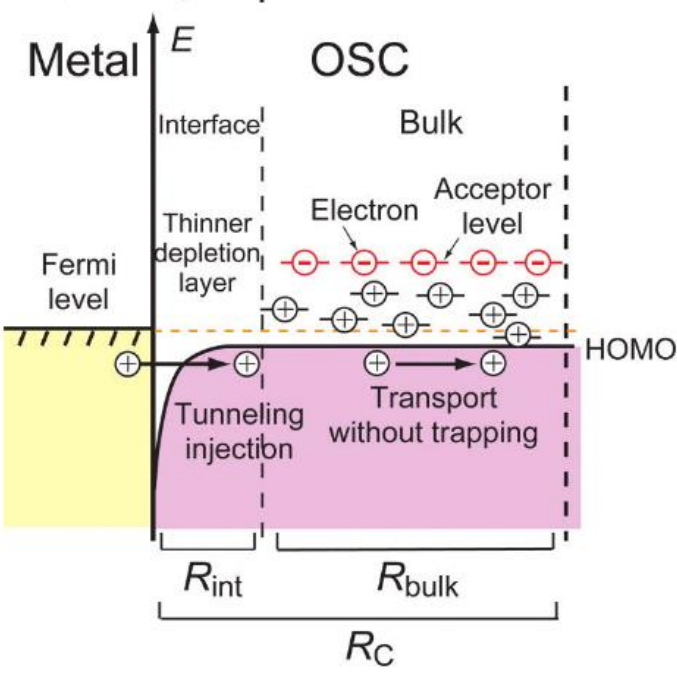

Figure 7. Energy level diagram showing the impact of contact doping on the width of the depletion region. (a) Contact without acceptor dopant. (b) Doping the contact with $\mathrm{FeCl} 3$ reduces the width of the Schottky barrier and generates charge carriers to fill trap states that exist in the access region. Reproduced with permission. ${ }^{[63]}$ Copyright 2012, AIP Publishing. 


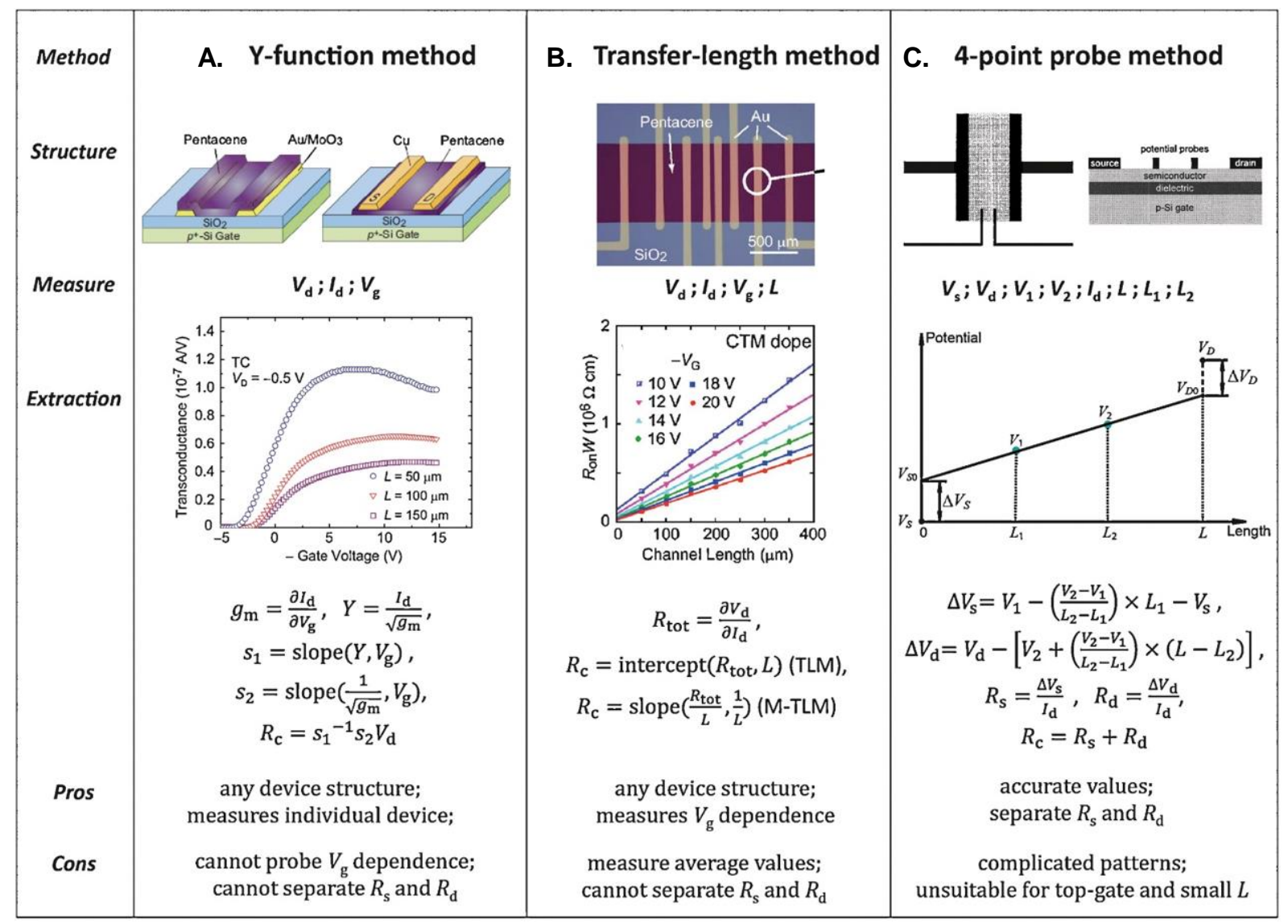

Figure 8. Description of some of the key methods used to extract contact resistance and mobility: a) the $Y$-function method, b) the TLM, and c) the gFPP. Reproduced with permission from ref. [33], copyright 2015, Elsevier, where a), b) and c) were adapted from ref. [101], [259] and [260], respectively. 


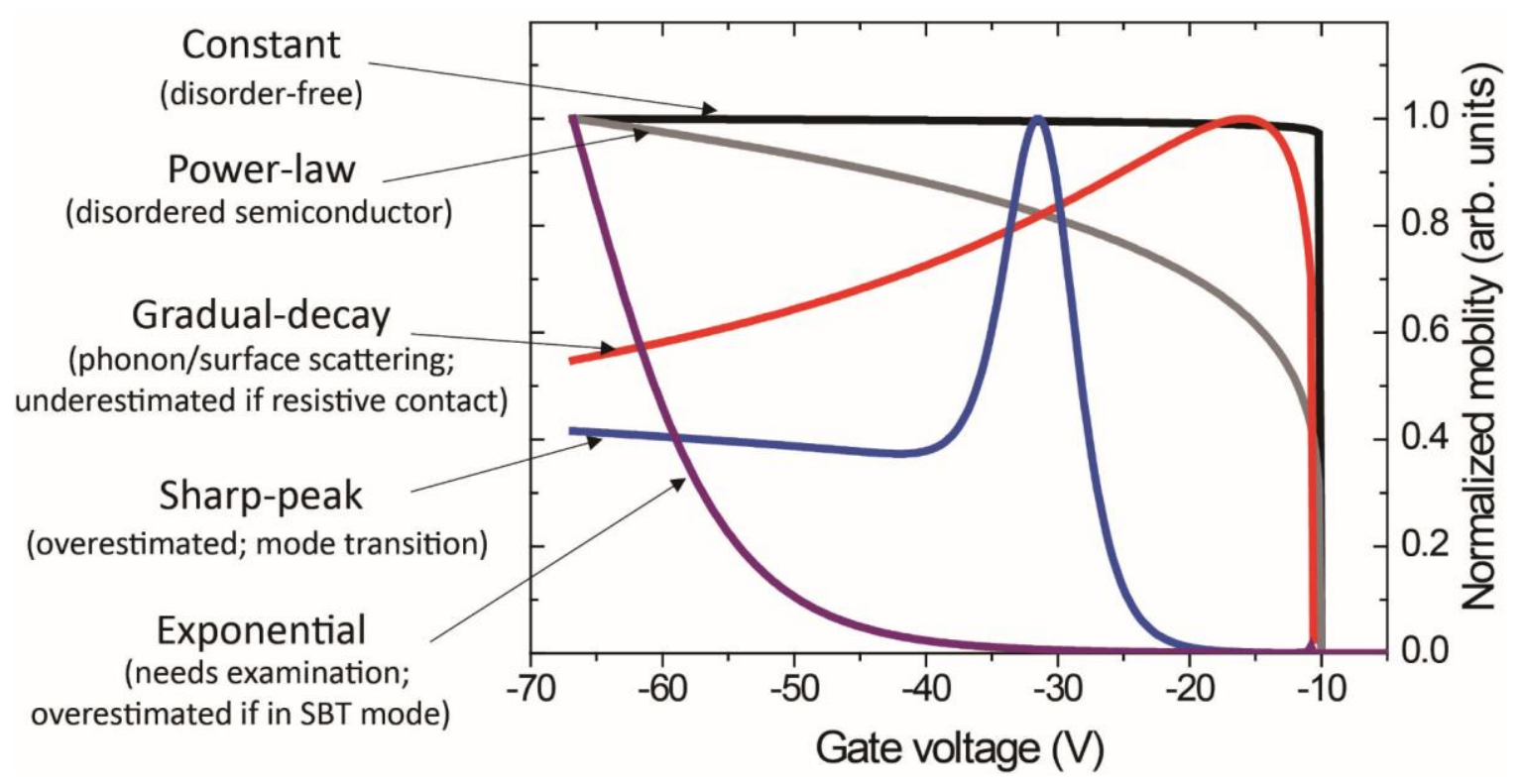

Figure 9. Normalised mobility vs. $V_{G}$ plots. This plot demonstrates the different $V_{G}$ dependent mobility behaviors and what conditions cause them. The black line represents constant mobility, the grey line represents power-law mobility. The red line indicates a gradually decaying mobility value, indicative of photon scattering or resistive contacts which result in underestimation. The blue line shows a shark peak due to gated contacts; after the peak in SBT mode the TFT passes $\mathrm{V}_{\text {TRAN }}$ into the TFT mode. If the mobility is extracted whilst in SBT mode then the value is overestimated, but mobility can be extracted from TFT mode at higher $\mathrm{V}_{\mathrm{G}}$. The purple line shows an exponential increase in the mobility in TFTs with gated Schottky contacts; the device only works in SBT mode and the mobility is overestimated. Reproduced with permission. ${ }^{[19]}$ Copyright 2017, American Physical Society. 


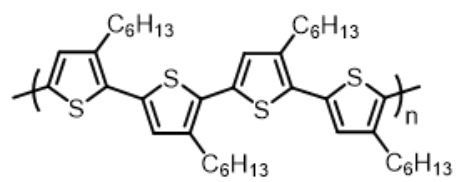

P1

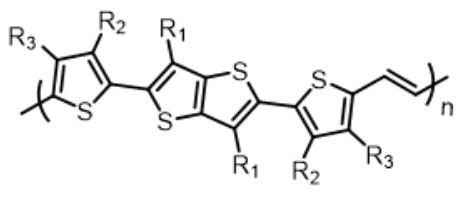

P4: $\mathrm{R}_{1}=\mathrm{C}_{14} \mathrm{H}_{29}, \mathrm{R}_{2}=\mathrm{R}_{3}=\mathrm{H}$

P5: $\mathrm{R}_{2}=\mathrm{C}_{14} \mathrm{H}_{29}, \mathrm{R}_{1}=\mathrm{R}_{3}=\mathrm{H}$

P6: $\mathrm{R}_{3}=\mathrm{C}_{14} \mathrm{H}_{29}, \mathrm{R}_{1}=\mathrm{R}_{2}=\mathrm{H}$

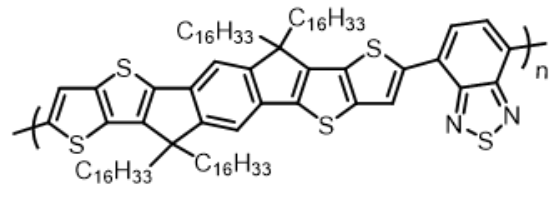

P9

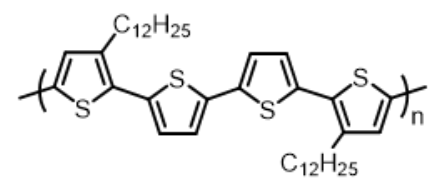

P2

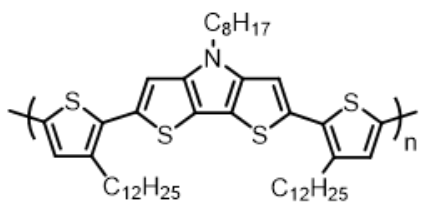

P7
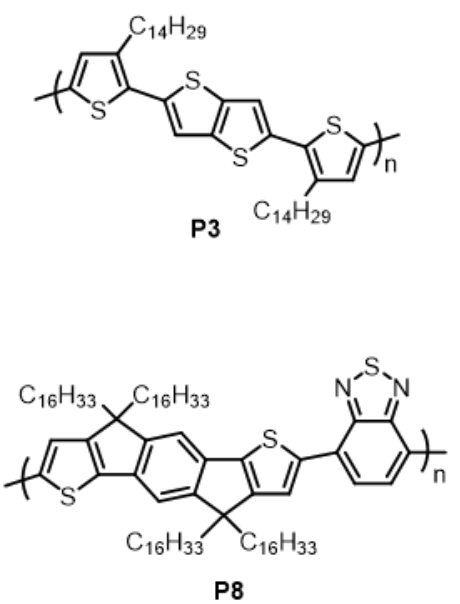

P8

Figure 10. Structures of polythiophenes and fused aromatic monomers containing copolymers. 

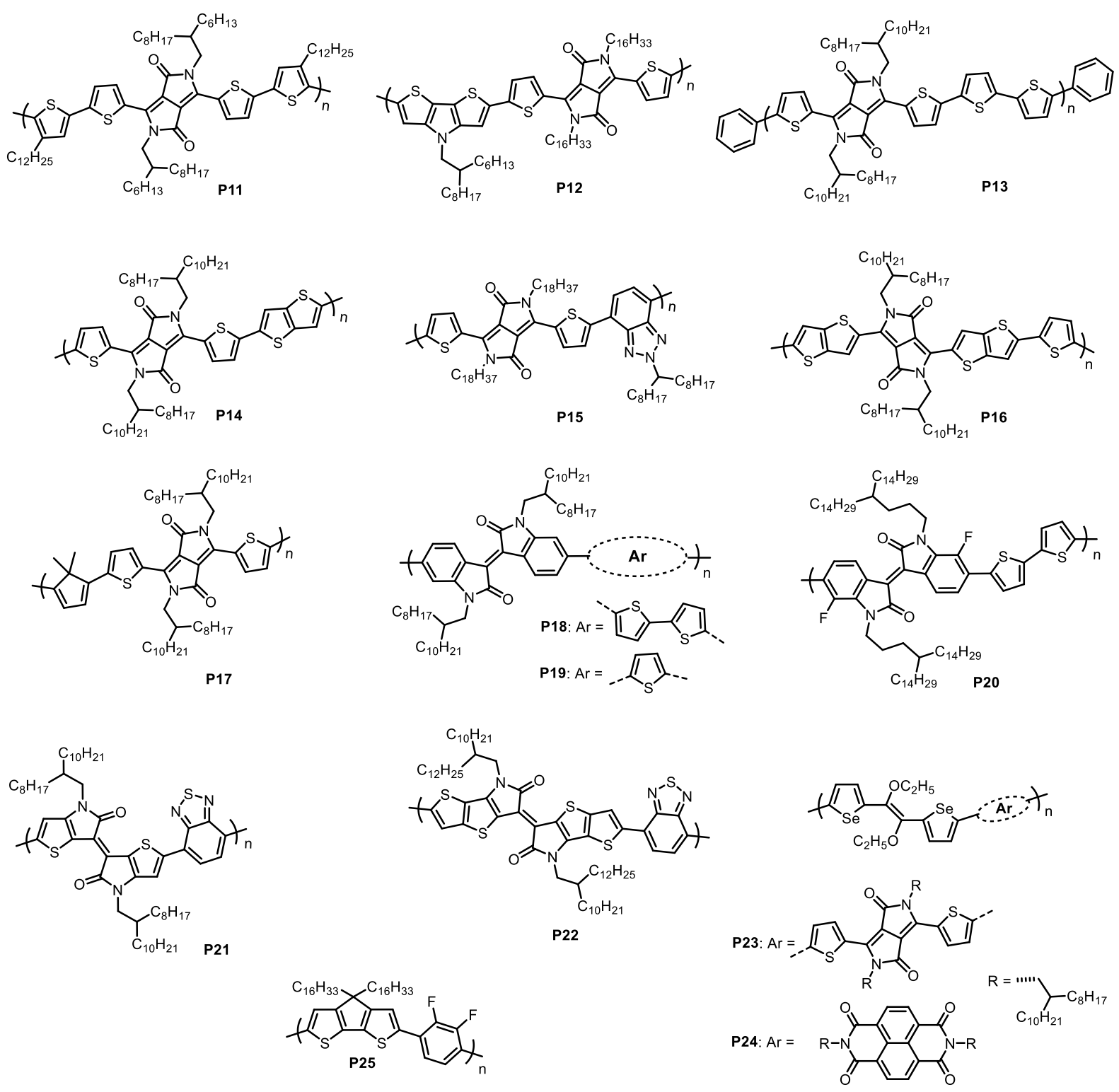

Figure 11. Structures of co-polymers incorporating monomers with noncovalent conformational locks. 

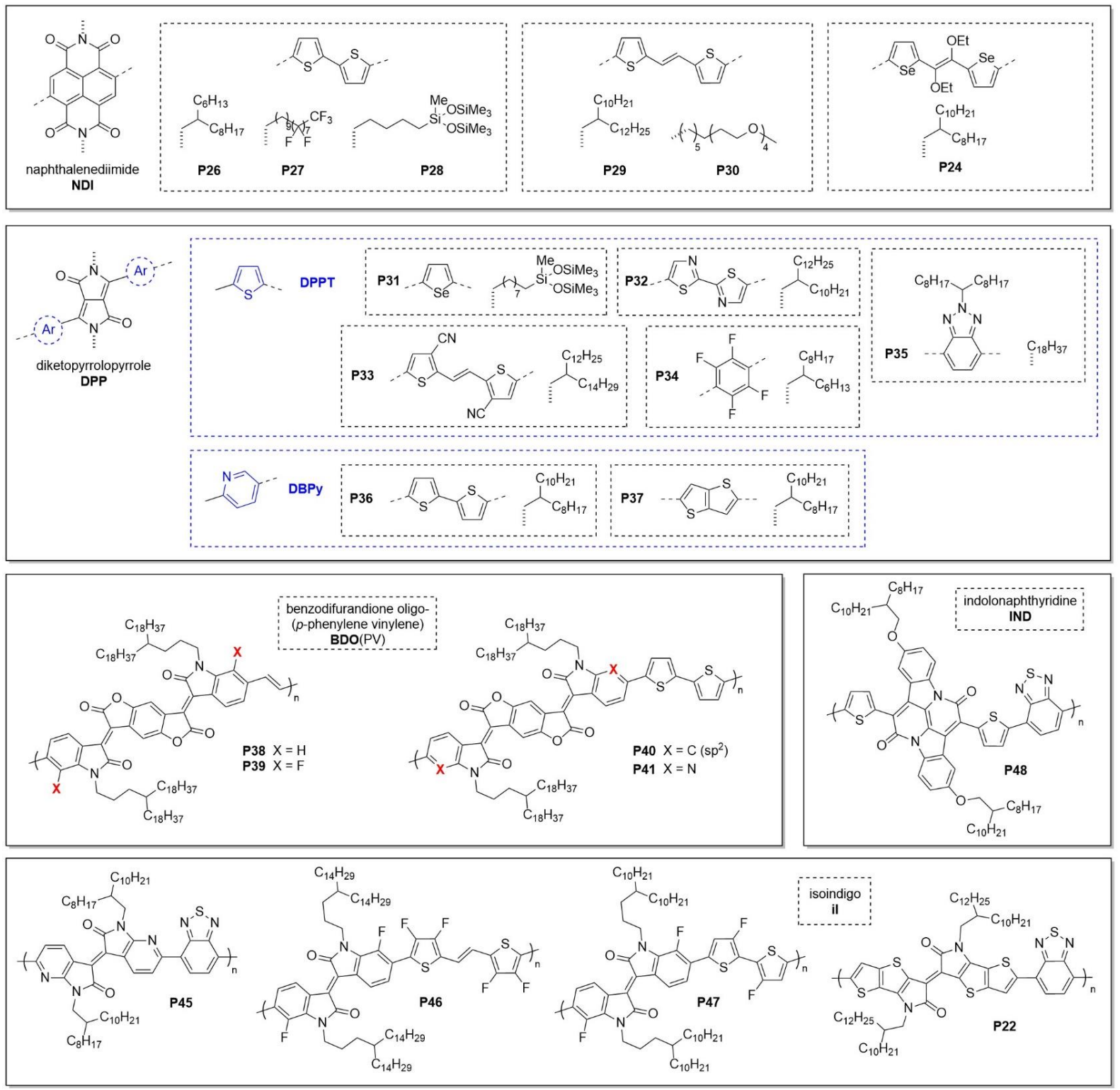

Figure 12. Structures of polymer in Table S1. 


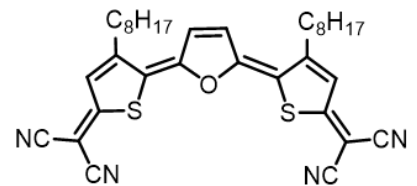

SM1

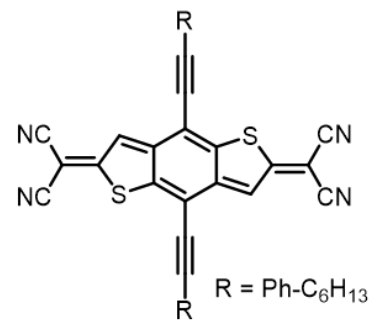

SM4

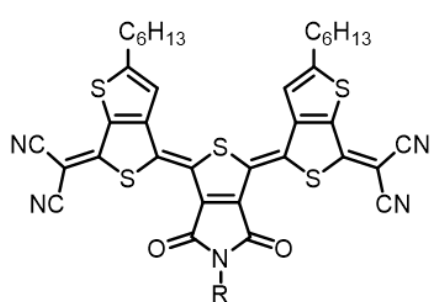

SM7:<smiles></smiles>

$\mathrm{R}=-\left(\mathrm{CH}_{2}\right)_{\mathbf{n}} \mathrm{CH}\left(\mathrm{C}_{10} \mathrm{H}_{21}\right)\left(\mathrm{C}_{12} \mathrm{H}_{25}\right)$ SM2: $a, n=1 ; b, n=2 ; c, n=3$<smiles>[R]c1c(C(=N)N)sc2c1sc1c([R])c(C(N)=C(N)N)sc12</smiles>

SM3<smiles></smiles>

a: $R=2$-EtHex

b: $\mathrm{R}=\mathrm{C}_{16} \mathrm{H}_{33}$

c: $\mathrm{R}=-\left(\mathrm{CH}_{2}\right)_{2} \mathrm{CH}\left(\mathrm{C}_{10} \mathrm{H}_{21}\right)\left(\mathrm{C}_{10} \mathrm{H}_{21}\right)$

SM5:<smiles>[Z11]c1cc2c(s1)/C(=c1/s/c(=c3/sc(=C(C#N)C#N)c4cc([AsH2])sc34)c3c1C(=O)N([R])C3=O)S2</smiles>

SM8:<smiles>[R]N1C(=O)C2C(=C1c1cc3sc(C(N)=O)cc3s1)C(=O)N([R])C2=C1Cc2sc(C(N)=C(N)C#N)cc2S1</smiles>

$\mathrm{R}=-\mathrm{CH}_{2} \mathrm{CH}\left(\mathrm{C}_{8} \mathrm{H}_{17}\right)\left(\mathrm{C}_{10} \mathrm{H}_{21}\right)$

SM6

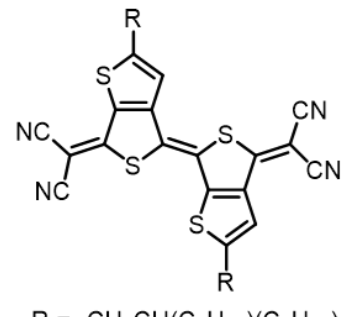

SM9

c: $\mathrm{R}=-\left(\mathrm{CH}_{2}\right)_{2} \mathrm{CH}\left(\mathrm{C}_{8} \mathrm{H}_{17}\right)\left(\mathrm{C}_{10} \mathrm{H}_{21}\right)$

Figure 13. Structure of quinoidal semiconductors incorporating dicyanomethylene end groups. 


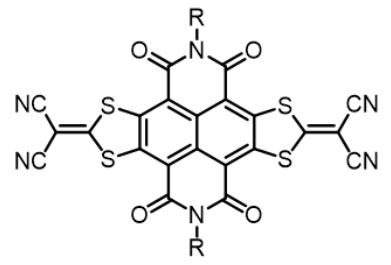

$\mathrm{R}=-\left(\mathrm{CH}_{2}\right) \mathrm{n} \mathrm{CH}\left(\mathrm{C}_{6} \mathrm{H}_{13}\right)\left(\mathrm{C}_{8} \mathrm{H}_{17}\right)$

SM10: $a, n=1 ; b, n=2 ; c, n=3$

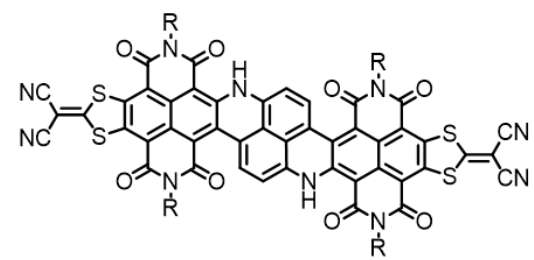

$\mathrm{R}=-\mathrm{CH}_{2} \mathrm{CH}\left(\mathrm{C}_{8} \mathrm{H}_{17}\right)\left(\mathrm{C}_{10} \mathrm{H}_{21}\right)$

SM13

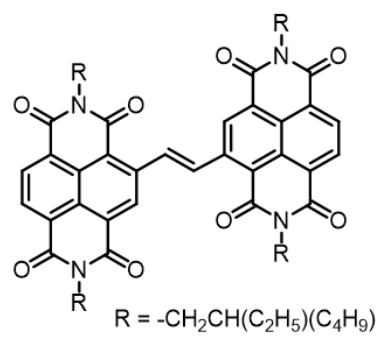

SM16

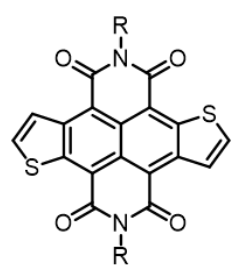

$\mathrm{R}=-\mathrm{CH}_{2} \mathrm{C}_{3} \mathrm{~F}_{7}$

SM19<smiles></smiles>

$\mathrm{R}=-\mathrm{CH}_{2} \mathrm{CH}\left(\mathrm{C}_{8} \mathrm{H}_{17}\right)\left(\mathrm{C}_{10} \mathrm{H}_{21}\right)$

SM11

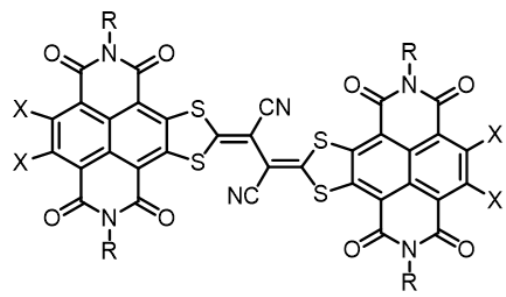

SM12a: $\mathrm{R}=-\mathrm{C}_{8} \mathrm{H}_{17} ; \mathrm{X}=\mathrm{H}$ SM12b: $\mathrm{R}=-\mathrm{CH}_{2} \mathrm{CH}\left(\mathrm{C}_{8} \mathrm{H}_{17}\right)\left(\mathrm{C}_{10} \mathrm{H}_{21}\right) ; \mathrm{X}={ }_{-\mathrm{S}}^{-\mathrm{S}}-\mathrm{CN}_{\mathrm{CN}}^{\mathrm{CN}}$

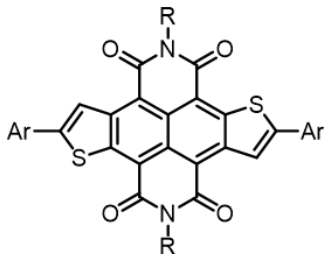

$\mathrm{R}=-\left(\mathrm{CH}_{2}\right){ }_{2} \mathrm{CH}\left(\mathrm{C}_{10} \mathrm{H}_{21}\right)\left(\mathrm{C}_{12} \mathrm{H}_{25}\right)$ SM14a: $\mathrm{R}=$ Benzothiophene SM14b: R = Naphthothiophene

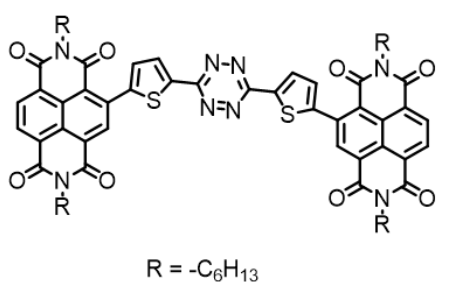

SM17

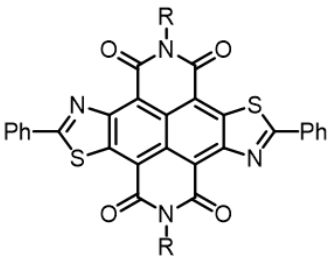

$\mathrm{R}=-\mathrm{CH}_{2} \mathrm{CH}\left(\mathrm{C}_{8} \mathrm{H}_{17}\right)\left(\mathrm{C}_{10} \mathrm{H}_{21}\right)$

SM15

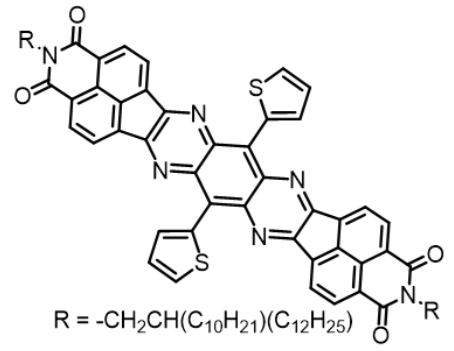

SM18<smiles></smiles>

$\mathrm{R}=-\mathrm{CH}_{2} \mathrm{C}_{3} \mathrm{~F}_{7}$

SM20

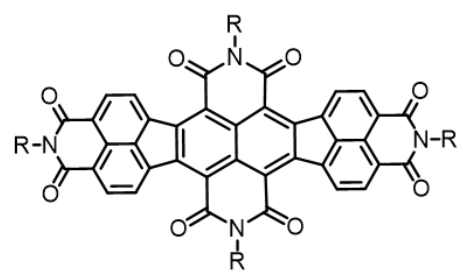

$\mathrm{R}=-\mathrm{C}_{8} \mathrm{H}_{17}$

SM21

Figure 14. Diimide containing n-type molecules based upon naphthalene cores. 


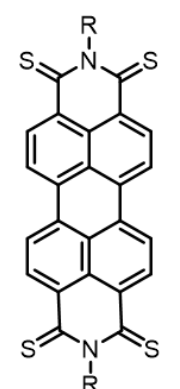

$\mathrm{R}=-\left(\mathrm{CH}_{2}\right)_{2} \mathrm{CH}\left(\mathrm{C}_{6} \mathrm{H}_{13}\right)\left(\mathrm{C}_{8} \mathrm{H}_{17}\right)$<smiles>[R]n1c(=O)c2cc3c(C#N)c(C#N)c4cc5c(=O)n([R])c6cc7c(C#N)c(C#N)c8cc(c1=O)c1c8c7c6c5c4c3c21</smiles>

$\mathrm{R}=-\left(\mathrm{CH}_{2}\right)_{3} \mathrm{CH}\left(\mathrm{C}_{8} \mathrm{H}_{17}\right)\left(\mathrm{C}_{10} \mathrm{H}_{21}\right)$ SM25

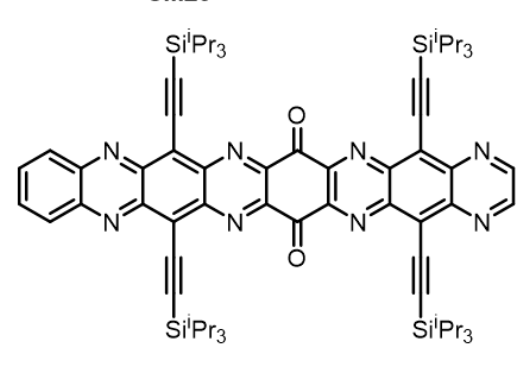

SM28

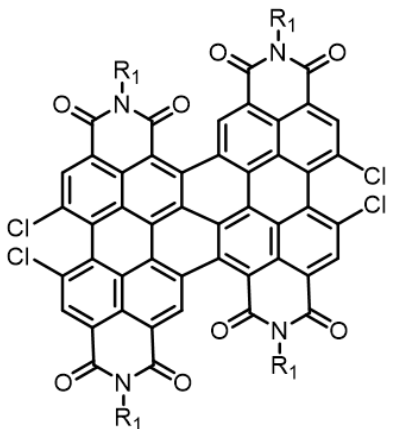

SM23a: $\mathrm{R}=-\mathrm{C}_{18} \mathrm{H}_{37}$ SM23b: $\mathrm{R}=-\mathrm{C}_{12} \mathrm{H}_{25}$

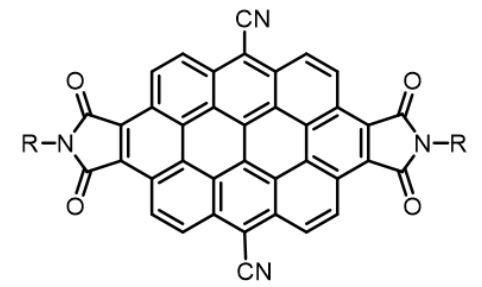

$\mathrm{R}_{1}=-\left(\mathrm{CH}_{2}\right)_{2} \mathrm{CH}\left(\mathrm{C}_{10} \mathrm{H}_{21}\right)\left(\mathrm{C}_{12} \mathrm{H}_{25}\right)$

SM26

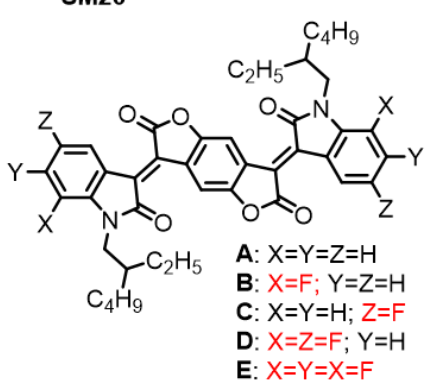

SM29

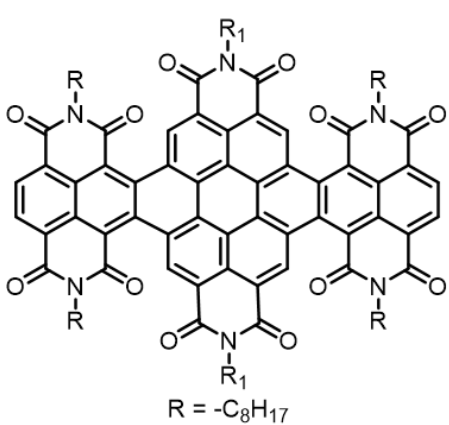

$\mathrm{R}_{1}=-\left(\mathrm{CH}_{2}\right)_{2} \mathrm{CH}\left(\mathrm{C}_{6} \mathrm{H}_{13}\right)\left(\mathrm{C}_{8} \mathrm{H}_{17}\right)$

SM24

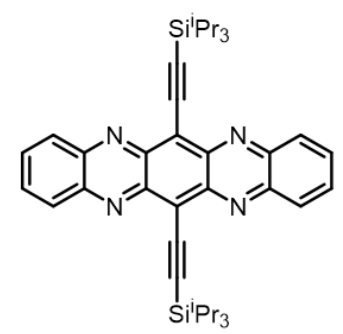

SM27<smiles>[R]N1C(=O)C(c2ccc([N])cc2)=c2nc3c(nc21)=C(c1ccc(C#N)cc1)C(=O)N3[R]</smiles>

$\mathrm{R}=-\mathrm{CH}_{2} \mathrm{CH}\left(\mathrm{C}_{4} \mathrm{H}_{9}\right)\left(\mathrm{C}_{6} \mathrm{H}_{13}\right)$

SM30

Figure 15. Extended dimiides, acenes and amide containing n-type molecules. 

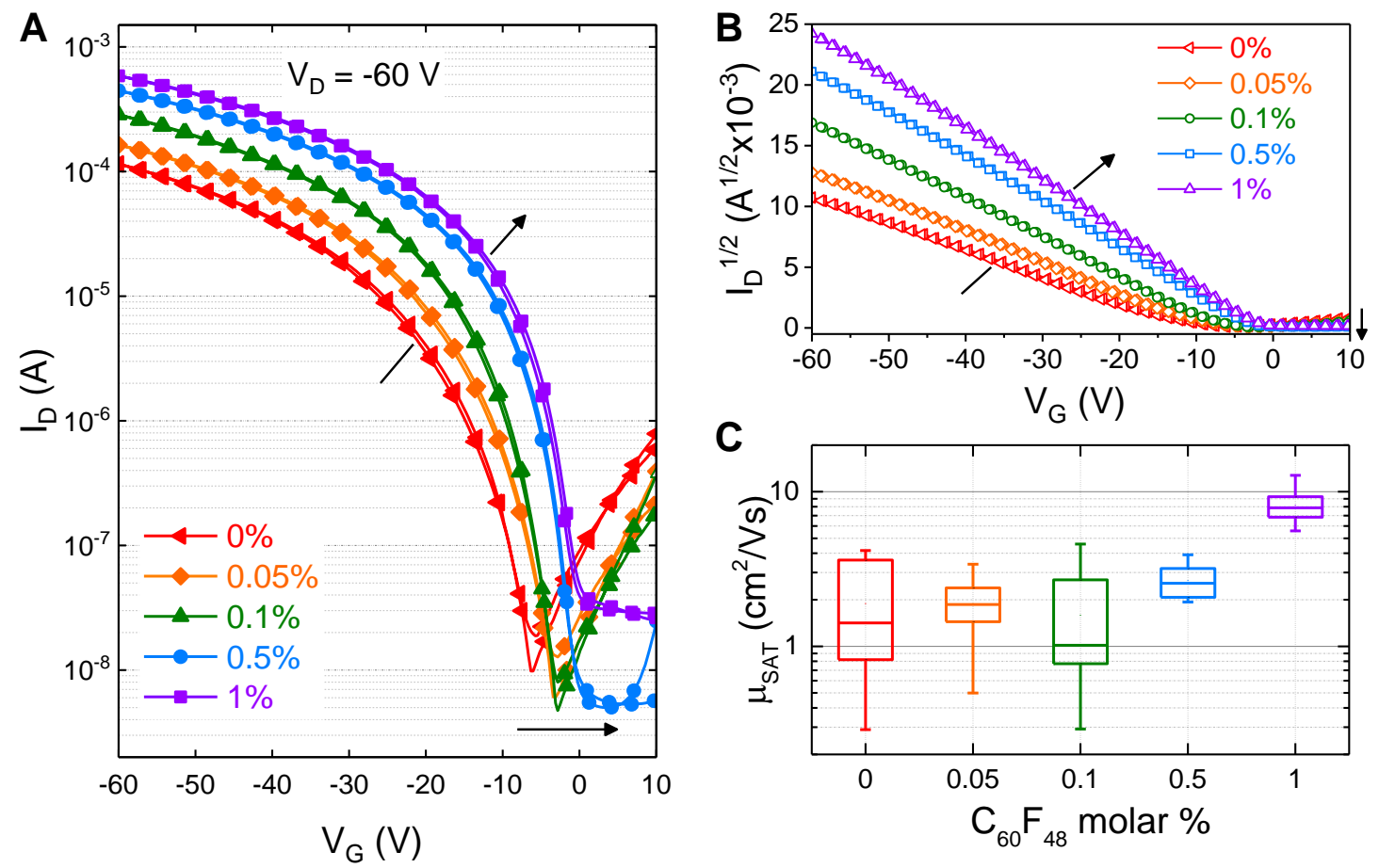

Figure 16. (a) Representative transfer characteristics, measured at $V_{D}=-60 \mathrm{~V}$, for a ternary blend system made using the small-molecule $\mathrm{C}_{8}$-BTBT and the conjugated polymer $\mathrm{C}_{16} \mathrm{IDT}$ BT, doped with the fluorinated fullerene $\mathrm{C}_{60} \mathrm{~F}_{48}$ at $0,0.05,0.1,0.5$ and $1 \%$ molar weight. The evolution of the transfer curves is typical for doped OTFT systems. (b) The $\sqrt{ } I_{D}$ vs. $V_{G}$ plot that correspond with (a). The channel length and width of the transistors were $80 \mu \mathrm{m}$ and $1000 \mu \mathrm{m}$, respectively. (c) A histogram showing the saturation mobility taken from 10 $\mathrm{C}_{8}$-BTBT:C ${ }_{16}$ IDT-BT blend OTFTs for each doping concentration $(0,0.05,0.1,0.5$ and $1 \%$ molar weight $\left.\mathrm{C}_{60} \mathrm{~F}_{48}\right)$. Reproduced with permission from Reproduced with permission. ${ }^{[58]}$ Copyright 2017, Wiley-VCH.

Table 1. Exemplary high mobility OTFT blend systems.

\begin{tabular}{|c|c|c|c|c|c|c|c|c|}
\hline & \multicolumn{3}{|c|}{ Blend materials } & \multirow{2}{*}{$\begin{array}{c}\text { Max. } \\
\mu_{\mathrm{h}} \mathrm{SAT} \\
{\left[\mathrm{cm}^{2} / \mathrm{Vs}\right]}\end{array}$} & \multirow[b]{2}{*}{ Dielectric } & \multirow[b]{2}{*}{ Geom. ${ }^{\text {a) }}$} & \multirow{2}{*}{$\begin{array}{c}\text { Solution deposition } \\
\text { technique }\end{array}$} & \multirow[b]{2}{*}{ Ref. } \\
\hline & Small molecule & Polymer & Dopant & & & & & \\
\hline \multirow{2}{*}{ 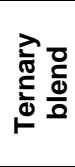 } & $\mathrm{C}_{8}$-BTBT & $\mathrm{C}_{16}$ IDT-BT & - & 4.7 & Cytop or PTFE & TG-BC & Spin-coating & $\begin{array}{l}{[52],} \\
{[58]}\end{array}$ \\
\hline & $\begin{array}{l}\mathrm{C}_{8}-\mathrm{BTBT} \\
\mathrm{C}_{8}-\mathrm{BTBT} \\
\text { diF-TES ADT }\end{array}$ & $\begin{array}{l}\mathrm{C}_{16} \text { IDT-BT } \\
\text { C }_{16} \text { IDT-BT } \\
\text { PTAA }\end{array}$ & $\begin{array}{l}\mathrm{C}_{60} \mathrm{~F}_{48} \\
\mathrm{BCF} \\
-\end{array}$ & $\begin{array}{l}13 \\
11 \\
2.4\end{array}$ & $\begin{array}{l}\text { Cytop or PTFE } \\
\text { Cytop } \\
\text { Cytop }\end{array}$ & $\begin{array}{l}\text { TG-BC } \\
\text { TG-BC } \\
\text { TG-BC }\end{array}$ & $\begin{array}{l}\text { Spin-coating } \\
\text { Spin-coating } \\
\text { Spin-coating }\end{array}$ & $\begin{array}{l}{[53]} \\
{[107]}\end{array}$ \\
\hline \multirow{9}{*}{$\begin{array}{l}\text { D } \\
\frac{c}{0} \\
\frac{0}{0} \\
\frac{\lambda}{0} \\
\frac{\mathbf{d}}{0}\end{array}$} & diF-TES ADT & PT-FAA & 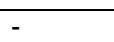 & 5 & Cytop & TG-BC & Spin-coating & [215] \\
\hline & diF-TES ADT & PTAA & $\mathrm{BCF}$ & 8.0 & Cytop & TG-BC & Spin-coating & [53] \\
\hline & TIPS-pentacene & PTAA & BCF & 3.7 & Cytop & TG-BC & Spin-coating & [53] \\
\hline & diF-TES ADT & PS & - & 6.7 & $\mathrm{SiO} 2$ & $B G-B C$ & Blade coating & [237] \\
\hline & TIPS-pentacene & PTAA & - & 1.1 & Cytop & TG-BC & Spin-coating & [107] \\
\hline & TIPS-pentacene & PS & - & 4.6 & $\mathrm{SiO} 2$ & $B G-B C$ & Blade coating & [241] \\
\hline & PS & DNTT precursor & - & 4.7 & $\mathrm{SiO} 2$ & BG-TC & Spin-coating & [242] \\
\hline & PSS & C8-ВTВT & - & 10.4 & $\mathrm{SiO} 2$ & BG-TC & Spin-coating & [235] \\
\hline & $\mathrm{C}_{10}$-DNBDT-NW & PMMA & - & 17 & SiO2 / PMMA & BG-TC & Edge-casting & [108] \\
\hline
\end{tabular}


Overestimated carrier mobility values reported in the recent years in the field of organic thin-film transistors (OTFTs) have contaminated the literature. In this review article, 30 years of OTFT carrier mobility data is examined in an effort to identify the actual progress achieved and summarise the key design strategies behind the high carrier mobility values for both $\mathrm{p}$ - and n-type organic semiconductors.

Keywords: organic semiconductors; organic field-effect transistor; carrier mobility; charge transport; contact resistance

Alexandra F. Paterson*, Saumya Singh, Kealan J. Fallon, Thomas Hodsden, Yang Han, Bob C. Schroeder, Hugo Bronstein, Martin Heeney, Iain McCulloch, and Thomas D.

Anthopoulos*

Recent Progress in High Mobility Organic Transistors: A Reality Check

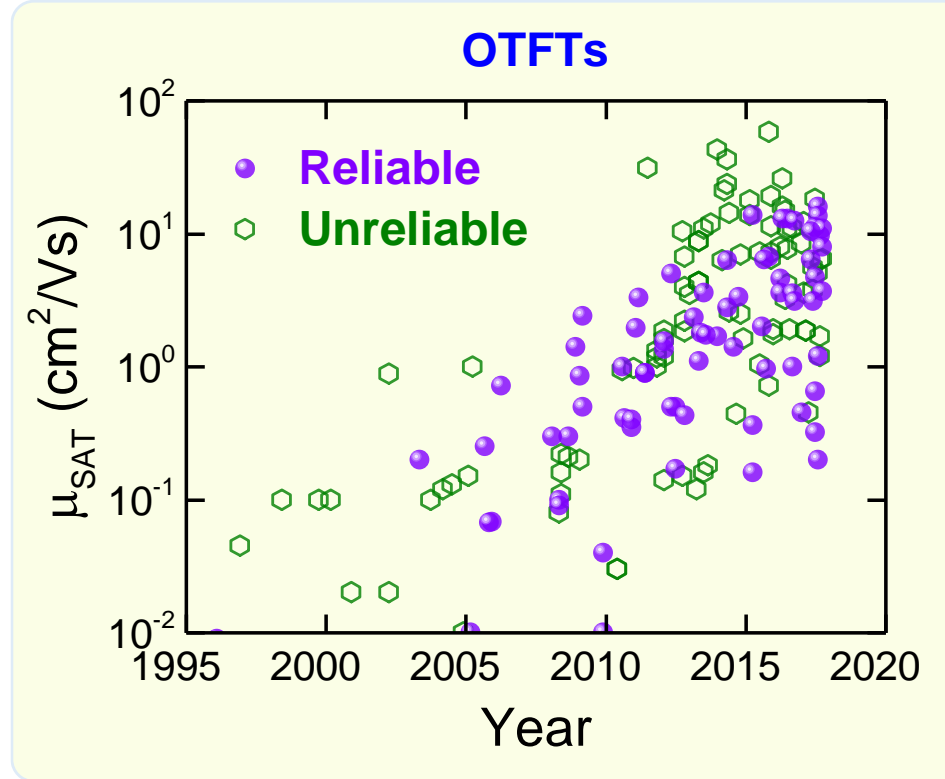


Copyright WILEY-VCH Verlag GmbH \& Co. KGaA, 69469 Weinheim, Germany, 2016.

\section{Supporting Information}

\section{Recent Progress in High Mobility Organic Transistors: A Reality Check}

Alexandra F. Paterson*, Saumya Singh, Kealan J. Fallon, Thomas Hodsden, Yang Han, Bob C. Schroeder, Hugo Bronstein, Martin Heeney, Iain McCulloch, and Thomas D.

Anthopoulos*
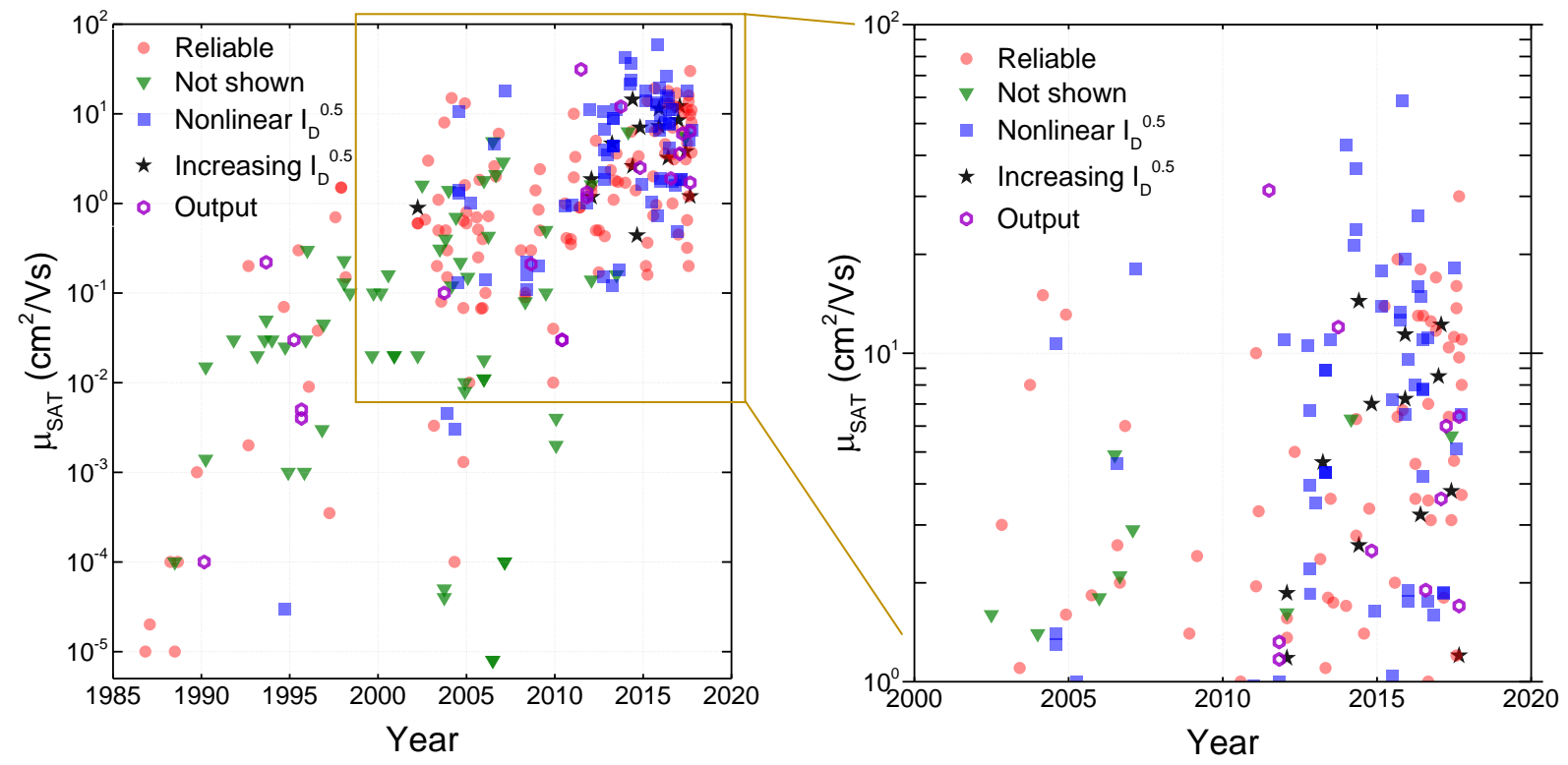

Figure S1. A close up of Figure 1(c) to show mobility values published since 2000 that have reported to be between 1 and $100 \mathrm{~cm}^{2} / \mathrm{Vs}$. The data is categorised by features in the experimental data, as compared to the requirements of the classical FET model: reliable (from the data sets shown, there are no obvious nonidealities), not shown (do not show the plot of $\mu$ vs. $\mathrm{V}_{\mathrm{G}}$ or $\mathrm{I}_{\mathrm{D}}{ }^{0.5}$ vs. $\mathrm{V}_{\mathrm{G}}$ ), nonlinear $\mathrm{I}_{\mathrm{D}}{ }^{0.5}$ (the kink or any s-shaped, nonlinear features in $\mathrm{I}_{\mathrm{D}}{ }^{0.5}$ vs. $V_{G}$ ), increasing $I_{D}{ }^{0.5}$ (the gradient of $I_{D}^{0.5}$ gets steeper with $V_{G}$ ) and output (non-saturated output characteristics). 
Table S1. Overview of polymers reporting electron mobilities above $0.5 \mathrm{~cm}^{2} /$ Vs between 2013-2017.

\begin{tabular}{|c|c|c|c|c|c|c|c|c|c|c|c|c|c|c|}
\hline & & $\begin{array}{l}\text { Reported } \\
\text { Acronym }\end{array}$ & $\begin{array}{c}\mathrm{M}_{\mathrm{n}}(\mathrm{kDa}) \\
/[\mathrm{[ \Xi ]}\end{array}$ & $\begin{array}{c}\mathrm{E}_{\text {Hомо }} / \mathrm{E}_{\text {LUMO }} \\
{[\mathrm{eV}]}\end{array}$ & $\begin{array}{l}\mathrm{E}_{\mathrm{g}}^{\text {opt }} \\
{[\mathrm{eV}]}\end{array}$ & $\begin{array}{l}\text { Reported } \mu_{e} \\
{\left[\mathrm{~cm}^{2} / \mathrm{Vs}\right]^{\mathrm{a})}}\end{array}$ & $\begin{array}{l}\text { Reported } \mu_{\mathrm{h}} \\
{\left[\mathrm{cm}^{2} / \mathrm{Vs}\right]^{(a)}}\end{array}$ & loNOFF & $\begin{array}{l}\mathrm{V}_{\mathrm{T}} \\
{[\mathrm{V}]}\end{array}$ & $\begin{array}{l}\text { Anneal } \\
\mathrm{T}\left[{ }^{\circ} \mathrm{C}\right]\end{array}$ & Geom. ${ }^{\text {b) }}$ & Device Structure ${ }^{c)}$ & $\begin{array}{l}\text { Operating } \\
\text { environment }\end{array}$ & Ref. \\
\hline \multirow{8}{*}{$\overline{\mathbf{z}}$} & P26 & NDI2HD-T2 & $98(2.8)$ & - (d) & 1.47 & $1.90(1.78)$ & - & $10^{4}$ & 36 & 220 & BG-TC & n-Si/SiO $/$ /OTS/drop/Au & $\mathrm{N}_{2}$ & {$[144]$} \\
\hline & P27 & & $28(20)$ & $-562 /-401$ & & $3.93(3.35)$ & - & $10^{5}$ & 7 & 280 & & & mphiont & [145] \\
\hline & 826 & NDIF-12 & $28(2.0)$ & $-5.62 /-4.01$ & 1.61 & $6.50(5.73)^{(e)}$ & - & $10^{5}$ & 14 & 280 & $B G-1 C$ & $\mathrm{p}-\mathrm{SI}_{\mathrm{SIO}} / \mathrm{OIS} / \mathrm{spIn} / \mathrm{Au}$ & ambient & \\
\hline & P28 & NDI2SiC6-T2 & $32(2.0)$ & $-5.27 /-3.83$ & 1.44 & 1.04 & - & $10^{3}$ & 22 & 300 & TG-BC & Glass/Ni-Au/spin/PMMA/Al & - & {$[146]$} \\
\hline & P29 & NDI-TVT & $70(2.0)$ & $-5.42 /-4.00$ & 1.42 & $1.8(1.5)$ & - & $10^{6}$ & 13 & 210 & TG-BC & $\begin{array}{c}\text { Glass/Ni- } \\
\mathrm{Au} / \mathrm{Cs}_{2} \mathrm{CO}_{3} / \text { spin/PMMA/Al }\end{array}$ & $\mathrm{N}_{2}$ & [147] \\
\hline & & & & & & 0.51 & - & $10^{6}$ & 15 & 250 & & & & [148] \\
\hline & P30 & NDI-RU & $24(2.9)$ & $-5.30 /-4.00$ & 1.36 & $1.64(1.12)^{(e)}$ & & $10^{6}$ & 6 & 250 & $B G-I C$ & 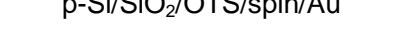 & $\mathrm{N}_{2}$ & \\
\hline & P24 & NDI-DESVS & $32(3.4)$ & $-5.48 /-4.12$ & 1.36 & 0.64 & - & $10^{2}$ & 17 & 200 & BG-TC & $\mathrm{p}-\mathrm{Si} / \mathrm{SiO}_{2} / \mathrm{HMDS} / \mathrm{spin} / \mathrm{Au}$ & ambient/vac. & {$[138]$} \\
\hline \multirow{7}{*}{ 品 } & P31 & DPPSe-SiC5 & $23(3.0)$ & $-5.10 /-3.49$ & 1.24 & $4.34(1.75)$ & $8.84(5.66)$ & $10^{1}$ & - & 220 & BG-TC & $\mathrm{n}$-Si/SiO $/$ /OTS/sheared/Au & $\mathrm{N}_{2}$ & {$[149]$} \\
\hline & P32 & 24-DPPBTz & $64(1.8)$ & $-5.35 /-4.06$ & 1.29 & $1.87(1.49)$ & $0.3(0.15)$ & $10^{6}$ & - & 260 & BG-TC & n-Si/SiO $/$ OTS/drop/Au & $\mathrm{N}_{2}$ & {$[150]$} \\
\hline & P33 & 2DPP-2CNTVT & $37(1.4)$ & $-5.49 /-4.18$ & 1.31 & 1.2 & - & $10^{3}$ & 30 & 200 & TG-BC & Glass/Ni-Au/spin/PMMA/Al & $\mathrm{N}_{2}$ & [151] \\
\hline & P34 & DPPPhF4 & $16(1.8)$ & $-5.65 /-4.18$ & 1.47 & 2.36 & - & $10^{4}$ & - & 280 & BG-TC & $\mathrm{Si} / \mathrm{SiO}_{2} / \mathrm{Au} / \mathrm{OTS} / \mathrm{spin} / \mathrm{Au}$ & $\mathrm{N}_{2}$ & [152] \\
\hline & P35 & $\begin{array}{l}\text { ((I-C18)-DPP- } \\
\text { (b-C17)-BTZ) }\end{array}$ & $63(3.2)$ & $-5.15 /-3.90$ & 1.25 & 1.5 & 2.4 & $10^{7}$ & - & 300 & TG-BC & Glass/Cr-Au/spin/PMMA/Au & $\mathrm{N}_{2}$ & [153] \\
\hline & P36 & DBPyBT & $26(3.6)$ & $-5.69 /-4.33$ & 1.65 & $6.30(4.54)$ & $2.78(2.20)$ & $10^{1}$ & - & 100 & TG-BC & $\mathrm{Si} / \mathrm{SiO}_{2} / \mathrm{Au} / \mathrm{spin} / \mathrm{CYTOP} / \mathrm{Al}$ & ambient & {$[155]$} \\
\hline & P37 & DBPyTT & $25(3.0)$ & $-5.70 /-4.30$ & 1.40 & $3.36(3.11)$ & $2.04(1.51)$ & $10^{2}$ & - & 200 & TG-BC & $\mathrm{Si} / \mathrm{SiO}_{2} / \mathrm{Au} / \mathrm{spin} / \mathrm{CYTOP} / \mathrm{Al}$ & ambient & [154] \\
\hline \multirow{7}{*}{ 옴 } & P38 & BDPPV-C3 & $30(2.3)$ & $-5.76 /-4.31$ & 1.45 & $1.40(1.12)$ & - & $10^{5}$ & 36 & 180 & TG-BC & $\mathrm{Si} / \mathrm{SiO}_{2} / \mathrm{Au} / \mathrm{spin} / \mathrm{CYTOP} / \mathrm{Al}$ & ambient & {$[156]$} \\
\hline & P39 & FBDOPPV-1 & $66(1.9)$ & $-6.19 /-4.26$ & 1.46 & $1.70(1.39)$ & - & $10^{5}$ & 18 & 100 & TG-BC & $\mathrm{Si} / \mathrm{SiO}_{2} / \mathrm{Au} / \mathrm{spin} / \mathrm{CYTOP} / \mathrm{Al}$ & ambient & {$[157]$} \\
\hline & P40 & BDOPV-2T & $77(3.0)$ & $-5.66 /-4.35$ & 1.31 & $1.74(1.42)$ & $0.47(0.20)$ & $10^{5}$ & - & 200 & TG-BC & n-Si/SiO $/$ Au/spin/CYTOP/Al & ambient & {$[158]$} \\
\hline & P41 & $\begin{array}{l}\text { Aza-BDOPV- } \\
2 T\end{array}$ & $52(2.6)$ & $-5.77 /-4.45$ & 1.32 & $3.22(1.63)$ & - & $10^{4}$ & - & 200 & TG-BC & $\mathrm{Si} / \mathrm{SiO}_{2} / \mathrm{Au} / \mathrm{spin} /{ }^{\mathrm{n}} \mathrm{C}_{8} \mathrm{H}_{18} / \mathrm{Al}$ & ambient & [159] \\
\hline & P42 & PBABDF-DT & $31(5.8)$ & $-5.70 /-4.04$ & 1.14 & $1.86(1.34)$ & - & $10^{4}$ & 24 & 260 & BG-TC & n-Si/SiO $/$ CYTOP/spin/Au & vacuum & {$[160]$} \\
\hline & P43 & $\mathrm{F}_{4} \mathrm{BDOPV}-2 \mathrm{~T}$ & $38(2.7)$ & $-5.66 /-4.35$ & 1.31 & $1.24(0.68)$ & - & $10^{3}$ & -17 & 160 & TG-BC & p-Si/SiO $/$ Ti-Au/spin/CYTOP/Al & ambient & [161] \\
\hline & P44 & BDOPV-TT & $21(2.9)$ & $-5.78 /-4.36$ & 1.42 & $1.37(0.91)$ & $1.70(0.8)$ & $10^{2}$ & 33 & 180 & TG-BC & $\mathrm{Si} / \mathrm{SiO}_{2} / \mathrm{Au} /$ spin/CYTOP/Al & ambient & [162] \\
\hline \multirow{4}{*}{$=$} & P45 & PAIIDBT & $14(1.6)$ & $-5.50 /-3.40$ & 1.70 & 1.0 & - & $10^{2}$ & - & 250 & TG-BC & (f)Glass/spin/PMMA/Al & $\mathrm{N}_{2}$ & {$[163]$} \\
\hline & P46 & P6F-C3 & $53(1.5)$ & $-5.95 /-3.80$ & 1.63 & $4.97(3.04)$ & - & $10^{6}$ & 55 & 200 & TG-BC & n-Si/SiO $/$ Au/spin/PMMA/Au & ambient & {$[164]$} \\
\hline & P47 & P2FIID-2FBT & $59(2.5)$ & $-5.10 /-3.64$ & 1.40 & $9.70(9.16)$ & $2.75(2.25)$ & $10^{3}$ & 57 & 180 & TG-BC & $\mathrm{SiO}_{2} / \mathrm{Ti}-\mathrm{Au} / \mathrm{OTS} /$ spin/PMMA/Al & ambient & {$[165]$} \\
\hline & P22 & ilTT (P1) & $17(1.6)$ & $-4.90 /-3.90$ & 1.05 & 0.7 & 0.4 & $10^{2}$ & 13 & 300 & TG-BC & Glass/Ti-Au/spin/PMMA/Au & $\mathrm{N}_{2}$ & {$[137]$} \\
\hline IND & P48 & INDTBT & $40(3.0)$ & $-4.97 /-3.74$ & 1.31 & 3.1 & 0.52 & $10^{4}$ & 74 & 190 & TG-BC & Glass/Au/spin/CYTOP/Al & $\mathrm{N}_{2}$ & {$[166]$} \\
\hline
\end{tabular}


a) Average mobility in brackets or average if only one mobility is reported; refer to Section 1 for discussion on reported mobilities and mobility analysis. ${ }^{\text {b) }}$ Device geometry: bottom-gate top-contact (BG-TC), top-gate bottom-contact (TG-BC). ${ }^{\text {c) }}$ Device structure is given stepwise from the substrate. Spin, drop and (solution) sheared refers to the organic semiconductor film processing condition. Note that some devices employ adhesion layers (e.g. Ni-Au), self-assembled monolayers (e.g. OTS) and/or electron transport layers (e.g. $\mathrm{Cs}_{2} \mathrm{CO}_{3}$ ). ${ }^{\text {d) }}$ Not reported. ${ }^{\text {e) }}$ 1-chloronaphthalene additive. ${ }^{\text {f) }}$ Source/drain material not reported.

Table S2. Overview of molecular semiconductors reporting electron mobilities above $0.1 \mathrm{~cm}^{2} /$ Vs between 2012-2017.

\begin{tabular}{|c|c|c|c|c|c|c|c|c|c|c|c|}
\hline & & $\begin{array}{c}\text { Thin film/ } \\
\text { single crystal }\end{array}$ & $\begin{array}{l}\text { Unipolar / } \\
\text { ambipolar }\end{array}$ & $\begin{array}{l}\text { Reported } \mu_{\mathrm{e}} \\
{\left[\mathrm{cm}^{2} / \mathrm{Vs}\right]^{\mathrm{a})}}\end{array}$ & $\mathrm{V}_{T}[\mathrm{~V}]$ & $\mathrm{I}_{\mathrm{on} / \mathrm{off}}$ & Geom. ${ }^{\text {b) }}$ & $\begin{array}{c}\text { Operating } \\
\text { environment }\end{array}$ & Device $^{c)}$ & Solvent ${ }^{d)}$ & Ref. \\
\hline \multirow{15}{*}{$\begin{array}{l}\text { 증 } \\
\frac{0}{0} \\
\frac{.0}{3}\end{array}$} & SM1 & thin film & n-type & $1.1(0.8)$ & 7 & $10^{5}$ & BG-TC & $\mathrm{N}_{2}$ & n-Si/SiO $/$ OTS/Spin/Au & THF & {$[168]$} \\
\hline & SM2a & & n-type & $0.57(0.50)$ & $5-14$ & - & BG-TC & ambient & n-Si/SiO $/$ OTS/Spin/Au & CF & {$[170]$} \\
\hline & SM2b & thın film & ambipolar & $0.22(0.18)$ & -3 to 9 & - & BG-TC & ambient & n-Si/SiO $/$ OTS/Spin/Au & CF & [170] \\
\hline & SM2c & thin film & ambipolar & $0.15(0.13)$ & $2-12$ & - & BG-TC & Ambient & n-Si/SiO $/$ OTS/Spin/Au & CF & {$[170]$} \\
\hline & SM3 & thin film & n-type & $0.45(0.29)$ & 6.4 & $10^{5}$ & BG-TC & $\mathrm{N}_{2}$ & $\mathrm{n}-\mathrm{Si} / \mathrm{SiO}_{2} / \mathrm{PETS} / \mathrm{Shear} / \mathrm{Au}$ & $\mathrm{CB}$ & [171] \\
\hline & SM4 & single crystal & n-type & $0.88(0.47)$ & - & $10^{4}$ & BG-TC & ambient & $\mathrm{n}-\mathrm{Si} / \mathrm{SiO}_{2} / \mathrm{OTS} / \mathrm{Drop} / \mathrm{Au}$ & $\mathrm{CB}$ & [172] \\
\hline & SM5b & thin film & & $0.5(0.4)$ & 10 & $10^{4}$ & TG-BC & $\mathrm{N} 2$ & Glass/Au/Spin/Cytop/Al & THN, Blend & {$[174]$} \\
\hline & SM6 & thin film & n-type & $0.22(0.12)$ & -41 & $10^{6}$ & BG-BC & ambient & $\mathrm{n}-\mathrm{Si} / \mathrm{SiO}_{2} / \mathrm{OTS} / \mathrm{Spin} / \mathrm{Au}$ & DCB & {$[176]$} \\
\hline & SM7a & thin film & n-type & $3.00(1.51)$ & -11 & $10^{5}$ & BG-BC & ambient & n-Si/SiO $/$ Au/OTS/Spin & $\mathrm{CF}$ & {$[177]$} \\
\hline & SM8a & thin film & n-type & $0.44(0.14)$ & 2.6 & $10^{3}$ & BG-BC & ambient & n-Si/SiO $/$ Au/OTS/Spin & CF & {$[177]$} \\
\hline & SM7b & thin film & n-type & $0.36(0.31)$ & -11 & $10^{2}$ & $B G-B C$ & ambient & n-Si/SiO $/$ Au/OTS/Spin & CF & [178] \\
\hline & SM8b & thin film & n-type & $0.48(0.37)$ & 0.8 & $10^{4}$ & BG-BC & ambient & n-Si/SiO $/$ Au/OTS/Spin & $\mathrm{CF}$ & {$[178]$} \\
\hline & SM7c & thin film & n-type & $5.2(4.2)$ & -14 & $10^{5}$ & BG-BC & ambient & n-Si/SiO $/$ Au/OTS/Spin & CF & {$[178]$} \\
\hline & SM8c & thin film & n-type & $0.1(0.09)$ & 5.2 & $10^{3}$ & BG-BC & ambient & n-Si/SiO $/$ Au/OTS/Spin & $\mathrm{CF}$ & {$[178]$} \\
\hline & SM9 & thin film & n-type & $0.32(0.2)$ & 7 & $10^{6}$ & BG-TC & $\mathrm{N}_{2}$ & n-Si/SiO $/$ OTS/Spin/Au & $\mathrm{CF}$ & [179] \\
\hline \multirow{7}{*}{ 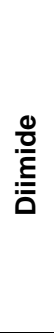 } & SM10b & thin film & n-type & $3.5(3)$ & 2 & $10^{7}$ & BG-BC & ambient or $\mathrm{N}_{2}$ & n-Si/SiO $/$ Au/OTS/Spin & $\mathrm{CF}$ & {$[182]$} \\
\hline & SM10b & thin film & n-type & $1.21(0.65)$ & 8.9 & $10^{7}$ & TG-BC & ambient or $\mathrm{N}_{2}$ & Glass/Au/Spin/Cytop/Al & $\mathrm{CF}$ & [182] \\
\hline & SM10c & thin film & n-type & $0.25(0.24)$ & 7.1 & $10^{6}$ & BG-BC & ambient or $\mathrm{N}_{2}$ & $\mathrm{n}-\mathrm{Si} / \mathrm{SiO}_{2} / \mathrm{Au} / \mathrm{OTS} / \mathrm{Spin}$ & $\mathrm{CF}$ & [182] \\
\hline & SM11 & thin film & n-type & $0.22(0.2)$ & -1 to 5 & $10^{6}$ & BG-BC & ambient & n-Si/SiO $/$ Au/OTS/Spin & $\mathrm{CF}$ & {$[183]$} \\
\hline & SM12a & thin film & n-type & $0.45(0.34)$ & - & $10^{6}$ & BG-TC & ambient & $\mathrm{n}-\mathrm{Si} / \mathrm{SiO}_{2} / \mathrm{OTS} / \mathrm{Spin} / \mathrm{Au}$ & $X Y L$ & [184] \\
\hline & SM12b & thin film & n-type & $0.35(0.31)$ & - & $10^{5}$ & BG-TC & ambient & $\mathrm{n}-\mathrm{Si} / \mathrm{SiO}_{2} / \mathrm{OTS} / \mathrm{Spin} / \mathrm{Au}$ & DCB & {$[184]$} \\
\hline & SM13 & thin film & n-type & $0.96(0.93)$ & - & $10^{3}$ & TG-BC & ambient & $\mathrm{SiO}_{2} / \mathrm{Au} / \mathrm{Spin} / \mathrm{Cytop} / \mathrm{Al}$ & TCE & [185] \\
\hline
\end{tabular}




\begin{tabular}{|c|c|c|c|c|c|c|c|c|c|c|c|}
\hline & SM14a & thin film & ambipolar & $0.17(0.14)$ & - & $10^{2}$ & BG-TC & ambient & n-Si/SiO $/ 2$ OTS/Spin/Au & $\mathrm{CF}$ & {$[187]$} \\
\hline & SM14b & thin film & ambipolar & $0.16(0.15)$ & - & $10^{2}$ & BG-TC & ambient & $\mathrm{n}-\mathrm{Si} / \mathrm{SiO}_{2} / \mathrm{OTS} / \mathrm{Spin} / \mathrm{Au}$ & DCB & {$[187]$} \\
\hline & SM15 & thin film & n-type & 0.15 & $13-18$ & $10^{7}$ & $B G-B C$ & ambient & $\mathrm{n}-\mathrm{Si} / \mathrm{SiO}_{2} / \mathrm{Au} / \mathrm{OTS} / \mathrm{Spin}$ & $\mathrm{CF}$ & [188] \\
\hline & SM16 & thin film & n-type & $0.37(0.24)$ & $10-30$ & $10^{7}$ & $B G-B C$ & ambient & $\mathrm{n}$-Si/SiO $/$ /Au/OTS/Spin & $\mathrm{CF}$ & [189] \\
\hline & SM17 & thin film & n-type & $0.17(0.14)$ & 1.7 & $10^{4}$ & TG-BC & $\mathrm{N}_{2}$ & $\mathrm{PES} / \mathrm{Ag} / \mathrm{IJ} / \mathrm{Cytop} / \mathrm{Al}_{2} \mathrm{O}_{3} / \mathrm{Al}$ & DCB & [190] \\
\hline & SM18 & thin film & n-type & $0.12(0.11)$ & - & $10^{6}$ & BG-TC & $\mathrm{N}_{2}$ & $\mathrm{n}-\mathrm{Si} / \mathrm{SiO}_{2} / \mathrm{OTS} / \mathrm{Spin} / \mathrm{Au}$ & $\mathrm{CF}$ & [191] \\
\hline & SM19 & single crystal & n-type & $1.59(1.27)$ & -2 & $10^{4}$ & BG-TC & ambient & $\mathrm{n}-\mathrm{Si} / \mathrm{SiO}_{2} / \mathrm{OTS} /$ place/Au & n.r. & [193] \\
\hline & SM20 & single crystal & n-type & 8.6 & $5-13$ & $10^{7}$ & BG-TC & ambient & $\mathrm{n}-\mathrm{Si} / \mathrm{SiO}_{2} / \mathrm{OTES} / \mathrm{grow} / \mathrm{Au}$ & $\mathrm{CF}$ & [192] \\
\hline & SM21 & single crystal & n-type & $1.75(1.5)$ & - & $10^{6}$ & BG-TC & $\mathrm{N}_{2}$ & $\mathrm{n}$-Si/SiO $/$ /OTS/place/Au & $\mathrm{CF}$ & [194] \\
\hline & SM22 & thin film & n-type & $0.19(0.16)$ & 12 & $10^{3}$ & $B G-B C$ & $\mathrm{~N}_{2}$ & $\mathrm{n}-\mathrm{Si} / \mathrm{SiO}_{2} / \mathrm{Au} / \mathrm{TDS} / \mathrm{Spin}$ & $\mathrm{CF}$ & [195] \\
\hline & SM23a & thin film & n-type & 0.7 & 21 & $10^{7}$ & BG-TC & ambient & n-Si/SiO $/$ OTS/Spin/Au & $\mathrm{CB}$ & [196] \\
\hline & SM23b & single crystal & n-type & 4.65 & - & - & BG-TC & ambient & n-Si/SiO $/$ /OTS/place/Ag & Toluene & [197] \\
\hline & SM24 & thin film & n-type & $0.44(0.37)$ & 49 & $10^{6}$ & BG-TC & ambient & $\mathrm{n}$-Si/SiO $/$ OTS/Spin/Au & $\mathrm{CF}$ & [198] \\
\hline & SM25 & thin film & n-type & 0.16 & $0-10$ & $10^{4}$ & TG-BC & ambient & $\mathrm{SiO}_{2} / \mathrm{Au} / \mathrm{Spin} / \mathrm{Cytop} / \mathrm{Al}$ & TCE & [199] \\
\hline & SM26 & thin film & n-type & $1.00(0.65)$ & -15 & $10^{5}$ & BG-TC & $\mathrm{N}_{2}$ & n-Si/SiO $/$ OTMS/Spin/Au & DCB & [200] \\
\hline Acene & SM27 & single crystal & n-type & $11(7.6)$ & $11-15$ & $10^{6}$ & BG-TC & vacuum & $\mathrm{n}-\mathrm{Si} / \mathrm{SiO}_{2} / \mathrm{AlO}_{x} / \mathrm{CDPA} / \mathrm{drop} / \mathrm{Au}$ & $\begin{array}{c}\text { Acetone } / \mathrm{CH}_{2} \mathrm{C} \\
\mathrm{I}_{2}\end{array}$ & [201] \\
\hline & SM28 & single crystal & n-type & 0.2 & - & $10^{4}$ & BG-TC & ambient & $\mathrm{n}-\mathrm{Si} / \mathrm{SiO}_{2} / \mathrm{OTS} / \mathrm{drop} / \mathrm{Ag}$ & $\mathrm{Tol} / \mathrm{CH}_{3} \mathrm{CN}$ & [202] \\
\hline Acono & SM29d & thin film & n-type & $12.6(7.6)$ & 8.7 & $10^{6}$ & BG-TC & ambient & $\mathrm{n}$-Si/SiO $/$ /Cytop/Spin/Au & CF/IPA & [203] \\
\hline Acene & SM30 & thin film & n-type & $0.16(0.13)$ & 23 & $10^{6}$ & TG-BC & ambient & Glass/buffer/Au/spin/cytop/Ag & DCB & [204] \\
\hline
\end{tabular}

a) Average mobility in brackets or average if only one mobility is reported; refer to Section 1 for discussion on reported mobilities and mobility analysis. ${ }^{b)}$ Device structure is given stepwise from the substrate. Spin, drop and (solution) sheared refers to the organic semiconductor film processing condition. ${ }^{c)}$ Device geometry: bottom-gate top-contact (BG-TC), top-gate bottom-contact (TG-BC). ${ }^{\text {d) }}$ Solvent: xylene (XYL), tetrahydrofuran (THF), chloroform (CF), chlorobenzene (CB), 1,2-dichlorobenzene (DCB), toluene (Tol), trichloroethylene (TCE), tetrahydronaphthalene (THN), isopropanol (IPA), not reported (n.r.). 
Adv. Mater. 2018, 30, 1801079 